Article

\title{
An Integrated Sustainable Supplier Selection Approach Based on Hybrid Information Aggregation
}

\author{
Xiongyong Zhou ${ }^{(1)}$ and Zhiduan $\mathrm{Xu}$ * \\ School of Management, Xiamen University, Xiamen 361005, China; xiongyongzhou@stu.xmu.edu.cn \\ * Correspondence: zhiduanx@xmu.edu.cn; Tel.: +86-189-5928-7116
}

Received: 15 June 2018; Accepted: 12 July 2018; Published: 19 July 2018

\begin{abstract}
With a great emphasis on both social and environmental responsibilities, sustainable supply chain management has gradually been adopted and promoted as an innovative business model. In sustainable supply chain practice, the choice of sustainable suppliers relates to the long-term development of a company. While the environmental performance of suppliers has been commonly considered, the social dimension has not yet received enough attention. This paper first proposes a novel criteria system for evaluating sustainable suppliers from three aspects and six dimensions, and then introduces an integrated evaluation model with a novel hybrid information aggregation. To verify the applicability and effectiveness of the proposed method, a real case of a large supermarket is introduced and analyzed. The research results show that (1) the indicator system based on Triple Bottom Line theory can serve as a framework of sustainable supplier selection for manufacturing and circulation enterprises; (2) the introduction of hybrid information aggregation can effectively handle the uncertainties of indicator scores under the realistic fuzzy environment and objectively reflect the intentions of the scorers; and (3) in comparison with the TOPSIS algorithm, the priority order finally obtained is consistent, but the proposed model shows more robustness in the sensitivity test.
\end{abstract}

Keywords: sustainable supplier selection; DEMATEL; ANP; fuzzy VIKOR; IVTFN; hybrid information aggregation; TBL theory

\section{Introduction}

The problems regarding violations of corporate ethics and national laws caused by the lack of environmental and social responsibility in supply chain operations have drawn great public concern in recent times [1,2]. On 31 August 2011, five environmental groups led by the Institute of Public and Environmental Affairs (IPE), a nonprofit organization in Beijing, revealed a pollution map with regard to the supply chain of the high-tech giant Apple in China after more than six months' investigation, which exposed dozens of labor rights violations, as well as safety and environmental offenses, made by 27 suspected suppliers of Apple. Subsequently, The Other Side of Apple II, a special report issued by IPE in association with other green groups strongly condemned Apple for the environmental and social irresponsibility of its business practices. Incidents included the long-term breach of environmental regulations by the factories of some suppliers, with more than ten violations of commitments to pollution and worker health accords, violations of international safety standards for the release of toxic metals such as copper and nickel, a lack of attention to the physical and mental health of the local community and public, and the disposal of hazardous wastes in a manner that violated local governmental legislation [3]. Initially, Apple denied all the charges and argued that they were just downstream purchasers that had no joint liability for bad behavior among other suppliers. However, Chinese environmental organizations and consumers did not agree with this statement, and started to boycott all Apple products. In the face of growing public pressure, Apple came to realize that they were unable to ignore the problem, since consumers place liability on the focal company in the product 
chain more often than not. For focal companies, they should not only manage their own behavior, but also strengthen the supervision of the operations of their suppliers. Consumers in modern society are increasingly concerned about whether the products they buy are environmentally sound, and whether the brands they trust maintain a responsible supply chain. In view of the public scrutiny and social pressure, core companies cannot only concern themselves with their own transparency and green obligations; the issue of whether upstream suppliers take sustainable initiatives is directly linked to the reputations of focal firms and the supply chain at large. Therefore, they should pay much more attention to sustainable supply chain management (SSCM), especially in terms of the choice of sustainable suppliers. For purchasing managers and researchers, how to establish a practical and pragmatic evaluation system and method focusing on sustainable suppliers has become a necessary but challenging issue [4-7].

The sustainable supplier selection (SSS) is a focus issue that has gained attention over the past five years [8,9]. Compared to traditional supplier selection which mainly concentrates on economic benefit and cost optimization [10-12], and green supplier evaluation that focuses on environmental performance $[2,13,14]$, investigation of the sustainability of suppliers also needs to consider their social responsibility. The indicators of responsibility to internal stakeholders around employee rights have been put forward: occupational health and safety $[4,15-17]$, training and practice $[15,18]$, and other legitimate rights $[4,15]$. However, few works paid attention to external stakeholders, much less did they establish a comprehensive evaluation framework and logic that could be used to measure the sustainability of the supplier. Therefore, the first potential contribution of this paper is to place a stronger emphasis on suppliers' social performance, and to propose a novel measure for SSS based on the logic of the Triple Bottom Line (TBL) theory [19]. This measure covers economic, green (environmental), and social factors, with a total of 24 indicators. Among them, from stakeholder theory we point out that suppliers' social responsibility is not only reflected in their duties to internal stakeholders (such as employees and shareholders), but also to external stakeholders (such as communities and the governments).

Considering the criteria of SSS, a multi-criteria decision-making (MCDM) approach provides an effective framework to solve the screen problem with different conflicting goals [6]. Some typical MCDM methods, such as the Analytic Network Process (ANP), have been widely used to solve supplier selection issues, while most studies have assumed that each cluster in the ANP has equal weight in the creation of a weighted supermatrix [20,21]. In addition, many used methods, including Artificial Neural Networks (ANNs), rarely consider the real existence of mutual influence and feedback among criteria during the process of weight determination [22]. To improve upon these shortcomings, we integrate the DEMATEL method, representing the related properties between indicators with the ANP method to calculate the weights of the various criteria. Compared with other studies proposing the DEMATEL-ANP method [21,23], we improve the method for remapping the ANP network structure, which effectively reduces computation costs.

TOPSIS and VIKOR are typical compromise programming technologies which focus on ranking and selecting a set of options [24]. Compared with the TOPSIS method, which may cause an improper effect known as "total rank reversal" [2], the fact that the best solution obtained by VIKOR is closer to the ideal solution makes VIKOR the most suitable method for selecting suppliers in the view of many authors [25]. In light of the above factors, this paper also uses a hybrid VIKOR technology as a decision-making tool to determine the optimal sustainable supplier before the weight definition through DEMATEL-ANP method is applied.

Moreover, this paper also introduces a set of hybrid information aggregation for practical evaluation, and combines this information set with the proposed integrated method. As qualitative factors and quantitative indicators often coexist simultaneously in the measure of supplier selection, accuracy and pragmatism cannot be achieved if those factors are scored by a single value type [26]. For the convenience of calculation or the limitation of the method, using mixed data as an input was generally not considered in the past; rather, it served to unilaterally adopt quantitative scoring 
or qualitative judgment. The hybrid information aggregation we proposed can reduce the vague and subjective impact of human judgments and preferences through mixed data forms to describe the comprehensive performance of potential suppliers, which includes the precise number, interval number, and fuzzy number. Note that the linguistic term, rather than the numerical form, is proposed for decision makers (DMs) to answer the relevant questions [4], due to its simplicity and tangibility in expressing perceptions [4], which can normally be transformed into fuzzy numbers. The use of an interval-valued triangular fuzzy number (IVTFN) is proposed in this paper to effectively reduce the uncertainty and ambiguity that exists in the supplier selection process [27].

A case of a retail enterprise is finally introduced to verify the applicability of the measure and feasibility of the proposed model with regard to the SSS problem. While most related literature in this field has focused on manufacturing companies [28-30], little attention is given to SSS of retail enterprises. As more and more retail companies, such as Wal-Mart and Migros, have proposed goals and plans for global sustainable procurement in recent years, the means of developing a comprehensive measure for sustainability and an effective assessment method to choose sustainable suppliers has become an urgent problem. We contribute theoretical supplements for the field of supplier selection and the question of sustainability by pointing out the limitations of the existing methods and proposing an effective model and information process approach to guide enterprises through the supply chain, especially in the retail industry, to select sustainable suppliers and implement sustainable practices.

The remainder of this paper is organized as follows: Section 2 reviews the literature on SSCM, SSS criteria, and evaluation methods. Section 3 introduces our methodology, including the DEMATEL-ANP-VIKOR algorithm and hybrid information aggregation. In Section 4, an empirical case of a retail enterprise is presented to solve the SSS problem by an integrated approach. Finally, in Section 5, we discuss the implications and offer conclusions and future study avenues.

\section{Literature Review}

\subsection{SSCM and Supplier Selection}

The earliest study of SSCM can be traced back to the 1990s, when the concept of sustainability mainly referred to environmental management. Drumwright [31] put forward the importance of social responsibility for companies in terms of purchasing, production, and consumption. In the same year, Murphy, et al. [32] suggested that priority should be placed on environmental issues over logistics management. In the late 1990s, the principles of green supply chains were proposed to change the traditional requirements and objective functions goals of operation management [33,34]. Elkington [19] further proposed the concept of TBL, focusing on the balance of economic, environmental, and social goals from a business perspective. Carter and Jennings [35] posed the dual relationship approach to analyze each system unit so as to assess change in the case where a sustainable solution was used. Mentzer, et al. [36] believed that sustainability in the supply chain is a systematic and strategic coordination of business operations and decisions within a company and its supply chain to increase the long-term comprehensive benefits. Linton, et al. [37] was the first to put forward the concept of SSCM, while Carter and Rogers [38] and Seuring and Müller [1] offered deeper explanations of this term. Specifically, SSCM was described as a strategic and transparent collection that covered four support aspects of sustainability, namely: risk management, transparency, strategy, and corporate culture [38], coordinating the systematic business process based on the TBL principle within internal organizations [1], to eventually get the trade-off from social, environmental, and economic objectives. Companies should have a formal mechanism to monitor and disclose responsible and sustainable issues in their supply chain [39] in order to gain both internal and external performance edges and reputations, as well as continuous competitive advantages [1,40,41].

As a critical part of SSCM, helping suppliers recognize the importance of sustainability and support them in improving their SSCM practices is a vital task for core enterprises [5]. Only by the efforts of sustainable initiatives taken through the integration of upstream and downstream 
partners, can sustainability in the supply chain be continued. The core enterprise can actively mobilize their suppliers to participate in environmental protection plans, doing charities, and maintaining cooperative partnerships, and encourage them to address SSCM initiatives and adopt more proactive environmental strategies [42]. In fact, suppliers who positively participate in the practice of SSCM can reduce the potential risks from environmental and political uncertainty, as well as economic volatility, through the full supply chain, and can ultimately earn the praise of downstream customers for outstanding performance in terms of sustainability [43].

Previous literature concerning supplier selection mostly focused on economic and environmental factors [44-49], while recent studies have begun to increase the consideration of suppliers' social performance when selecting sustainable suppliers [6,7,50]. Apparently, sustainable suppliers have dramatic differences in operation goals, contract models, relationships, and evaluation standards compared with traditional suppliers and green suppliers, as demonstrated in Table 1. To maximize the value of the entire supply chain, focal firms need to carefully select raw material suppliers and product distributors. As the front end, in sustainable supply chains (see in Figure 1), those raw material suppliers are the base of value development, transmission, and even enhancement. That means that sustainable suppliers play a crucial part in the implementation of SSCM initiatives, which can deliver the benefits of both environmental improvements and cost reductions within the supply chain to the downstream through material flows [29].

Table 1. The distinction between traditional suppliers, green suppliers, and sustainable suppliers.

\begin{tabular}{lllll}
\hline & Organizational Objectives & $\begin{array}{l}\text { Relationship in } \\
\text { Supply Chain }\end{array}$ & $\begin{array}{l}\text { The Number } \\
\text { of Suppliers }\end{array}$ & $\begin{array}{l}\text { Evaluation } \\
\text { Standards }\end{array}$ \\
\hline $\begin{array}{l}\text { Traditional } \\
\text { suppliers }\end{array}$ & Maximum benefit of economy & $\begin{array}{l}\text { Short-term and rival } \\
\text { strategy }\end{array}$ & $\begin{array}{l}\text { Scattered } \\
\text { suppliers }\end{array}$ & $\begin{array}{l}\text { Price, quality and } \\
\text { delivery }\end{array}$ \\
\hline $\begin{array}{l}\text { Green } \\
\text { suppliers }\end{array}$ & $\begin{array}{l}\text { Maximum benefits of } \\
\text { economy and environment }\end{array}$ & $\begin{array}{l}\text { Green cooperation and } \\
\text { competition }\end{array}$ & $\begin{array}{l}\text { Suppliers } \\
\text { integration }\end{array}$ & $\begin{array}{l}\text { Economy and } \\
\text { environment }\end{array}$ \\
\hline $\begin{array}{l}\text { Sustainable } \\
\text { suppliers }\end{array}$ & $\begin{array}{l}\text { Maximum benefits of } \\
\text { economy, society and } \\
\text { environment }\end{array}$ & $\begin{array}{l}\text { Partner for creating } \\
\text { new value through } \\
\text { SSCM }\end{array}$ & $\begin{array}{l}\text { Suppliers } \\
\text { integration }\end{array}$ & Considering the \\
TBL factors
\end{tabular}

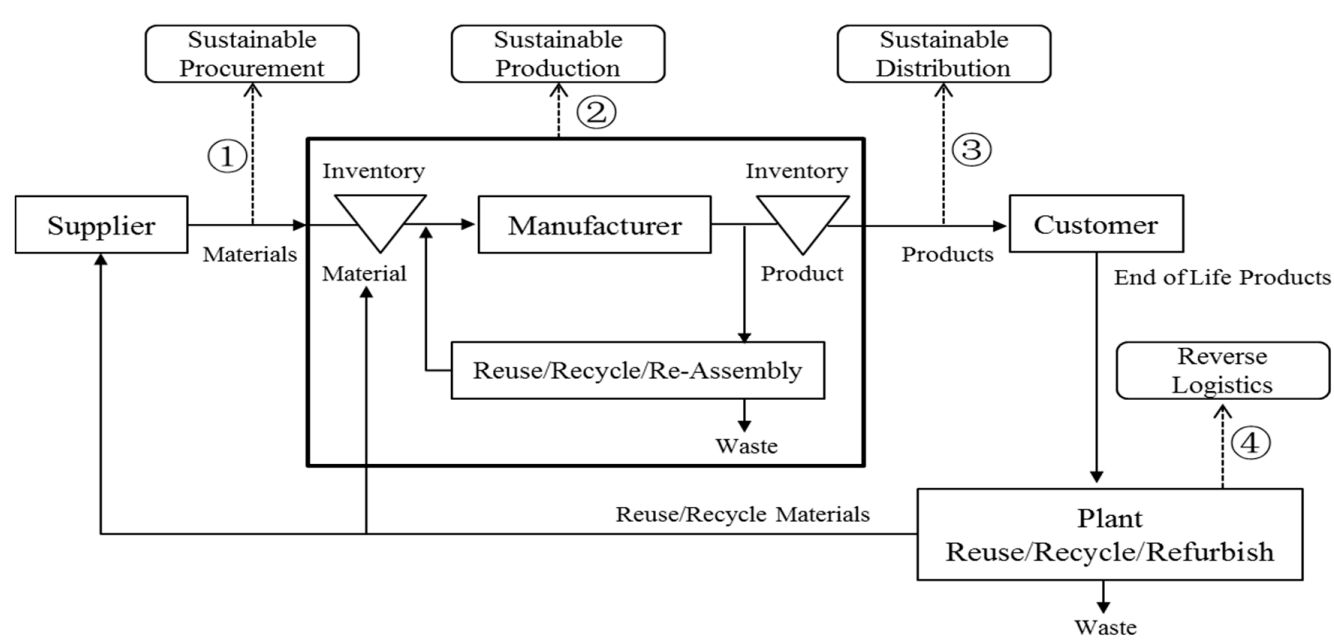

Figure 1. The main activities in a typical SSCM [8].

\subsection{Sustainable Supplier Selection Criteria}

The evaluation system of supplier selection can be traced to the work of Dickson [51], who earlier presented a measure coving 23 economic indicators. Weber, et al. [52] reordered the priority of indicators most proposed by Dickson [51] based on citation frequency over the past two decades, and further revealed the evolution trend of these classical criteria. They found that some criteria, 
like price, quality, delivery time, production equipment, and capacity, still occupied the primary positions, whereas other indicators changed significantly as a result of shifts of focus by academia and industry. For example, the relative importance of financial conditions was on the rise, while the ranking of location dropped, since the geographical position was no longer a restraining factor for suppliers due to the rapid development of the logistics industry. After the 1990s, the measure of supplier selection received more attention when some scholars refined partial factors including purchased price, product quality, and delivery time, and further proposed second-grade and even third-grade indicators in order to make assessments quantifiable and comparable $[10,46,48]$. The cost (or purchase unit price), for instance, was subdivided into fixed costs, design costs, supply costs, technical expenses, after-sales service costs, and inventory costs, and so forth. Later on, with the view of Business Process Reengineering (BPR) causing great repercussions [53], capabilities including resource integration, supply flexibility, and information technology have received unprecedented attention [54], and were also added to the supplier evaluation system for core enterprises to measure their suppliers' performance. In the face of the competitive environment that came with economic globalization, the ability and responsibility of suppliers are expected to remain at a much higher level, in terms of factors such as compliance with local regulations, assuming client responsibilities proactively, identifying supply chain risks, and so forth. As global attention has turned to sustainable development [55] and Green supply chain management (GSCM) [56], environmental performance has gradually become a crucial factor in the selection of potential suppliers (especially green suppliers), while social performance was hardly mentioned until corporate social responsibility (CSR) [31] and the TBL theory [19] drew much attention to it. Some scholars have focused on this issue but have not yet established a generally accepted measure for supplier social responsibility $[7,9,17,18,57]$.

Based on the three dimensions in the TBL framework [19], indicators affecting supplier selection in the last 20 years or so were classified into the economic, environmental, and societal metrics. The research on traditional supplier evaluation generally only concerned economic performance $[45,58-$ 61]. Table 2 summarizes a segment of the most frequent economic indicators in the previous literature. With increasing emphasis on global environmental issues and the enhancement of ecological awareness, it was not surprising that environmental performance has become the essential assessment indicator for suppliers in the selection system [13,14,62-65]. Table 3 summarizes the environmental indicators that have been widely recognized and used in the past. Although the study on CSR has been not a new topic and has already borne fruit, research on integrating CSR (and also sustainability) with supplier selection has emerged only in recent years $[63,66,67]$. In reality, the internal stakeholders (such as shareholders) and external stakeholders (such as governments, local communities, non-governmental organizations, and consumers) in the supply chain are constantly putting social responsibility pressure on the firm itself $[66,68]$. Corporate behaviors and practices in terms of social responsibility, such as the voluntary integration of sustainable concerns into their commercial operations, influence all levels of the supply chain, but especially business partners [69]. Enterprises gradually recognized that their initiatives in SSCM will eventually exert an impact on their social image, reputation, and long-term benefits [70], and are responsible for the environmental, well-being, and security requirements of the laborers who manufacture their products, no matter whether they are direct employees or whether they come from the suppliers who provide them with raw materials or semi-finished products [71]. Table 4 provides some important sustainable criteria from the existing literature. Most authors have emphasized concern for employee responsibility, in the form of occupational health and safety [4,15-17,72], training and practice $[15,18]$, and other legitimate rights $[4,15]$. The rights of stakeholders have also been recognized by many researchers $[4,7,29,72]$, but the concept is more general because groups such as laborers, shareholders, governments, and so forth are all stakeholders of the company, and it is obviously not sufficient to describe rights using such an indicator. Information disclosure reveals the willingness of enterprises to fulfill their social responsibilities to some degree [4,29], but it is usually hard to measure performance by a single factor. Few papers pay attention to external stakeholders, except for their influence on the local community [73,74]; criteria like taxation, charitable investments, and shareholder 
contracts, are rarely included in the evaluation systems of sustainable suppliers. Nevertheless, the indicators proposed in the past three years, such as ethical and legal issues [17], discrimination and diversity [7], sustainability risks [57], supportive activities [16], and trust and partnerships [18], have some reference values. In general, the current social dimension for sustainable suppliers lacks the systematic consideration of responsibilities to internal and external stakeholders, focusing rather on only one or a few objects. This paper therefore attempts to establish a novel criteria framework of SSS for retail enterprises, especially those existing in the emerging economy whose SSCM initiatives got off to a late start.

\subsection{The Measures}

Through reviewing and combing through over 300 papers published from 2000 to 2017 (on the "topic, abstract and keywords" in regards to "sustainable supplier") from databases such as the Web of Science, Springer, Wiley, and Scopus, as well as in-depth consultations with experts in various industries, based on the TBL theory and stakeholder theory, a comprehensive measure for SSS in the retail industry was formulated. Given the trade-off between economic, environmental, and societal objectives, this measure covers six aspects (and a total of 24 sub-criteria), namely: Corporate Reputation (AS1), Operational Management (AS2), Product Advantage (AS3), Service Capability (AS4), Green Impact (AS5), and Social Responsibility (AS6). One of the most innovative parts among these aspects is the introduction of the main content of supplier social responsibility, which is not only reflected in suppliers' duties to internal stakeholders (such as employees and shareholders), but also to external stakeholders (such as community and the government). Among the sub-criteria, in addition to the reservation of some traditional, highly cited criteria such as procurement costs, financial status, product quality, supply flexibility, responsiveness, etc., we also considered other, new indicators according to corporate practices and expert opinion, including position in industry, contractual capacity, strategic alliance, learning, business process management, customer satisfaction, maintenance and compensation, governmental relations, and shareholder contracts; explanations are presented in Table 5. The proposed measure attempts to objectively reflect the actual capabilities and potential of alternative suppliers to maintain the long-term benefits of the supply chain through cooperation with partners. 
Table 2. The economic supplier selection criteria.

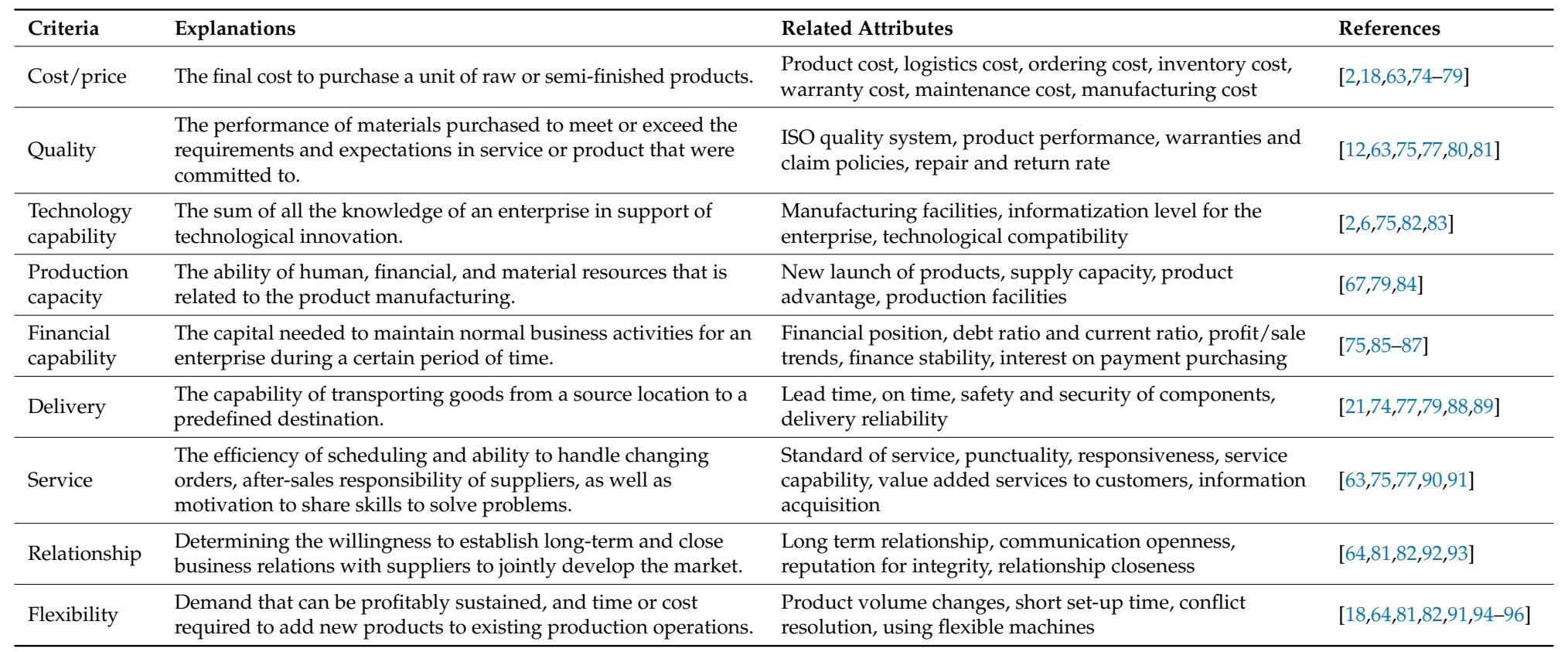

Table 3. The environmental supplier selection criteria.

\begin{tabular}{llll}
\hline Criteria & Explanations & Related Attributes \\
\hline Green image & $\begin{array}{l}\text { The identity that consumers prioritize environmental conservation } \\
\text { and sustainable business practices. }\end{array}$ & $\begin{array}{l}\text { Ratio of green customers to total customers, green customers } \\
\text { market share, green materials coding and recording }\end{array}$ \\
\hline $\begin{array}{l}\text { Environmental } \\
\text { management } \\
\text { system }\end{array}$ & $\begin{array}{l}\text { A system that comprehensively evaluates the internal and external } \\
\text { environmental performance of an organization. }\end{array}$ & $\begin{array}{l}\text { Environmental certificates such as ISO 14000, green process } \\
\text { planning, regulatory compliance, environmental policies }\end{array} \quad[63,75,77,80,81,97,98]$ \\
\hline $\begin{array}{l}\text { Environmental } \\
\text { competencies }\end{array}$ & $\begin{array}{l}\text { The capacity to balance the containment relationships between } \\
\text { economic and environmental performance for an enterprise. }\end{array}$ & $\begin{array}{l}\text { Technical transformation ability, ability to change process and } \\
\text { product for reducing the impact on natural resources, carbon } \\
\text { footprint reduction }\end{array} \quad[14,50,66,80,97,100-102]$ \\
\hline Pollution control & The control of pollutants that are released into air, water, or soil. & $\begin{array}{l}\text { Remediation, end-of-pipe controls, air emissions, waste water, } \\
\text { pollution control capability, pollution reduction capability }\end{array} \quad[66,74,78,97,99]$ \\
\hline
\end{tabular}


Table 3. Cont

\begin{tabular}{llll}
\hline Criteria & Explanations & Related Attributes & References \\
\hline Green product & $\begin{array}{l}\text { Environmentally conscious products, which are pollution-free, } \\
\text { resource-saving, or renewable and recyclable. }\end{array}$ & $\begin{array}{l}\text { Use of recycled and nontoxic materials, green packaging, reuse, } \\
\text { re-manufacture, disposal }\end{array} \quad[6,13,14,81,97]$ \\
\hline $\begin{array}{l}\text { Resource } \\
\text { consumption }\end{array}$ & The use of non-renewable, or less often, renewable resources. & $\begin{array}{l}\text { Consumption of resources in terms of raw material, energy, } \\
\text { and water }\end{array} \quad[68,75,78,97]$ \\
\hline ECO-design & $\begin{array}{l}\text { An approach to designing products with special consideration for } \\
\text { the environmental impacts of the product during its whole lifecycle. }\end{array}$ & $\begin{array}{l}\text { Design for resource efficiency, design of products for reuse, } \\
\text { recycle, and recovery of material, design for reduction or } \\
\text { elimination of hazardous materials }\end{array} \quad[13,77,85,89,97,98,103]$ \\
\hline GSCM & $\begin{array}{l}\text { Considering environmental issues on supply chain; focusing the } \\
\text { coordination between economy and environment. }\end{array}$ & $\begin{array}{l}\text { Commitment of senior managers to support and improve green } \\
\text { supply chain management initiatives, GSCM practice }\end{array} \quad[6,14,50,66,78,81,104,105]$ \\
\hline $\begin{array}{l}\text { Green technology } \\
\text { innovation }\end{array}$ & $\begin{array}{l}\text { The ability to continuously update environmental technologies to } \\
\text { achieve the goal of minimizing the sum of product life cycle costs. }\end{array}$ & $\begin{array}{l}\text { Green technology capabilities, recycling product design, } \\
\text { renewable product design, redesign of product, green R\&D } \\
\text { project, green process }\end{array} \quad$ [66,77,78,99,105-107] \\
\hline
\end{tabular}

Table 4. The social supplier selection criteria.

\begin{tabular}{llll}
\hline Criteria & Explanations & Related Attributes \\
\hline $\begin{array}{l}\text { The rights of } \\
\text { the employee }\end{array}$ & $\begin{array}{l}\text { A group of legal rights and claimed human rights having to do } \\
\text { with labor relations between workers and their employers. }\end{array}$ & $\begin{array}{l}\text { Staff training on sustainable issues, equity labor sources, } \\
\text { disciplinary and security practices, employee contracts }\end{array}$ \\
\hline $\begin{array}{l}\text { The rights of } \\
\text { stakeholders }\end{array}$ & $\begin{array}{l}\text { The right or welfare belonging to the person who holds the stake } \\
\text { or some relevant interests in the private sector. }\end{array}$ & $\begin{array}{l}\text { Partnership standards, share level, stakeholder empowerment, } \\
\text { stakeholder engagement, consumers education, }\end{array}$ \\
\hline $\begin{array}{l}\text { Work safety } \\
\text { and health }\end{array}$ & Concerned with the safety, health, and welfare of people at work. 68,99,108] & Health and safety incidents, health and safety practices \\
\hline $\begin{array}{l}\text { Local } \\
\text { community } \\
\text { influence }\end{array}$ & $\begin{array}{l}\text { Neighboring relations between the company and the local } \\
\text { government, the community and all residents, representing the } \\
\text { public image of the organization. }\end{array}$ & $\begin{array}{l}\text { Service infrastructure, social pathologies, regulatory and public } \\
\text { services, grants and donations, supporting community projects }\end{array}$ \\
\hline $\begin{array}{l}\text { Respect for } \\
\text { the law and } \\
\text { policy }\end{array}$ & $\begin{array}{l}\text { Enterprises comply with all laws and regulations of the country, } \\
\text { assume legal obligations, and promote good social public morals. }\end{array}$ & $\begin{array}{l}\text { Regulatory and public services, ethical issues and legal } \\
\text { complain, power }\end{array}$ \\
\hline $\begin{array}{l}\text { Staff } \\
\text { Training }\end{array}$ & $\begin{array}{l}\text { The process of enhancing the skills, capabilities, and knowledge } \\
\text { of employees for a particular job. }\end{array}$ & $\begin{array}{l}\text { Flexible working arrangements, job opportunities, career } \\
\text { development }\end{array}$ \\
\hline $\begin{array}{l}\text { Information } \\
\text { disclosure }\end{array}$ & $\begin{array}{l}\text { Providing information to stakeholders about the materials used, } \\
\text { carbon emissions, toxins released during production, and so on. }\end{array}$ & $\begin{array}{l}\text { Transparency, information publicity, voluntary disclosure, } \\
\text { public disclosure }\end{array}$ \\
\hline $\begin{array}{l}\text { Child and } \\
\text { forced labor }\end{array}$ & $\begin{array}{l}\text { The employment of children in any work that deprives them of } \\
\text { their childhood and ability to attend regular school. }\end{array}$ & $\begin{array}{l}\text { Child labor avoidance } \\
{[15,18,66,68,29,43,63]}\end{array}$ \\
\hline
\end{tabular}


Table 5. The measures of SSS.

\begin{tabular}{|c|c|c|c|}
\hline Primary Criteria & Second Grade Criteria & Explanations & Reference/Basis \\
\hline \multirow{4}{*}{$\begin{array}{l}\text { Corporate } \\
\text { Reputation (CR) }\end{array}$} & Position in industry* & The market appeal, voice and dominant ability. & [111] \\
\hline & Financial status & $\begin{array}{l}\text { Funds-collection and application within a certain } \\
\text { period, reflecting whether the capital flow is smooth. }\end{array}$ & {$[75,85]$} \\
\hline & Contractual capacity* & The actual ability to perform economic contracts. & [112] \\
\hline & Strategic alliance * & The compatibility of long-term strategies and plans. & [113] \\
\hline \multirow{4}{*}{$\begin{array}{l}\text { Operational } \\
\text { Management (OM) }\end{array}$} & $\begin{array}{l}\text { Business process } \\
\text { management }\end{array}$ & $\begin{array}{l}\text { The ability to coordinate logistics, business, and } \\
\text { information flow, and to discover, analyze, optimize, } \\
\text { and automate business processes. }\end{array}$ & {$[114,115]$} \\
\hline & Technical support & $\begin{array}{l}\text { The ability to use computer and network technology } \\
\text { to make decisions. }\end{array}$ & {$[75,82]$} \\
\hline & Quality management & $\begin{array}{l}\text { Through quality planning, control, assurance and } \\
\text { improvement to ensure product consistency. }\end{array}$ & {$[12,99]$} \\
\hline & Learning * and Innovation & $\begin{array}{l}\text { Through learning to enable firms to make } \\
\text { continuous innovations, and improve their ability to } \\
\text { adapt to the change. }\end{array}$ & {$[18,75]$} \\
\hline \multirow{4}{*}{$\begin{array}{l}\text { Product Advantage } \\
\text { (PA) }\end{array}$} & Procurement cost & $\begin{array}{l}\text { Constituted by the purchase price and the costs } \\
\text { incurred for the purchase of goods. }\end{array}$ & {$[91,99]$} \\
\hline & Product quality & $\begin{array}{l}\text { The embodiment of the use value of products, } \\
\text { including the intrinsic quality and appearance } \\
\text { quality. }\end{array}$ & [90] \\
\hline & Supply flexibility & $\begin{array}{l}\text { The ability to quickly respond to different product } \\
\text { demands. }\end{array}$ & [101] \\
\hline & Product market share & $\begin{array}{l}\text { The proportion of a company's sales volume (or } \\
\text { sales profit) in the market. }\end{array}$ & {$[112,116]$} \\
\hline \multirow{4}{*}{$\begin{array}{l}\text { Service Capability } \\
\text { (SC) }\end{array}$} & Responsiveness & $\begin{array}{l}\text { The ability to quickly identify, react to, and recover } \\
\text { from the changes. }\end{array}$ & [99] \\
\hline & Timely delivery & $\begin{array}{l}\text { The ability to deliver goods on time, usually } \\
\text { expressed on a timely delivery rate. }\end{array}$ & {$[88,99]$} \\
\hline & Customer satisfaction * & $\begin{array}{l}\text { How the products and services supplied by a } \\
\text { company meet or surpass customer expectation. }\end{array}$ & {$[110,116]$} \\
\hline & $\begin{array}{l}\text { Maintenance and } \\
\text { Compensation * }\end{array}$ & $\begin{array}{l}\text { The after-sales service ability for defective products } \\
\text { or equipment, including recall. }\end{array}$ & {$[16,18]$} \\
\hline \multirow{4}{*}{ Green Impact (GI) } & Pollution production & $\begin{array}{l}\text { Environmental pollution caused by the production } \\
\text { of products. }\end{array}$ & {$[104,117]$} \\
\hline & Pollution control & $\begin{array}{l}\text { Control and reduce the pollution caused by the } \\
\text { production process. }\end{array}$ & [99] \\
\hline & Energy consumption & $\begin{array}{l}\text { The consumption of energy or power produced in } \\
\text { the production. }\end{array}$ & {$[75,118]$} \\
\hline & Ecologic design & $\begin{array}{l}\text { Consideration of the environmental impact of the } \\
\text { entire product life cycle at the design stage. }\end{array}$ & [85] \\
\hline \multirow{4}{*}{$\begin{array}{l}\text { Social Responsibility } \\
\text { (SR) }\end{array}$} & Labor relations record & $\begin{array}{l}\text { Historic records revealing the relationship between } \\
\text { labor and enterprise. }\end{array}$ & [99] \\
\hline & Governmental relations * & $\begin{array}{l}\text { The ability of an enterprise to be trusted, supported, } \\
\text { and cooperated with the government }\end{array}$ & [110] \\
\hline & $\begin{array}{l}\text { Community welfare } \\
\text { investment }\end{array}$ & Charity and welfare services to local communities. & [74] \\
\hline & Shareholder contract * & $\begin{array}{l}\text { Safeguarding the interests of shareholders and } \\
\text { bringing value to the shareholders. }\end{array}$ & [119] \\
\hline
\end{tabular}

The symbol * represents the new indicator.

\subsection{Supplier Selection Methods}

Approaches to supplier selection have gone through three main stages of evolution [120]. Early studies on supplier selection normally adopted qualitative methods such as the Heuristics of Judgment, Bidding, and Consultation Choice [121]. However, due to the overdependence on the subjective 
judgment of DMs, this type of method was less accepted by subsequent procurement managers. They instead tried to use quantitative methods, such as the Entropy method, to get easy access to the relative weights of the criteria for ranking their suppliers [122]. Nonetheless, authors later found that many criteria, like "strategic alliance" and "innovation intention", could not be directly quantified. Though some of their sub-criteria may be quantifiable, they could not entirely represent or replace the concepts of the original criteria. Combination methods (quantitative and qualitative) have, therefore, appeared and become the mainstream in field of supplier selection. Currently, models and methods that were applied generally include the following four categories: (a) MCDM methods (for example, AHP, ANP, TOPSIS, VIKOR, and so forth); (b) Mathematical Programming (MP) models (for example, DEA, Linear Programming (LP), Nonlinear Programming (NLP), Multi-objective Programming (MOP), and so forth); (c) Artificial Intelligence Technology (AIT) (for example, Grey Relation Analysis (GRA), ANN, Case-based Reasoning (CBR), Decision Support Systems (DSS), and so forth); and (d) Other Hybrid Models which are basically an integration of the above methods that assembled unique advantages of each technique and provided more sophisticated structures to assess supplier performance [7,123]. Moreover, from fuzzy set theory, introducing fuzzy numbers with various forms to characterize the uncertainty of information is also quite commonly adopted in this field [124]. Table 6 shows the diverse extended forms of typical portfolio models used in the supplier selection area.

Table 6. The typical extended methods for supplier selection.

\begin{tabular}{|c|c|c|c|}
\hline Methods & Extension & Forms & References \\
\hline \multirow{9}{*}{ AHP } & Fuzzy AHP & Fuzzy AHP & {$[77,125,126]$} \\
\hline & \multirow{8}{*}{ Integrated AHP } & AHP and ANN & [127] \\
\hline & & $\mathrm{AHP}$ and $\mathrm{GA}^{1}$ & {$[128]$} \\
\hline & & AHP and DEA & [129] \\
\hline & & AHP and GRA & {$[130]$} \\
\hline & & $\mathrm{AHP}$ and MP & [126] \\
\hline & & AHP and Fuzzy TOPSIS & {$[16,131,132]$} \\
\hline & & AHP and VIKOR & [29] \\
\hline & & AHP and Entropy and TOPSIS & [49] \\
\hline \multirow{11}{*}{ ANP } & Fuzzy ANP & Fuzzy ANP & {$[6,133]$} \\
\hline & \multirow{10}{*}{ Integrated ANP } & ANP and DEA & [134] \\
\hline & & ANP and QFD ${ }^{2}$ & {$[17]$} \\
\hline & & ANP and IPA ${ }^{3}$ & [135] \\
\hline & & ANP and RST ${ }^{4}$ & [104] \\
\hline & & ANP and PROMETHEE & [136] \\
\hline & & ANP and VIKOR & [137] \\
\hline & & ANP and LP & {$[138]$} \\
\hline & & DEMATEL & {$[139,140]$} \\
\hline & & TOPSIS & [141] \\
\hline & & Fuzzy ANP and SWOT ${ }^{5}$ & [142] \\
\hline \multirow{6}{*}{ DEA } & \multirow{6}{*}{ Fuzzy DEA } & Fuzzy DEA & {$[100,143]$} \\
\hline & & DEA and ANN & [144] \\
\hline & & DEA, ANP and ANN & [63] \\
\hline & & DEA and MOLP 6 & [100] \\
\hline & & DEA and RST & [5] \\
\hline & & DEA and $\mathrm{DE}^{7}$ and $\mathrm{MODE}^{8}$ & [30] \\
\hline \multirow{5}{*}{ GRA } & Fuzzy GRA & Fuzzy GRA & [103] \\
\hline & \multirow{4}{*}{ Integrated GRA } & GRA and AHP & [145] \\
\hline & & GRA and ANP & {$[2,146]$} \\
\hline & & $\mathrm{GS}^{9}$ and RST & [50] \\
\hline & & GRA and DEMATEL & {$[147,148]$} \\
\hline \multirow{3}{*}{ TOPSIS } & Fuzzy TOPSIS & Fuzzy TOPSIS & {$[65,66,68,149]$} \\
\hline & \multirow{2}{*}{ Integrated TOPSIS } & DEMATEL-ANP-TOPSIS & [76] \\
\hline & & TOPSIS and ANN & [72] \\
\hline
\end{tabular}


Table 6. Cont.

\begin{tabular}{cccc}
\hline Methods & Extension & Forms & References \\
\hline \multirow{3}{*}{ VIKOR } & Fuzzy VIKOR & Fuzzy VIKOR & {$[25]$} \\
\cline { 2 - 4 } & \multirow{3}{*}{ Integrated VIKOR } & VIKOR and AHP & {$[29]$} \\
& & VIKOR and NGT ${ }^{10}$ & {$[109]$} \\
& & VIKOR and fuzzy ELECTRE & {$[150]$} \\
\hline
\end{tabular}

${ }^{1}$ GA: Genetic Algorithm; ${ }^{2}$ QFD: Quality Function Deployment; ${ }^{3}$ IPA: Importance Performance Analysis; ${ }^{4}$ RST: Rough Set Theory; ${ }^{5}$ SWOT: Superiority Weakness Opportunity Threats; ${ }^{6}$ MOLP: Multiple Objective Linear Programming; ${ }^{7}$ DE: Differential Evolution; ${ }^{8}$ MODE: Multi-objective Differential Evolution; ${ }^{9}$ GS: Grey System; ${ }^{10}$ NGT: Nominal Group Technique.

MCDM, a centralized decision-making method for ranking and choosing the optimal alternative in limited (infinite) programs under a conflicting and non-commensurable situation, has wide applications in many fields, including engineering, military, economy, technology, and management $[5,6,72]$. In the multiple criteria framework for supplier selection, single-goal methods would hardly solve the problem, as cost indicators and benefit indicators are often contradictory. MCDM methods such as the TOPSIS and VIKOR techniques, relying on consolidation function measuring the "closeness to the ideal solution", are proved to be typical compromise programming technologies $[24,151]$ which can logically and effectively address SSS issues with multiple objectives. Compared with a large number of the extensions of the TOPSIS method in the past decade, the improved forms of the VIKOR algorithm have just appeared in recent years. However, VIKOR is technically superior to TOPSIS, mainly because the final optimal solution obtained by VIKOR is closer to the ideal solution than that of TOPSIS [24].

Before using the VIKOR algorithm to acquire priority ranking, criteria weights need to be determined first. Expert experience and the weighted average method are universally used in reality [28], but such methods barely consider possible judgment biases that DMs may make, and rarely inspect any potential inconsistencies within the model [12]. The AHP, ANP, and ANN methods have been applied to address such limitations; however, these methods assume that indicators are internally independent, and therefore, ignore the possible interdependencies among them [49,63], which may yield erroneous weights. As the relationships between calculated weights can deviate from the actual phenomenon, scholars for this concern have considered combining the DEMATEL method with the ANP to calculate weights $[28,76,152]$. DEMATEL can analyze the interplay among the evaluation indexes and obtain a more intuitive index network structure which may help to redefine the relationship between the first-and second-level indexes under ANP, so as to acquire more accurate and objective criteria weights. This weight acquisition approach has seldom been applied in SSS, and existing studies almost always stop at the combination of the DEMATEL, ANP and VIKOR methods, rarely expanding further.

On the other hand, as the input of VIKOR, the value of indicators is not always easy to observe directly due to the complexity and uncertainty of the SSS problem. Fuzzy number is therefore introduced to be an effective extension to characterize the vagueness and uncertainty in the data process [81]. Interval number [152,153], triangular fuzzy number [25,154], trapezoidal fuzzy number [12], intuitionistic fuzzy number [155], two-tuple linguistic information [156], generalized interval trapezoidal fuzzy number [157], and other different forms of fuzzy number have been widely applied to be information aggregation under the VIKOR method, but there are hardly any applications introducing IVTFN into the VIKOR method, and this fuzzy number is seldom used to describe the characteristics of indicators for sustainable suppliers. As Kuo and Liang [27] and Lin and Tseng [26] have verified the applicability and effectiveness of the IVTFN in performance evaluation, we thereby consider introducing this data type into the SSS problem as the semantic expression of qualitative indicators. 


\section{Methodology}

An improved integrated MCDM model with hybrid information aggregation for SSS has been proposed; it includes four phases. The first phase involves identification of the criteria used to evaluate the social performance of suppliers. In this study, the measure is determined from both literature reviews and discussions with the experts in the industry, especially retailing. After that, it integrates the DEMATEL method to examine the interrelationships between the indicators with the ANP method to calculate the criteria weights. In the third stage, hybrid data type is introduced to describe quantitative and qualitative criteria of candidate suppliers to the aggregate hybrid information set for subsequent decision. In the final phase, the VIKOR method is adopted to rank and determine the optimal sustainable supplier according to the mixed information set, while a sensitivity analysis is conducted to test the robustness of the proposed model. The technical route of the integrated method is shown in Figure 2.

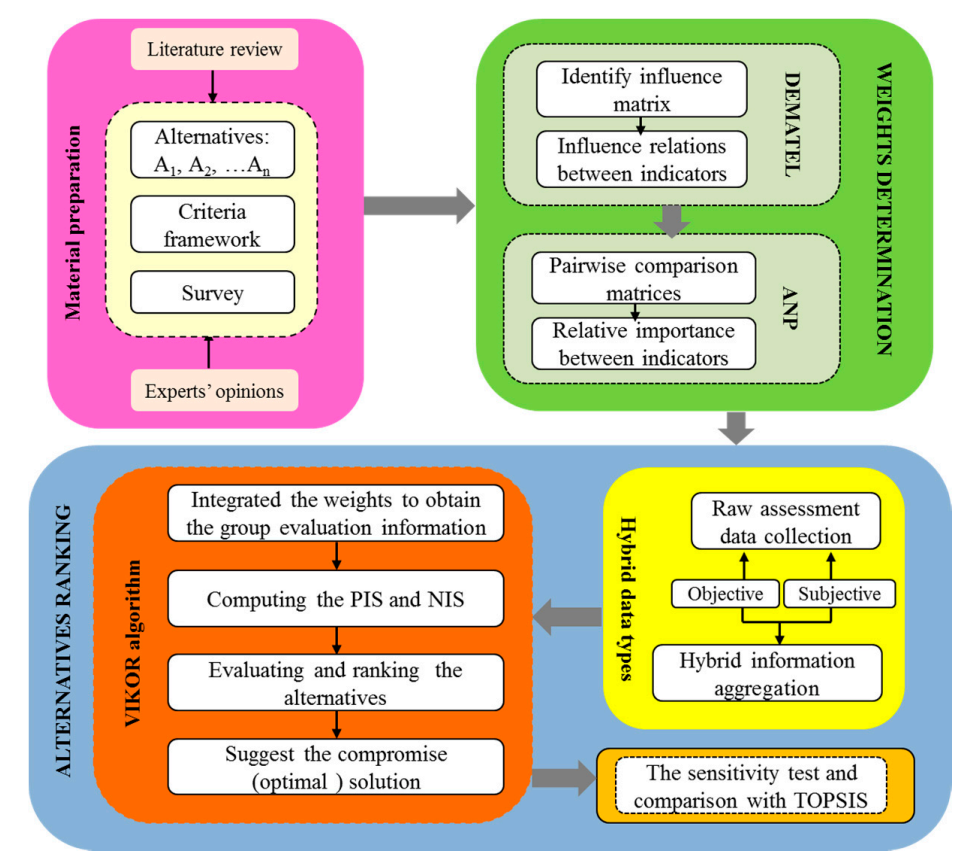

Figure 2. The proposed integrated hybrid-valued MCDM model for a sustainable supplier.

\subsection{DEMATEL-ANP-VIKOR}

\subsubsection{Combining the DEMATEL and ANP to Obtain Criteria Weights}

The ANP is the general form of AHP proposed by Saaty [158], which considers the inter-dependency and relationship between the factors group in a super-matrix way, and can calculate the criteria weights in the network structure through a systematic decision process which reflects the logical relationship of the factors. However, Ou Yang, Shieh, Leu and Tzeng [20] pointed out that the weight of each cluster should not be equal in obtaining a weighted super-matrix, because this method ignores the prior consideration of the interrelationship between factors. Then, the DEMATEL, a method that is increasingly being applied to identify the potential interrelationships among factors and to analyze strong or weak correlations based on the graph theory and matrix tools [159], is considered in combintation with ANP in weight determination. An empirical study indicates the effectiveness of this integrated method $[20,76,160]$, which employs the DEMATEL method to calculate the degree of impact between the indicators before determining the relative importance among the criteria in ANP. Based on this logic, we further improve the DEMATEL-ANP method by simplifying the process of obtaining a network relationships map of influence, which not only does not change the results, but 
can effectively reduce the amount of calculation. The process of the DEMATEL-ANP algorithm is as follows [161,162]:

- Step 1: Calculating the initial average matrix through expert marks. Given the integer scale from 0 to 4 ("No impact (0)", "Low impact (1)", "Moderate impact (2)", "High impact (3)", and "Super-high impact (4)", respectively), inviting experts to answer the direct effects that they think criterion $i$ imposed on another criterion $j$, as indicated by $a_{i j}$. We can obtain an average matrix $A=\left[a_{i j}\right]_{n \times n}$ by any direct matrix set, of which factors in matrix $A$ are the mean values integrated from the initial experts' judgments.

- Step 2: Deriving the full direct/indirect impact matrix and normalizing the direct impact matrix $D$, as shown in Equation (1).

$$
\begin{aligned}
& D=k \times A, \text { where } \\
& k=\min \left(\frac{1}{\max _{1 \leq i \leq n} \sum_{j=1}^{n}\left|a_{i j}\right|}, \frac{1}{\max _{1 \leq j \leq n} \sum_{i=1}^{n}\left|a_{i j}\right|}\right)
\end{aligned}
$$

- Step 3: Obtaining the total impact matrix $T$ through Equation (2); I represents the identity matrix.

$$
T=D^{1}+D^{2}+D^{3}+\cdots=\sum_{i=1}^{+\infty} D^{i}=D \cdot(I-D)^{-1}
$$

- Step 4: Defining the sum of rows and sums of columns, respectively, as vectors $R$ and $C$ in the total impact matrix $T$ via Equations (3)-(5), of which element $(i, j)$ can be denoted as $t_{i j}$, and

$$
\begin{gathered}
T=\left(t_{i j}\right)_{n \times n^{\prime}} i, j \in\{1,2, \cdots, n\} \\
R=\sum_{j=1}^{n} t_{i j} \\
C=\sum_{i=1}^{n} t_{i j}
\end{gathered}
$$

Notably, $\left(c_{i}+r_{i}\right)$ is donated as the center degree which represents the relative importance of factor $i$ while $\left(c_{i}-r_{i}\right)$ is denoted as the cause degree, indicating the relationship between factor $i$ and the others. If $\left(c_{i}-r_{i}\right)$ is positive, then factor $i$ affects the other factors. Otherwise, it is corrupted by other effects [163-165].

- Step 5: Generating a causal diagram of the primary index to identify the relationship between the primary indicators and their importance according to the value of center degree $\left(c_{i}+r_{i}\right)$ and cause degree $\left(c_{i}-r_{i}\right)$.

- Step 6: Identifying the relationship between the primary indicators according to the DEMATEL method, setting the thresholds [162], and removing the indicators with a weaker impact, re-determining the incidence relation between the indicators, and drawing the influence relation diagram while combining it with the actual situation of the secondary indicators to map the ANP network structure.

- Step 7: Constructing judgment matrix $W$, assuming that in the network structure of ANP the indicators for the goal $G$ in the control layer are indicated as $S_{1}, S_{2}, S_{3}, \cdots, S_{m}$ while the element set in the network layer is indicated as $C_{1}, C_{2}, C_{3}, \cdots, C_{n}$, where elements $c_{i 1}, c_{i 2}, c_{i 3}, \cdots, c_{i n}(i=$ $1,2, \cdots n)$ are in $C_{i}$. Regarding $S_{i}$ in the control layer as the indicator, and $c_{j k}$ in $C_{j}$ as the sub-criteria, and comparing the degree of impact $c_{j k}$ influenced by the other elements in $C_{i}$, allows for the construction of the judgment matrix under the indicator $S_{i}$. On this basis, the normalized feature vector $W_{i 1}^{(j k)}, W_{i 2}^{(j k)}, \ldots W_{i n}^{(j k)}$ can be calculated as the ordering vector of the 
network element. By repeating the above steps for $k=1,2, \cdots, n_{i}$, the following matrix can be obtained by Equation (6).

$$
W_{i j}=\left\{\begin{array}{ccc}
W_{i 1}^{(j 1)} & \cdots & W_{i 1}^{\left(j n_{j}\right)} \\
\vdots & & \vdots \\
W_{i n_{1}}^{(j 1)} & \cdots & W_{i n_{1}}^{\left(j n_{j}\right)}
\end{array}\right\}
$$

- Step 8: Contributing to pairwise comparisons. According to the structure of the judgment matrix $W$, the relative importance of the clusters and factors forming the ANP decision network is obtained through expert pairwise comparisons. The relative importance of the calculated factors is attained by comparing the results of the individual indicators [146].

- Step 9: Solving the unweighted super-matrix, the weighted super-matrix, and the limit super-matrix. By combining with the interactional ordering vector of all network layer elements to form a super-matrix $\widetilde{W}$ under the control element $S_{i}$ and normalizing each column, we can then obtain the weight matrix $E$, which is composed of the ordering vectors. As is shown in Equation (7), $e_{i j}$ represents the influence weight of element group $i$ on group $j$ under the criterion $S_{i}$ in the control layer. If these two factors have no impact on each other, then $e_{i j}=0$. The resulting weighted super-matrix, as shown in Equation (8), is the sum of the elements of each column equal to 1 . Then, we make a stability process for the weighted super-matrix to calculate the limit relative ordering vector $\lim _{k \rightarrow+\infty} \bar{W}^{k}$. If this limit is convergent and unique, then the column $i$ is the ranking of the element $i$ relative to the other elements in the network layer under the criterion, namely, the weight value of each element relative to the highest target.

$$
\begin{gathered}
E=\left(\begin{array}{ccc}
e_{i 1} & \cdots & e_{i 1} \\
\vdots & & \vdots \\
e_{i n_{i}} & \cdots & e_{i n_{i}}
\end{array}\right) \\
\bar{W}=E \times \widetilde{W}=\left(\bar{W}_{i j}\right)=\left(e_{i j} \times \widetilde{W}_{i j}\right)
\end{gathered}
$$

\subsubsection{Ranking Candidate Suppliers Using the VIKOR Technique}

\section{The Algorithm Principle of VIKOR and Comparison with TOPSIS}

The VIKOR technique is a MCDM method proposed by Opricovic in 1998, which both considers maximizing the group benefit and minimizing the individual regret of the opposition [151] to solve the optimal compromise solution. Compared with another typical MCDM method, TOPSIS, which defines that the optimal solution should be the shortest distance from the positive ideal solution (PIS) and the longest distance from the negative ideal solution (NIS) [65], VIKOR uses the group-decision consolidation function $Q$ to measure the distance between the potential and the ideal solutions. TOPSIS determines the final rankings through the calculation of the aggregate function $\varepsilon_{i}=d^{-} /\left(d^{-}+d^{+}\right)$, while $d^{-}$and $d^{+}$represent the distance from the NIS and PIS, respectively. However, this function has a theoretical limitation that the final scheme obtained is not always the closest to the ideal solution. We illustrate this further in Figure 3. Assuming that the distance between $A_{k}$ and the NIS is the same as that of PIS (that is, $d^{+}=d^{-}$), for any alternative $A_{i}$, it will always prevail over $A_{k}$, as long as it satisfies the requirement that the distance to the NIS be longer than to the PIS (that is, $d^{-}>d^{+}$) for $\varepsilon_{i}=\frac{d^{-}}{d^{-}+d^{+}}>0.5=\varepsilon_{k}$. Even though the scheme is closer to the PIS (that is, $d_{k}^{+}>d_{i}^{+}$), the priority position will not change under the TOPSIS method. 


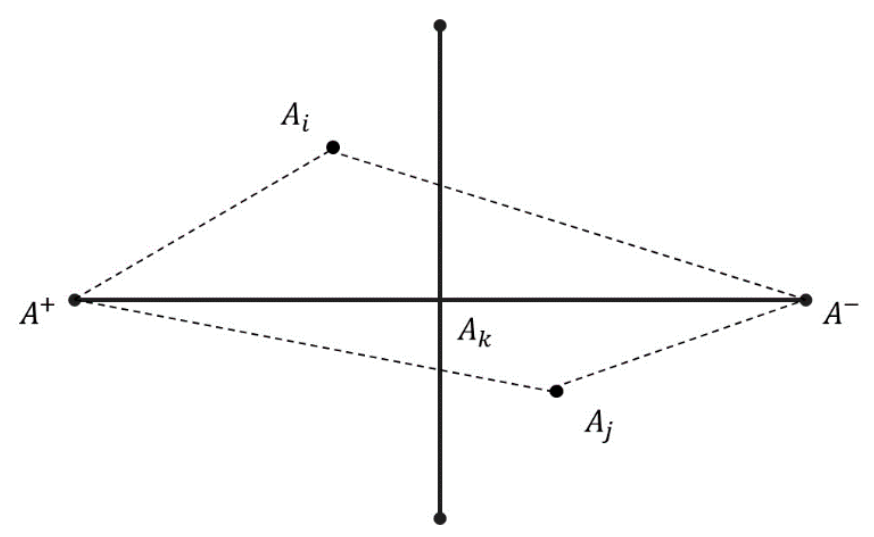

Figure 3. The distance measurement of TOPSIS.

In addition, the location of PIS and NIS are of importance to the actual decision, but the TOPSIS method cannot observe the relative importance between the alternatives and these two points [24]. In short, the TOPSIS method is more suitable for solving the risk decision problem, while the VIKOR scheme is applicable to those DMs that tend to maximize team effectiveness. Since the choice of sustainable suppliers needs to consider the comprehensive benefits from the economic, environmental, and societal aspects, the VIKOR algorithm is better-suited.

\section{The Computational Procedure of VIKOR}

- Step 1: Assembling and transforming the original quantitative data based on transaction records, market performances, and the qualitative information judged by the scorers, integrating the weights obtained through the DEMATEL-ANP method to get the group evaluation information, and further build a streamlined fuzzy evaluation matrix, as shown in Equations (9) and (10) for the weight.

$$
\begin{gathered}
X=\left(\begin{array}{ccc}
\widetilde{x}_{11} & \cdots & \widetilde{x}_{1 n} \\
\vdots & & \vdots \\
\widetilde{x}_{m 1} & \cdots & \widetilde{x}_{m n}
\end{array}\right)=\left[\widetilde{x}_{i j}\right]_{m \times n} \\
w=\left[\widetilde{w}_{1}, \widetilde{w}_{2}, \cdots, \widetilde{w}_{n}\right], \widetilde{w}_{i} \geq 0
\end{gathered}
$$

where $\widetilde{x}_{i j}$ represents the performance of $c_{j}$ under alternative $A_{i}, i=1,2, \cdots, m, j=1,2, \cdots, n . w_{j}$ represents the weight of $c_{j}$ as determined by the DEMATEL-ANP method.

Considering the different importance level of each criterion $c_{j}$, and constructing the weighted interval decision fuzzy matrix, $\widetilde{V}=\left[\widetilde{v}_{i j}\right]$, where $\widetilde{v}_{i j}=\widetilde{x}_{i j}(\cdot) \widetilde{w}_{j}=\left[\left(a_{i j}, a_{i j}^{\prime}\right), b_{i j},\left(c_{i j}, c^{\prime}{ }_{i j}\right)\right], i=1,2, \cdots, m$; $j=1,2, \cdots, n$.

- Step 2: After determining the decision matrix, the PISs $\left(A^{* 1}\right.$ and $\left.A^{* 2}\right)$ and NIS $\left(A^{-1}\right)$ can be attained, as shown in Equations (11)-(13), where $B$ represents the beneficial criteria and $C$ represents the cost criteria.

$$
\begin{gathered}
A^{* 1}=\left\{\widetilde{x}_{1}^{*}, \widetilde{x}_{2}^{*}, \cdots, \widetilde{x}_{n}^{*}\right\}=\left\{\left(\max _{i} \widetilde{x}_{i j} \mid j \in B\right) \operatorname{or}\left(\min _{i} \widetilde{x}_{i j} \mid j \in C\right)\right\} \\
j=1,2, \cdots, n=\left\{\left[\left(l_{1}^{*}, l_{1}^{*}\right), m_{1}^{*},\left(r_{1}^{*}, r_{1}^{*}\right)\right],\left[\left(l_{2}^{*}, l_{2}^{*}\right), m_{2}^{*},\left(r_{2}^{\prime *}, r_{2}^{*}\right)\right], \cdots,\left[\left(l_{n}^{*}, l_{n}^{*}\right), m_{n}^{*},\left(r^{\prime *}, r_{n}^{*}\right)\right]\right\} \\
A^{* 2}=\left\{\widetilde{v}_{1}^{*}, \widetilde{v}_{2}^{*}, \cdots, \widetilde{v}_{n}^{*}\right\}=\left\{\left(\max _{i} \widetilde{v}_{i j} \mid j \in B\right) \operatorname{or}\left(\min _{i} \widetilde{v}_{i j} \mid j \in C\right)\right\} \\
j=1,2, \cdots, n=\left\{\left[\left(a_{1}^{*}, a_{1}^{\prime *}\right), b_{1}^{*},\left(c_{1}^{\prime}, c_{1}^{*}\right)\right],\left[\left(a_{2}^{*}, a_{2}^{*}\right), b_{2}^{*},\left(c_{2}^{\prime *}, c_{2}^{*}\right)\right], \cdots,\left[\left(a_{n}^{*}, a_{n}^{\prime *}\right), b_{n}^{*},\left(c^{\prime *}, c_{n}^{*}\right)\right]\right\} \\
A^{-1}=\left\{\widetilde{x}_{1}^{-}, \widetilde{x}_{2}^{-}, \cdots, \widetilde{x}_{n}^{-}\right\}=\left\{\left(\min _{i} \widetilde{x}_{i j} \mid j \in B\right) \operatorname{or}\left(\max _{i} \widetilde{x}_{i j} \mid j \in C\right)\right\} \\
j=1,2, \cdots, n=\left\{\left[\left(l_{1}^{-}, l_{1}^{\prime}\right), m_{1}^{-},\left(r_{1}^{\prime}, r_{1}^{-}\right)\right],\left[\left(l_{2}^{-}, l_{2}^{\prime}\right), m_{2}^{-},\left(r_{2}^{\prime}, r_{2}^{-}\right)\right], \cdots,\left[\left(l_{n}^{-}, l_{n}^{\prime}\right), m_{n}^{-},\left(r_{n}^{\prime}, r_{n}^{-}\right)\right]\right\}
\end{gathered}
$$


- $\quad$ Step 3: Following Equations (14)-(17) to obtain the $\widetilde{S}_{i}$ and $\widetilde{R}_{i}$ values of the potential supplier, respectively:

$$
\begin{gathered}
\widetilde{S}_{i}=\sum_{j=1}^{n}\left(\frac{\widetilde{s}_{i j}^{U}+\widetilde{s}_{i j}^{L}}{2}\right) \\
\widetilde{R}_{i}=\max _{j}\left(\frac{\widetilde{s}_{i j}^{U}+\widetilde{s}_{i j}^{L}}{2}\right), i=1,2, \cdots, m \\
\widetilde{s}_{i j}^{U}=\sum_{j \in B} \frac{\sqrt{\frac{1}{3}\left[\left(a_{j}^{*}-a_{j}\right)^{2}+\left(b_{j}^{*}-b_{j}\right)^{2}+\left(c_{j}^{*}-c_{j}\right)^{2}\right]}}{\sqrt{\frac{1}{3}\left[\left(l_{j}^{*}-l_{j}^{-}\right)^{2}+\left(m_{j}^{*}-m_{j}^{-}\right)^{2}+\left(r_{j}^{*}-r_{j}^{-}\right)^{2}\right]}}+\sum_{j \in C} \frac{\sqrt{\frac{1}{3}\left[\left(a_{j}-a_{j}^{*}\right)^{2}+\left(b_{j}-b_{j}^{*}\right)^{2}+\left(c_{j}-c_{j}^{*}\right)^{2}\right]}}{\sqrt{\frac{1}{3}\left[\left(l_{j}^{-}-l_{j}^{*}\right)^{2}+\left(m_{j}^{-}-m_{j}^{*}\right)^{2}+\left(r_{j}^{-}-r_{j}^{*}\right)^{2}\right]}} \\
\widetilde{s}_{i j}^{L}=\sum_{j \in B} \frac{\sqrt{\frac{1}{3}\left[\left(a_{j}^{\prime *}-a_{j}^{\prime}\right)^{2}+\left(b_{j}^{*}-b_{j}\right)^{2}+\left(c_{j}^{\prime *}-c_{j}^{\prime}\right)^{2}\right]}}{\sqrt{\frac{1}{3}\left[\left(l_{j}^{*}-l_{j}^{\prime}\right)^{2}+\left(m^{\prime}{ }_{j}^{*}-m_{j}^{\prime}\right)^{2}+\left(r_{j}^{\prime *}-r_{j}^{\prime}\right)^{2}\right]}}+\sum_{j \in C} \frac{\sqrt{\frac{1}{3}\left[\left(a_{j}^{\prime}-a_{j}^{\prime *}\right)^{2}+\left(b_{j}-b_{j}^{*}\right)^{2}+\left(c_{j}^{\prime}-c_{j}^{\prime *}\right)^{2}\right]}}{\sqrt{\frac{1}{3}\left[\left(l_{j}^{\prime}-l_{j}^{\prime *}\right)^{2}+\left(m_{j}^{\prime}-m_{j}^{\prime *}\right)^{2}+\left(r_{j}^{\prime}-r_{j}^{\prime *}\right)^{2}\right]}}
\end{gathered}
$$

- $\quad$ Step 4: Acquiring the corresponding $\widetilde{Q}_{i}$ basis of $\widetilde{S}_{i}$ and $\widetilde{R}_{i}$ through Equation (18):

$$
\widetilde{Q}_{j}=v\left(\widetilde{S}_{j}-\widetilde{S}^{*}\right) /\left(\widetilde{S}^{-}-\widetilde{S}^{*}\right)+(1-v)\left(\widetilde{R}_{j}-\widetilde{R}^{*}\right) /\left(\widetilde{R}^{-}-\widetilde{R}^{*}\right)
$$

where $\widetilde{S}^{*}=\min _{j} \widetilde{S}_{j} ; \widetilde{S}^{-}=\max _{j} \widetilde{S}_{j} ; \widetilde{R}^{*}=\min _{j} \widetilde{R}_{j} ; \widetilde{R}^{-}=\max _{j} \widetilde{R}_{j}$.

In equation (18), $v$ represents the decision mechanism coefficient. When (1) $v$ is greater than 0.5 , the final decision is made by most people; (2) when $v$ is approximately equal to 0.5 , the final decision is made with actual approval; and (3) when $v$ is smaller than 0.5 , the final decision is made by fewer people. Generally, it is assumed that $v$ equals 0.5 for pursuing the maximization of group utility and minimizing the individual regrets in the VIKOR method.

- Step 5: Obtaining the ranks of the alternatives according to the value of $\widetilde{Q}_{j}, \widetilde{S}_{j}$ and $\widetilde{R}_{j}$ respectively. Notably, the smaller the $\widetilde{Q}_{j}$ value is, the better the scheme may be.

- Step 6: After determining the sorting scheme, checking whether the compromise can be accepted. If the following two conditions are met, the compromise solution according to the $\widetilde{Q}_{j}$ value will be the best alternative.

Condition 1. If $Q\left(A^{(2)}-A^{(1)}\right) \geq D Q$, where $D Q=1 /(J-1)$, J represents the quantity of candidate suppliers and $A^{(1)}$ and $A^{(2)}$ are the ranking first and second alternatives in ascending order according to the $Q$ value, that is, $Q\left(A^{(2)}\right)$ is expressed as the second minimum $Q$ and $Q\left(A^{(1)}\right)$ is expressed as the first minimum $Q$, then the corresponding option for $Q\left(A^{(1)}\right)$ (with a minimum $Q$ value) will be the optimal solution or the compromise.

Condition 2. Alternatives $Q\left(A^{(1)}\right)$ must both satisfy the optimal order by $S$ and/or $R$ values in ascending order.

If one of the above conditions is not satisfied, then only a set of compromise schemes can be obtained, namely,

1. If Condition 2 is not met, the final set contains $A^{(1)}$ and $A^{(2)}$;

2. If Condition 1 is not met, the final set contains $A^{(1)}, A^{(2)}, \cdots, A^{(L)}$, where the maximum value of $L$ in $A^{(L)}$ is decided by $Q\left(A^{(L)}-A^{(1)}\right)<D Q$.

\subsection{Hybrid Data Type and Information Aggregation}

Since qualitative factors and quantitative indicators often coexist simultaneously in the measure of supplier selection, it cannot be accurate and in line with reality if those factors are scored by a single value type. This paper proposes hybrid information aggregation which can reduce the vague and subjective impact of human judgments and preferences through mixed data forms to describe 
the comprehensive performance of potential suppliers, which includes the precise number, interval number, and fuzzy number.

\subsubsection{Precise Number}

The economic assessment criteria of a sustainable supplier like cost, price, and order response rate can be characterized as precise numbers in line with market performance and transaction records. For the numeric data $h_{i j}$, we use Equation (19) to eliminate the effects of the dimension through a normalization procedure, and then donated $r_{i j}$ after the processing in which $B$ and $C$ are express as the beneficial indicator and cost indicator, separately.

$$
r_{i j}=\left\{\begin{array}{l}
\frac{h_{i j}}{\max _{j} h_{i j}}, 1 \leq i \leq m, 1 \leq j \leq n, h_{i j} \in B \\
\frac{\min _{j} h_{i j}}{h_{i j}}, 1 \leq i \leq m, 1 \leq j \leq n, h_{i j} \in C
\end{array}\right.
$$

\subsubsection{Interval Number}

The interval number is able to depict the uncertainty of the quantitative data in the decision-making process. Through setting the interval, some quantitative indicators that do not have an accurate value can be measured. The distance measure for any two intervals can be defined as follows:

Definition 1. For any two interval numbers $\widetilde{Y}_{1}=\left[\widetilde{Y}_{1}{ }^{l}, \widetilde{Y}_{1}{ }^{u}\right]$ and $\widetilde{Y}_{2}=\left[\widetilde{Y}_{2}{ }^{l}, \widetilde{Y}_{2}{ }^{u}\right]$, the distance can be calculated using Equation (20).

$$
d\left(\widetilde{Y}_{1}, \widetilde{Y}_{2}\right)=\frac{\sqrt{2}}{2} \sqrt{\left(\widetilde{Y}_{1}^{l}-\widetilde{Y}_{2}^{l}\right)^{2}+\left(\widetilde{Y}_{1}^{u}-\widetilde{Y}_{2}^{u}\right)^{2}}
$$

The interval number $\left[y_{i j}^{l}, y_{i j}^{u}\right]$ can be donated as $\left[r_{i j}^{l}, r_{i j}^{u}\right]$ after standardized processing while

$$
\begin{aligned}
& r_{i j}^{l}=\frac{y_{i j}^{l}}{\max _{j} x_{i j}^{u}}, r_{i j}^{l}=\frac{y_{i j}^{u}}{\max _{j} x_{i j}^{u i}}, 1 \leq i \leq m, 1 \leq j \leq n,\left[y_{i j}^{l}, y_{i j}^{u}\right] \in B \\
& r_{i j}^{u}=\frac{\min _{j} y_{i j}^{l}}{y_{i j}^{u}}, r_{i j}^{l}=\frac{\min _{j} y_{i j}^{l}}{y_{i j}^{l}}, 1 \leq i \leq m, 1 \leq j \leq n,\left[y_{i j}^{l}, y_{i j}^{u}\right] \in C
\end{aligned}
$$

\subsubsection{Interval-Valued Triangular Fuzzy Number}

Definition and Graphic Demonstration

Consider an MCDM problem, let $A=\left\{A_{1}, A_{2}, \cdots, A_{m}\right\}$ be a finite set of feasible alternatives and $C=\left\{C_{1}, C_{2}, \cdots, C_{n}\right\}$ be a finite set of criteria. The vector of the criteria weights $w=\left\{w_{1}, w_{2}, \cdots, w_{n}\right\}$ is unknown, but it satisfies $w_{j} \geq 0, j=1,2, \cdots, n, \sum_{j=1}^{n} w_{j}=1$.

Definition 2. Assuming that the performance of alternative $A_{i}$ regarding any item of evaluation criteria $C_{j}$ is defined as $\widetilde{X}_{i j}$, and $\widetilde{X}_{i j}=\left[\widetilde{x}_{i j}\right]_{m \times n}$ is a fuzzy matrix that contains the major evaluating qualitative factors, we define $\widetilde{x}_{i j}$ as an interval-valued triangular fuzzy number (IVTFN) [166], as shown in Figure 4.

$$
\widetilde{x}=\left\{\begin{array}{l}
\left(x_{1}, x_{2}, x_{3}\right) \\
\left(x_{1}^{\prime}, x_{2}, x_{3}^{\prime}\right)
\end{array}, 0<x_{1} \leq x^{\prime} \leq x_{2} \leq x_{3}^{\prime} \leq x_{3}\right.
$$

Then $\widetilde{x}_{i j}$ can be also demonstrated as $\widetilde{x}=\left[\left(x_{1}, x_{1}^{\prime}\right) ; x_{2} ;\left(x^{\prime}{ }_{3}, x_{3}\right)\right]$. 


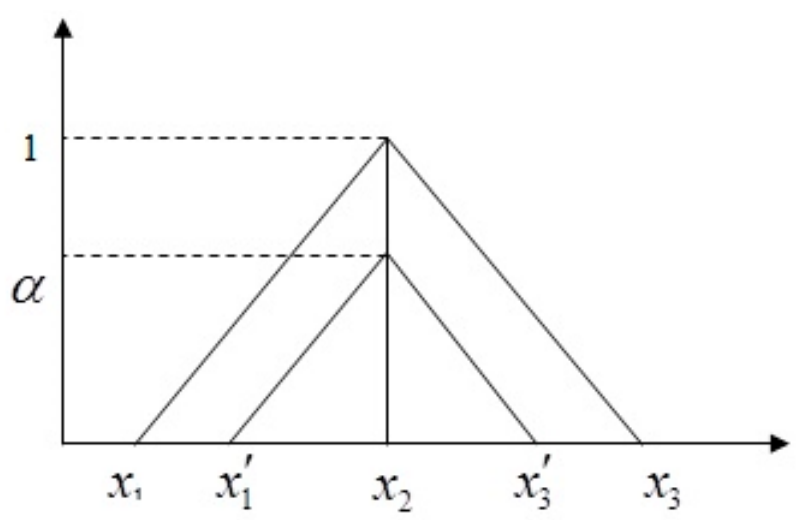

Figure 4. The diagram form of IVTFNs [166].

Arithmetic Operations

According to Definition 2, we can define two IVTFNs as $\widetilde{x}=\left[\left(x_{1}, x_{1}^{\prime}\right) ; x_{2} ;\left(x_{3}^{\prime}, x_{3}\right)\right]$ and $\widetilde{y}=\left[\left(y_{1}, y_{1}^{\prime}\right) ; y_{2} ;\left(y^{\prime}{ }_{3}, y_{3}\right)\right]$, separately. Then the arithmetic rules for these two IVTFNs are represented as follows [166]:

(1) Addition:

$$
\widetilde{x}+\widetilde{y}=\left[\left(x_{1}, x_{1}^{\prime}\right) ; x_{2} ;\left(x^{\prime}{ }_{3}, x_{3}\right)\right]+\left[\left(y_{1}, y_{1}^{\prime}\right) ; y_{2} ;\left(y^{\prime}{ }_{3}, y_{3}\right)\right]=\left[\left(x_{1}+y_{1}, x_{1}^{\prime}+y_{1}^{\prime}\right) ; x_{2}+y_{2} ;\left(x_{3}^{\prime}+y_{3}^{\prime}{ }_{3}, x_{3}+y_{3}\right)\right]
$$

(2) Subtraction:

$$
\widetilde{x}-\widetilde{y}=\left[\left(x_{1}, x_{1}^{\prime}\right) ; x_{2} ;\left(x_{3}^{\prime}, x_{3}\right)\right]-\left[\left(y_{1}, y_{1}^{\prime}\right) ; y_{2} ;\left(y^{\prime}{ }_{3}, y_{3}\right)\right]=\left[\left(x_{1}-y_{1}, x_{1}^{\prime}-y_{1}^{\prime}\right) ; x_{2}-y_{2} ;\left(x_{3}^{\prime}-y_{3}^{\prime}, x_{3}-y_{3}\right)\right]
$$

(3) Multiplication:

$$
\widetilde{x} \otimes \widetilde{y}=\left[\left(x_{1}, x_{1}^{\prime}\right) ; x_{2} ;\left(x_{3}^{\prime}, x_{3}\right)\right] \otimes\left[\left(y_{1}, y_{1}^{\prime}\right) ; y_{2} ;\left(y^{\prime}{ }_{3}, y_{3}\right)\right]=\left[\left(x_{1} y_{1}, x^{\prime}{ }_{1} y_{1}^{\prime}\right) ; x_{2} y_{2} ;\left(x_{3}^{\prime} y^{\prime}{ }_{3}, x_{3} y_{3}\right)\right]
$$

(4) Multiplication figure with IVTFNs:

$$
k \times \widetilde{x}=\left[\left(k x_{1}, k x_{1}^{\prime}\right) ; k x_{2} ;\left(k x_{3}^{\prime}, k x_{3}\right)\right],
$$

where $k$ is an arbitrary positive real number.

(5) Reciprocal value:

$$
\frac{1}{\widetilde{x}}=\left[\left(\frac{1}{x_{3}}, \frac{1}{x_{3}^{\prime}}\right) ; \frac{1}{x_{2}} ;\left(\frac{1}{x_{1}^{\prime}}, \frac{1}{x_{1}}\right)\right]
$$

Distance Measure

Definition 3. Suppose $\widetilde{X}=\left[X^{L}, X^{U}\right]$ and $\widetilde{Y}=\left[Y^{L}, Y^{U}\right]$ are two arbitrary IVTFNs, the normalized Euclidean distance can be calculated as follows [27]:

$$
\begin{gathered}
d(\widetilde{X}, \widetilde{Y})=\sqrt{\frac{1}{6} \sum_{x, y=1}^{3}\left[\left(\widetilde{X}^{L}-\widetilde{Y}^{L}\right)^{2}+\left(\widetilde{X}^{U}-\widetilde{Y}^{U}\right)^{2}\right]} \\
d(\widetilde{X}, \widetilde{Y})^{L}=\sqrt{\frac{1}{3} \sum_{x, y=1}^{3}\left[\left(\widetilde{X}^{L}-\widetilde{Y}^{L}\right)^{2}\right]} \\
d(\widetilde{X}, \widetilde{Y})^{U}=\sqrt{\frac{1}{3} \sum_{x, y=1}^{3}\left[\left(\widetilde{X}^{U}-\widetilde{Y}^{U}\right)^{2}\right]}
\end{gathered}
$$


Definition 4. Let $\widetilde{O}=[(0,0) ; 0 ;(0,0)]$ be an initial solution. Considering any two IVTFNs, $\widetilde{X}$ and $\widetilde{Y}$, If $d(\widetilde{X}, \widetilde{O})<d(\widetilde{Y}, \widetilde{O})$, then $\widetilde{X}$ is closer to the initial solution than $\widetilde{Y}[27,167]$.

\section{Date Processing of Linguistic Variables}

Linguistic terms are expressed in the form of natural language phrases; such simple and understandable terms can be used by DMs who have the subjective intentions to make qualitative judgments for the alternatives. Semantic variable types are normally transformed into triangular fuzzy numbers or intuitionistic fuzzy numbers, and the transformation standards are unified [166]. This paper transforms the partial semantic variables into IVTFNs, while the evaluation scale and the corresponding value of IVTFNs are shown in Table 7.

Table 7. The linguistic terms for rating the alternatives.

\begin{tabular}{ccc}
\hline Linguistic Preference & Abbreviation & IVTFNs \\
\hline Very poor & VP & $(0,0,0,1,1.5)$ \\
Poor & P & $(0,0.5,1,2.5,3.5)$ \\
Moderately poor & MP & $(0,1.5,3,4.5,5.5)$ \\
Fair & F & $(2.5,3.5,5,6.5,7.5)$ \\
Moderately good & MG & $(4.5,5.5,7,8,9.5)$ \\
Good & G & $(5.5,7.5,9,9.5,10)$ \\
Very good & VG & $(8.5,9.5,10,10,10)$ \\
\hline
\end{tabular}

\section{The Empirical Case of a Retail Enterprise}

An empirical case study of SSS for a retail company is discussed in this section to illustrate the applicability and feasibility of the proposed measure and methodology. In the following chapter, we will discuss the background, data collection, and the evaluation processes respectively.

\subsection{Background and Problem Descriptions}

Sustainability in the supply chain is viewed by many as essential to delivering long-term profitability; this is particularly true for retail sector. Before 2016, some international retail giants such as Wal-Mart, Migros, and Hy-Vee successively called for the full procurement of sustainable marine food products. The Chinese government suggested that the large-scale retail supermarkets in China begin with a pilot implementation of sustainable seafood procurement plans; the FX Supermarket chain was among them. Founded in 2000, FX Supermarket is one of the first circulation enterprises and agricultural industrialization enterprises in China that introduced fresh products into modern supermarkets, focusing on agro-food, daily necessities, clothing, and so forth. After years of entrepreneurship and rapid development, FX has grown into one of largest commercial enterprises, with more than 300 large and medium-sized supermarket branches, an annual turnover of almost $\$ 10$ billion, and 60,000 employees. FX has mastered the advantages of the upstream supply chain, of which fresh food is its biggest feature; the fresh produce area of each store has reached over 40 percent, and fresh agricultural and sideline products account for more than 50 percent of the total sales in the group.

For FX Supermarket, as they did not pre-determine the measure and corresponding method for sustainable suppliers of seafood (in fact, their previous procurement standards only focus on several traditional indicators such as cost, logistics, certification, and so forth, and some assessment methods they used were mainly experience-based judgment or weighted average), they finally contacted us to help them study this issue. Due to the different types of seafood, we chose "cuttlefish" as the initial research object. In accordance with the previous transaction records of FX's cuttlefish suppliers, we were eventually told that there were four main alternative suppliers (A1, A2, A3, and A4) after a preliminary screening. Since these alternatives have different advantages in social performance, as 
shown in Table 8, the optimal sustainable supplier cannot be directly chosen, and needs to determine through a comprehensive and systematic examination.

Table 8. The differentiated characteristics of the four potential suppliers.

\begin{tabular}{cllll}
\hline \multicolumn{1}{c}{ A1 } & \multicolumn{1}{c}{ A2 } & \multicolumn{1}{c}{ A3 } & \multicolumn{1}{c}{ A4 } \\
\hline \multirow{2}{*}{ Feature } & Newly-built & Competitive & Longer established & Second largest \\
\hline \multirow{2}{*}{ Strengths } & $\begin{array}{l}\text { Lower price } \\
\text { Higher delivery }\end{array}$ & $\begin{array}{l}\text { Substitutable } \\
\text { Moderate in price }\end{array}$ & $\begin{array}{l}\text { Good reputation } \\
\text { Quality assurance }\end{array}$ & $\begin{array}{l}\text { Quality assurance } \\
\text { Strategic alliance }\end{array}$ \\
\hline \multirow{2}{*}{ Weaknesses } & $\begin{array}{l}\text { Weaker voice in the } \\
\text { supply chain }\end{array}$ & Substitute product & $\begin{array}{l}\text { Weaker delivery } \\
\text { and response }\end{array}$ & $\begin{array}{l}\text { Smaller community } \\
\text { contributions }\end{array}$ \\
\hline
\end{tabular}

As most of the previous literature focused on supplier selection of manufacturing companies, but less on retail companies, we were inspired to develop a general measure for SSS and explore a feasible evaluation method. The integrated method of DEMATEL-ANP-VIKOR with hybrid information aggregation is finally proposed to help FX Supermarket select the suitable sustainable supplier from the above four alternative suppliers.

\subsection{Data Collection}

The data were collected within three phases. The first phase of our research investigates the interrelations of the dimension and criteria according to performance measure for sustainable suppliers from May to June 2017. In this stage, we originally issued 15 invitations to experts in the industry, 40 invitations to retail companies, and 5 to research institutions. Finally, a total of 20 experts, including 5 from industry associations, 4 from research institutes, and 11 (purchasing managers) from different retail enterprises were invited to fill the questionnaire for influence relationships of sustainable supplier evaluation criteria. The scale of pairwise comparison of the influence relationship using a score from 0-4 is shown in Appendix A. We sent a paper questionnaire and electronic questionnaire to each expert; experts had the choice of returning it by e-mail or post. Each questionnaire took about $5-10$ min to compete. The data from the questionnaire were used in DEMATEL. In the second phase, after a month, we invited those 20 experts to help rate relative importance of the dimension and criteria in performance measure for sustainable supplier based on the pairwise comparison. The scale using scores from 0-9 is presented in Appendix B. Each questionnaire took about 10-15 min to compete. The data from the questionnaire were used in ANP. In the last phase, we invited 4 senior managers from the financial sector, the procurement sector, and the market sector in FX Supermarket to rate the social performance of four cuttlefish suppliers according to the history transaction record and market performance, as well as their experience and knowledge. The questionnaire for quantitative and qualitative criteria ratings is shown in Appendix C. Each questionnaire took about 10-20 min to compete. The data from the questionnaire were used in VIKOR. The entire process of data collection lasted three months, from May to July 2017.

\subsection{Identifying the Relationships between Dimensions and Criteria}

As described, through the data mining of a large quantity of pertinent literature, and through consultations with some executives from FX Supermarket and experts in the industry, this paper establishes an evaluation index system for SSS, as shown in Table 9 (more introduction and references can be found in Section 2.3). This measure consists of 6 primary indicators (AS1-AS6) and 24 secondary indicators (C1-C24). We adopt the hybrid raw data (precise value, interval numbers, and fuzzy numbers) to obtain information aggregation to represent the actual performance of each indicator. In Table 9, $B$ is expressed as the benefit-type indicator (the bigger the better), while $C$ is expressed as the cost-type indicator (the smaller the better). 
Table 9. The criteria evaluation system for sustainable supplier.

\begin{tabular}{|c|c|c|c|c|}
\hline $\begin{array}{l}\text { Primary } \\
\text { Criteria }\end{array}$ & Second Grade Criteria & Criteria Type & Data Type & Classification \\
\hline \multirow{4}{*}{ CR (AS1) } & Position in industry (c1) & Qualitative & Linguistic variable $^{1}$ & B \\
\hline & Financial status (c2) & Qualitative & Linguistic variable & B \\
\hline & Contractual capacity (c3) & Qualitative & Linguistic variable & B \\
\hline & Strategic alliance (c4) & Qualitative & Linguistic variable & B \\
\hline \multirow{4}{*}{ OM (AS2) } & Business process management (c5) & Qualitative & Linguistic variable & B \\
\hline & Technical support (c6) & Qualitative & Linguistic variable & B \\
\hline & Quality management (c7) & Qualitative & Linguistic variable & B \\
\hline & Learning \& Innovation (c8) & Qualitative & Linguistic variable & B \\
\hline \multirow{4}{*}{ PA(AS3) } & Procurement cost ( $\mathrm{c} 9$ ) & Quantitative & Interval number & $\mathrm{C}$ \\
\hline & Product quality (c10) & Qualitative & Linguistic variable & $\mathrm{B}$ \\
\hline & Supply flexibility (c11) & Quantitative & Precise number & $\mathrm{B}$ \\
\hline & Product market share (c12) & Quantitative & Precise number & B \\
\hline \multirow{4}{*}{ SC (AS4) } & Responsiveness (c13) & Quantitative & Precise number & B \\
\hline & Timely delivery (c14) & Quantitative & Precise number & $\mathrm{B}$ \\
\hline & Customer satisfaction (c15) & Qualitative & Linguistic variable & $\mathrm{B}$ \\
\hline & Maintenance \& Compensation (c16) & Qualitative & Linguistic variable & $\mathrm{B}$ \\
\hline \multirow{4}{*}{ GI (AS5) } & Pollution production (c17) & Qualitative & Linguistic variable & $\mathrm{C}$ \\
\hline & Pollution control (c18) & Qualitative & Linguistic variable & $\mathrm{B}$ \\
\hline & Energy consumption (c19) & Qualitative & Linguistic variable & $\mathrm{C}$ \\
\hline & Ecologic design (c20) & Qualitative & Linguistic variable & $\mathrm{B}$ \\
\hline \multirow{4}{*}{ SR (AS6) } & Labor relations record (c21) & Qualitative & Linguistic variable & B \\
\hline & Governmental relations (c22) & Qualitative & Linguistic variable & $\mathrm{B}$ \\
\hline & Community welfare investment (c23) & Qualitative & Linguistic variable & $\mathrm{B}$ \\
\hline & Shareholder contract (c24) & Qualitative & Linguistic variable & B \\
\hline
\end{tabular}

${ }^{1}$ Linguistic variable will be transformed into the IVTFN in group information aggregate.

\subsection{Determining the Weights Using DEMATEL-ANP}

Within the measure of SSS, the target layer includes six decision aspects which are not independent of each other. For example, OM, PA, and SC clearly interact with each other, while there may be a mutual impact among CR, SR, and GI. Hence, the relationship among the elements in the target layer should be determined before solving this model.

- Step 1: Lining up a panel of 20 experts from the associations, enterprises, and researchers in the academy to judge and score the direct influence among the primary criteria applying the Delphi law, of which the indicator values were scored in accordance with the $0-4$ scores. The 20 expert-scoring tables are gathered to calculate the arithmetic mean and are listed as a $7 \times 7$ direct-relation matrix $\mathrm{A}$, as shown in Table 10.

Table 10. The direct-relation matrix A.

\begin{tabular}{ccccccc}
\hline & AS1 & AS2 & AS3 & AS4 & AS5 & AS6 \\
\hline AS1 & 0 & 2.95 & 3.15 & 3.25 & 3.05 & 3.25 \\
AS2 & 2.8 & 0 & 2.8 & 3 & 2.2 & 2.25 \\
AS3 & 3 & 2.5 & 0 & 2 & 2.25 & 2 \\
AS4 & 3.1 & 1.95 & 2.2 & 0 & 1.65 & 2 \\
AS5 & 2.25 & 2 & 2.7 & 2.05 & 0 & 2.3 \\
AS6 & 3 & 2.1 & 2.3 & 2.15 & 2.25 & 0 \\
\hline
\end{tabular}

- Step 2: Obtaining the normalized direct-relation matrix $D$ through Equation (1), and then acquiring the comprehensive influence matrix $T$ by Equation (2), as shown in Table 11. 
Table 11. The comprehensive impact matrix $T$ of the objective hierarchical elements.

\begin{tabular}{ccccccc}
\hline & AS1 & AS2 & AS3 & AS4 & AS5 & AS6 \\
\hline AS1 & 1.727 & 0.770 & 0.851 & 0.825 & 0.769 & 0.797 \\
AS2 & 0.778 & 1.526 & 0.740 & 0.724 & 0.644 & 0.663 \\
AS3 & 0.738 & 0.624 & 1.544 & 0.634 & 0.608 & 0.611 \\
AS4 & 0.709 & 0.569 & 0.634 & 1.489 & 0.550 & 0.581 \\
AS5 & 0.676 & 0.577 & 0.665 & 0.610 & 1.459 & 0.601 \\
AS6 & 0.739 & 0.605 & 0.672 & 0.641 & 0.608 & 1.498 \\
\hline
\end{tabular}

- Step 3: Constructing the causal map according to expert advice and repeated tests to get the threshold, which is equal to 0.55 . If the value in the composite impact matrix is less than 0.55 , it means that there is a clear correlation between the indicators, so the criteria with negligible relationships should be removed. Then, the influencing degree $C$, influenced degree $R$, the center degree $C+R$, and the cause degree $C-R$ are calculated, as shown in Table 12. Finally, the causal map is drawn according to $C+R$ and $C-R$, as shown in Figure 5, where the pointing arrow represents the degree of the impact exerted by other factors.

Table 12. The adjusted composite effect matrix.

\begin{tabular}{cccccccccc}
\hline & AS1 & AS2 & AS3 & AS4 & AS5 & AS6 & C & C+R & C-R \\
\hline AS1 & 0.727 & 0.770 & 0.851 & 0.825 & 0.769 & 0.797 & 4.738 & 9.105 & 0.372 \\
AS2 & 0.778 & 0.000 & 0.740 & 0.724 & 0.644 & 0.663 & 3.550 & 6.694 & 0.405 \\
AS3 & 0.738 & 0.624 & 0.000 & 0.634 & 0.608 & 0.611 & 3.214 & 6.776 & $(0.348)$ \\
AS4 & 0.709 & 0.569 & 0.634 & 0.000 & 0.000 & 0.581 & 2.492 & 5.925 & $(0.942)$ \\
AS5 & 0.676 & 0.577 & 0.665 & 0.610 & 0.000 & 0.601 & 3.129 & 5.758 & 0.499 \\
AS6 & 0.739 & 0.605 & 0.672 & 0.641 & 0.608 & 0.000 & 3.265 & 6.517 & 0.013 \\
R & 0.727 & 0.770 & 0.851 & 0.825 & 0.769 & 0.797 & - & - & - \\
\hline
\end{tabular}

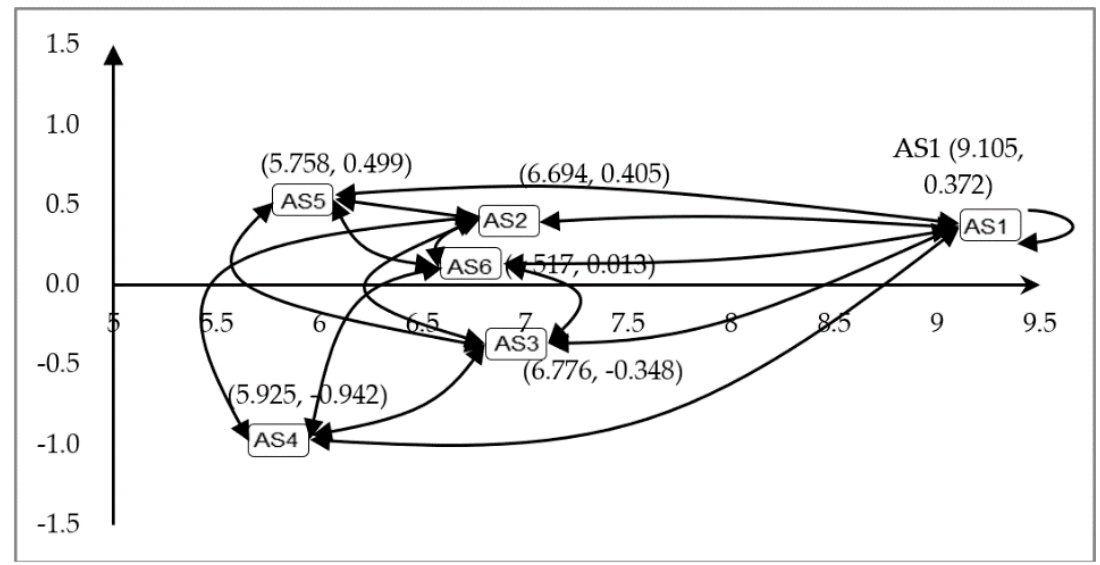

Figure 5. The cause-and-effect diagram of the primary criteria.

- Step 4: After determining the relationship between indicators through the DEMATEL, the ANP network of the sustainable suppliers' decision would be constructed, as shown in Figure 6, where the arrow pointing represents the mutual interdependence and feedback among the criteria, as shown in Appendix D. 


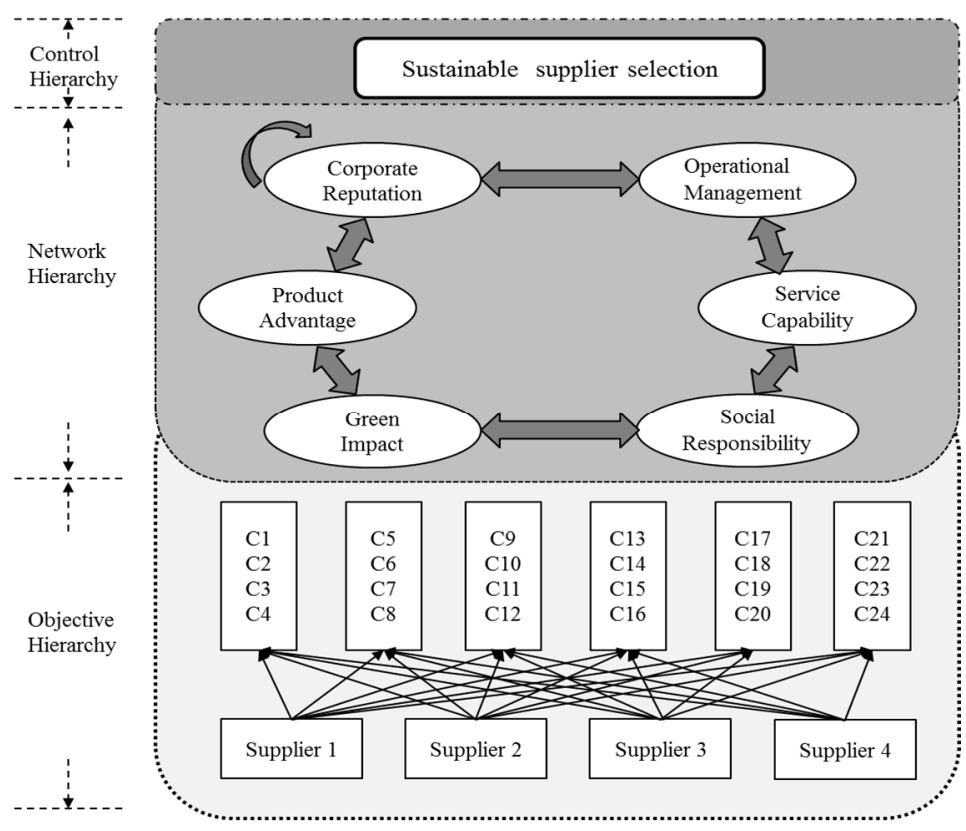

Figure 6. The map of the ANP network structure.

- Step 5: According to the causal relationship between the indicators, the judgment matrix of scale 1-9 is established, and then the unweighted super-matrix, weighted super-matrix, and limit super-matrix are obtained in succession. This paper considers the importance of the interplay of the 6 primary indicators and the 24 secondary indicators. Through the Super Decision software, the judgment matrix of the pairwise comparison in the manner of a questionnaire is inputted to compute and then perform the consistency test. Thereafter, choosing the factors to be judged in turn, the construction of the judgment matrix is repeated and its weight is determined. Finally, the unweighted super-matrix, weighted super-matrix, and limit super-matrix are established, as shown in the Appendixs E-G.

- Step 6: Achieving the weight of the indicator. On the basis of the results of the limit super-matrix, the weight of the indicators of the alternatives can be obtained, as shown in Table 13.

Table 13. The weights of the factors affecting the sustainable suppliers.

\begin{tabular}{ccccccccc}
\hline & \multicolumn{4}{c}{ AS1(0.112) } & \multicolumn{5}{c}{ AS2(0.132) } \\
\cline { 2 - 10 } & $c_{1}$ & $c_{2}$ & $c_{3}$ & $c_{4}$ & $c_{5}$ & $c_{6}$ & $c_{7}$ & $c_{8}$ \\
\hline Local weight & 0.237 & 0.319 & 0.241 & 0.203 & 0.203 & 0.156 & 0.271 & 0.370 \\
Global weight & 0.033 & 0.044 & 0.033 & 0.028 & 0.029 & 0.022 & 0.038 & 0.052 \\
\hline & \multicolumn{4}{c}{ AS3(0.229) } & & & AS4(0.150) & \\
\cline { 2 - 10 } & $c_{9}$ & $c_{10}$ & $c_{11}$ & $c_{12}$ & $c_{13}$ & $c_{14}$ & $c_{15}$ & $c_{16}$ \\
\hline Local weight & 0.311 & 0.268 & 0.230 & 0.191 & 0.419 & 0.144 & 0.297 & 0.140 \\
Global weight & 0.068 & 0.059 & 0.050 & 0.042 & 0.063 & 0.022 & 0.045 & 0.021 \\
\hline & \multicolumn{4}{c}{ AS5(0.147) } & & & AS6(0.230) & \\
\cline { 2 - 10 } & $c_{17}$ & $c_{18}$ & $c_{19}$ & $c_{20}$ & $c_{21}$ & $c_{22}$ & $c_{23}$ & $c_{24}$ \\
\hline Local weight & 0.120 & 0.302 & 0.207 & 0.371 & 0.318 & 0.264 & 0.145 & 0.273 \\
Global weight & 0.016 & 0.039 & 0.027 & 0.048 & 0.071 & 0.059 & 0.032 & 0.061 \\
\hline
\end{tabular}




\subsection{Evaluating the Social Performance of Suppliers Using VIKOR}

After obtaining the weight of the primary and secondary indicators of the sustainable supplier through the DEMATEL-ANP method, this paper then carries out the numerical operation of the sustainable supplier model according to the fuzzy VIKOR method. In the data collection, the quantitative evaluation criteria are gained through the real data of the procurement and operation of FX Supermarket in 2016-2017, as shown in Table 14; the qualitative evaluation criteria are acquired by the score of the semantic value of the qualitative indicators of the four potential sustainable suppliers, as shown in Table 15.

Table 14. The quantitative evaluation values of the potential sustainable suppliers of FX.

\begin{tabular}{ccccccc}
\hline & & C9 (USD/box) & C11 (\%) & C12 (\%) & C13 (\%) & C14 (\%) \\
\hline \multirow{5}{*}{ D1 } & A1 & {$[9,13]$} & 30 & 8 & 80 & 96 \\
& A2 & {$[11,15]$} & 18 & 14 & 78 & 92 \\
& A3 & {$[12,16]$} & 10 & 40 & 92 & 83 \\
& A4 & {$[13,17]$} & 15 & 32 & 81 & 86 \\
\hline \multirow{5}{*}{ D2 } & A1 & {$[11,15]$} & 13 & 9 & 82 & 95 \\
& A2 & {$[13,17]$} & 16 & 17 & 80 & 90 \\
& A3 & {$[15,19]$} & 12 & 37 & 90 & 86 \\
& A4 & {$[14,18]$} & 7 & 30 & 82 & 93 \\
& A1 & {$[8,12]$} & 9 & 7 & 81 & 94 \\
D3 & A2 & {$[10,14]$} & 14 & 18 & 82 & 88 \\
& A3 & {$[16,20]$} & 11 & 36 & 87 & 83 \\
& A4 & {$[10,14]$} & 8 & 29 & 83 & 90 \\
\hline \multirow{5}{*}{ D4 } & A1 & {$[12,16]$} & 10 & 8 & 81 & 95 \\
& A2 & {$[10,14]$} & 14 & 15 & 80 & 90 \\
& A3 & {$[17,21]$} & 13 & 39 & 91 & 88 \\
& A4 & {$[11,15]$} & 7 & 29 & 92 & 91 \\
\hline
\end{tabular}

Table 15. The subjective evaluation value scored by DMs from enterprise FX.

\begin{tabular}{|c|c|c|c|c|c|c|c|c|c|c|c|c|c|c|c|c|}
\hline \multirow{2}{*}{ Criteria } & \multicolumn{4}{|c|}{ D1 } & \multicolumn{4}{|c|}{ D2 } & \multicolumn{4}{|c|}{ D3 } & \multicolumn{4}{|c|}{ D4 } \\
\hline & A1 & A2 & A3 & A4 & A1 & A2 & A3 & A4 & A1 & A2 & A3 & A4 & A1 & A2 & A3 & A4 \\
\hline $\mathrm{C} 1$ & F & MG & VG & VG & F & MG & VG & VG & F & MG & VG & VG & F & MG & VG & VG \\
\hline $\mathrm{C} 2$ & F & $\mathrm{F}$ & $\mathrm{G}$ & G & MG & $\mathrm{P}$ & VG & $\mathrm{G}$ & F & $\mathrm{F}$ & MG & G & $\mathrm{MP}$ & MG & $\mathrm{G}$ & $\mathrm{G}$ \\
\hline $\mathrm{C} 3$ & VG & MG & MG & MG & VG & F & $\mathrm{G}$ & MG & VG & G & $\mathrm{F}$ & $\mathrm{F}$ & VG & MG & MG & G \\
\hline $\mathrm{C} 4$ & $\mathrm{~F}$ & $\mathrm{G}$ & $\mathrm{F}$ & G & MG & MG & MG & VG & $\mathrm{F}$ & VG & MP & MG & $\mathrm{F}$ & G & $\mathrm{F}$ & $\mathrm{G}$ \\
\hline C5 & $\mathrm{P}$ & F & MG & VG & VP & MP & F & VG & $\mathrm{MP}$ & MG & MG & VG & $\mathrm{P}$ & F & G & VG \\
\hline C6 & F & F & $\mathrm{F}$ & VG & $\mathrm{MP}$ & $\mathrm{F}$ & F & VG & MG & MG & F & VG & F & MP & F & VG \\
\hline C7 & $\mathrm{P}$ & MP & G & G & MP & $\mathrm{P}$ & G & VG & MP & MP & MG & MG & MP & MP & VG & G \\
\hline C8 & VG & MG & $\mathrm{MP}$ & $\mathrm{F}$ & VG & $\mathrm{G}$ & MP & MG & VG & $\mathrm{F}$ & $\mathrm{P}$ & MP & G & MG & MP & $\mathrm{F}$ \\
\hline $\mathrm{C} 10$ & MG & $\mathrm{F}$ & $\mathrm{G}$ & G & G & MG & VG & $\mathrm{G}$ & $\mathrm{F}$ & F & MG & G & MG & MP & G & G \\
\hline C15 & MG & MP & MP & G & G & MP & MP & VG & $\mathrm{F}$ & MP & P & MG & MG & P & MP & G \\
\hline C16 & VG & MG & MG & G & VG & G & $\mathrm{F}$ & G & VG & $\mathrm{F}$ & MG & G & VG & MG & G & MG \\
\hline C17 & VG & MG & F & G & VG & G & MG & VG & G & $\mathrm{F}$ & MP & G & VG & MG & F & MG \\
\hline C18 & MG & MG & MG & G & G & MG & F & G & G & F & MG & G & F & G & G & G \\
\hline C19 & MG & F & MG & F & G & MG & G & F & F & MP & $\mathrm{F}$ & MG & MG & $\mathrm{F}$ & MG & $\mathrm{MP}$ \\
\hline $\mathrm{C} 20$ & VP & F & G & MG & $\mathrm{VP}$ & $\mathrm{MP}$ & VG & G & $\mathrm{VP}$ & MG & G & $\mathrm{F}$ & $\mathrm{VP}$ & F & MG & G \\
\hline C21 & G & MG & G & VG & VG & F & G & VG & MG & MG & VG & VG & G & G & MG & VG \\
\hline C22 & MG & MP & MG & MG & G & P & G & MG & MG & MP & F & F & F & MP & F & G \\
\hline $\mathrm{C} 23$ & MG & F & MG & VP & MG & $\mathrm{MP}$ & G & $\mathrm{MP}$ & $\mathrm{F}$ & MG & MG & $\mathrm{P}$ & G & $\mathrm{F}$ & F & VP \\
\hline $\mathrm{C} 24$ & VG & MG & $\mathrm{F}$ & MG & VG & G & F & MG & VG & MG & MP & F & VG & F & MG & G \\
\hline
\end{tabular}

- Step 1: Normalizing the objective evaluation data. The numerical and interval data in Table 14 are normalized to eliminate the influence of the index dimension through Equations (18)-(20).

- Step 2: The semantic variables of the subjective evaluation information given by the scorers in Table 15 are transformed into the form of IVTFNs to construct the decision matrix. The evaluation 
information of the subjective and objective indicators is then aggregated to obtain a comprehensive evaluation matrix, as shown in Table 16.

- Step 3: According to the weight obtained by the DEMATEL-ANP method, the weighted interval triangular fuzzy matrix is constructed. Based on the above comprehensive evaluation matrix, the VIKOR method is used to choose the optimal alternative before the PISs $\left(A^{* 2}\right.$ and $\left.A^{* 1}\right)$ and NIS $\left(A^{-1}\right)$ are obtained through Equations (11)-(13).

- $\quad$ Step 4: The $\widetilde{S}_{i j}^{U}$ and $\widetilde{S}_{i j}^{L}$ of the potential sustainable suppliers are calculated through Equations (14)-(17), and then $\widetilde{S}_{i}$ and $\widetilde{R}_{i}$ are obtained. Further, we can acquire the cases of $v$ by taking different parameters according to Equation (18), as shown in Table 17.

- Step 5: Ranked by $\widetilde{S}_{i}, \widetilde{R}_{i}$, and $\widetilde{Q}_{i}$; the smaller the $\widetilde{Q}_{i}$ value is, the better the corresponding alternative. Then, the appropriate target supplier is selected after the validity test. The priority order of the alternative sustainable suppliers is $A_{4} \succ A_{1} \succ A_{3} \succ A_{2}$, given by the $\widetilde{Q}_{i}$ values, while the sustainable supplier $A_{4}$ has the smallest $\widetilde{Q}$ value. In order to determine whether the selected scheme satisfies Condition 1 and Condition 2 of the evaluation criteria, we can calculate $Q\left(A_{1}\right)-Q\left(A_{4}\right)=0.372>1 / 3$, which is proved to meet the Condition 1 , coupled with Condition 2 (that $A_{4}$ is also the optimal scheme ordered by $\widetilde{S}_{i}$ and $\widetilde{R}_{i}$ ). Furthermore, suppose the $v$ value equates to $0,0.5$, and 1 , respectively, the $\widetilde{Q}_{i}$ values corresponding to $A_{4}$ are still the smallest and, therefore, the supplier $A_{4}$ can be considered as the optimally sustainable supplier of the FX Supermarket based on the decision making process.

\subsection{The Sensitivity Analysis}

Through the sensitivity analysis, it can be determined whether the potential changes of the weights will cause deviations from the initial results [146]. This paper will adopt the perturbation method to test the sensitivity of the criteria weights to evaluate the robustness of the model. As previously defined, $w_{j}$ represents the initial weight of any criterion $c_{j}$ in the measures, and we let $w_{j}^{\prime}=\gamma w_{j}$ after a disturbance, where $0<w_{j}^{\prime}<1$. Then, the variation range of parameter $\gamma$ can be expressed as $0<\gamma<1 / w_{j}$. Owing to the normalization of the weight vector, the rest of the weights will also change because of the variation of $w_{j}$, and are denoted as $w^{\prime}{ }_{k}=\eta w_{k}, k \neq j, k=1,2, \cdots, m$, and $w_{j}^{\prime}+\sum_{k \neq i, k=1}^{m} w^{\prime}{ }_{k}=1$. This is equivalent to $\gamma w_{j}+\eta \sum_{k \neq i, k=1}^{m} w_{k}=1$, then $\eta=\left(1-\gamma w_{j}\right) /\left(1-w_{j}\right)$. For each criteria weight $w_{j}$, when setting a different parameter $\gamma$, the corresponding potential supplier priority can be obtained under the VIKOR method. In the proposed model, $\gamma$ is set to $4,2,1 / 2$, and $1 / 4$, respectively, and the experiment is repeated 40 times. As shown in Figure 7, the results show that the $\widetilde{Q}_{i}$ value of supplier $A_{4}$ is still the smallest during 40 experiments, and supplier $A_{1}$ has 37 experiments in which it was generally consistent in second place (only in the 11th, 19th, and 26th experiments did it rank third), which means that the proposed model is relatively insensitive to the change of the criteria weights. Thus, we conclude that the robustness of the overall model is evident, and $A_{4}$ is the optimal sustainable supplier, while there is a small probability $(7.5 \%)$ of it changing the order of the remaining suppliers. 
Table 16. The matrix of intervals triangular fuzzy numbers of individual information aggregations.

\begin{tabular}{|c|c|c|c|c|c|c|}
\hline & $\mathrm{C} 1$ & $\mathrm{C} 2$ & $\mathrm{C} 3$ & $\mathrm{C} 4$ & $\mathrm{C} 5$ & $\mathrm{C} 6$ \\
\hline A1 & {$[(2.5,3.5), 5,(6.5,7.5)]$} & {$[(2.38,3.5), 5,(6.38,7.5)]$} & {$[(8.5,9.5), 10,(10.0,10)]$} & {$[(3.0,4.0), 5.5,(6.88,8.0)]$} & {$[(0,0.63), 1.25,(2.65,3.5)]$} & {$[(2.38,3.5), 5,(6.38,7.5)]$} \\
\hline A2 & {$[(4.5,5.5), 7,(8.0,9.5)]$} & {$[(2.38,3.25), 4.5,(5.88,7)]$} & {$[(4.25,5.5), 7,(8.0,9.13)]$} & {$[(6,7.5), 8.75,(9.25,9.88)]$} & {$[(2.38,3.5), 5,(6.38,7.5)]$} & {$[(2.38,3.5), 5,(6.38,7.5)]$} \\
\hline A3 & {$[(8.5,9.5), 10,(10,10)]$} & {$[(6,7.5), 8.75,(9.25,9.88)]$} & {$[(4.25,5.5), 7,(8.0,9.13)]$} & {$[(2.38,3.5), 5,(6.38,7.5)]$} & {$[(4.25,5.5), 7.0,(8,9.13)]$} & {$[(2.5,3.5), 5,(6.5,7.5)]$} \\
\hline \multirow[t]{2}{*}{ A4 } & {$[(8.5,9.5), 10,(10,10)]$} & {$[(5.5,7.5), 9,(9.0,10.0)]$} & {$[(4.25,5.5), 7,(8.0,9.13)]$} & {$[(6,7.5), 8.75,(9.25,9.88)]$} & {$[(8.5,9.5), 10,(10.0,10.0)]$} & {$[(8.5,9.5), 10,(10.0,10)]$} \\
\hline & $\mathrm{C} 7$ & $\mathrm{C} 8$ & C9 & $\mathrm{C} 10$ & C11 & C12 \\
\hline A1 & {$[(1.25,2.5), 4,(5.5,6.5)]$} & {$[(7.75,9), 9.75,(9.88,10)]$} & {$[(7.14,7.69), 8.33,(9.09,10.0)]$} & {$[(4.25,5.5), 7,(8.0,9.13)]$} & {$[(10,10), 10,(10,10)]$} & {$[(2.1,2.1), 2.11,(2.1,2.1)]$} \\
\hline A2 & {$[(0.0,1.25), 2.5,(4,5.0)]$} & {$[(4.25,5.5), 7,(8.0,9.13)]$} & {$[(6.67,7.14), 7.69,(8.33,9.09)]$} & {$[(2.38,3.5), 5,(6.38,7.5)]$} & {$[(6.0,6.0), 6,($} & {$[(4.2,4.2), 4.21,(4.2,4.2)]$} \\
\hline A3 & {$[(6,7.5), 8.75,(9.25,9.88)]$} & {$[(0.0,1.25), 2.5,(4.0,5.0)]$} & {$[(5.26,5.56), 5.88,(6.25,6.67)]$} & {$[(6,7.5), 8.75,(9.25,9.88)]$} & {$[(3.3,3.3), 3.3,(3.3,3.3)]$} & {$[(10,10), 10,(10.0,10.0)]$} \\
\hline \multirow[t]{2}{*}{ A4 } & {$[(6,7.5), 8.75,(9.25,9.88)]$} & {$[(2.38,3.5), 5,(6.38,7.5)]$} & {$[(6.25,6.67), 7.14,(7.69,8.33)]$} & {$[(5.5,7.5), 9,(9.5,10.0)]$} & {$[(5.0,5.0), 5.0,(5.0,5.0)]$} & {$[(7.9,7.9), 7.89,(7.9,7.9)]$} \\
\hline & $\mathrm{C} 13$ & C14 & C15 & C16 & C17 & C18 \\
\hline A1 & {$[(9.0,9.0), 9,(9.0,9.0)]$} & {$[(10,10.0), 10,(10,10.0)]$} & {$[(4.25,5.5), 7,(8.0,9.13)]$} & {$[(8.5,9.5), 10,(10.0,10.0)]$} & {$[(7.75,9), 9.75,(9.88,10)]$} & {$[(4.5,6.0), 7.5,(8.38,9.25)]$} \\
\hline A2 & {$[(8.9,8.9), 8.89,(8.9,8.9)]$} & {$[(9.5,9.5), 9.47,(9.5,9.5)]$} & {$[(0.0,1.25), 2,5,(4.0,5.0)]$} & {$[(4.25,5.5), 7,(8.0,9.13)]$} & {$[(4.25,5.5), 7,(8.0,9,13)]$} & {$[(4.25,5.5), 7,(8.0,9.13)]$} \\
\hline A3 & {$[(10,10.0), 10,(10,10.0)]$} & {$[(8.9,8.9), 8.95,(8.9,8.9)]$} & {$[(0.0,1.25), 2.5,(4.0,5.0)]$} & {$[(4.25,5.5), 7,(8.0,9.13)]$} & {$[(2.38,3.5), 5,(6.38,7.5)]$} & {$[(4.25,5.5), 7,(8.0,9.13)]$} \\
\hline \multirow[t]{2}{*}{ A4 } & {$[(9.1,9.1), 9.11,(9.1,9.1)]$} & {$[(9.5,9.5), 9.47,(9.5,9.5)]$} & {$[(6,7.5), 8.75,(9.25,9.88)]$} & {$[(5.25,7), 8.5,(9.13,9.88)]$} & {$[(6,7.5), 8.75,(9.25,9.88)]$} & {$[(5.5,7.5), 9,(9.5,10.0)]$} \\
\hline & C19 & $\mathrm{C} 20$ & $\mathrm{C} 21$ & $\mathrm{C} 22$ & $\mathrm{C} 23$ & $\mathrm{C} 24$ \\
\hline A1 & {$[(4.25,5.5), 7,(8.0,9.13)]$} & {$[(0.0,0.0), 0,(1.0,1.5)]$} & {$[(6,7.5), 8.75,(9.25,9.88)]$} & {$[(4,25,5.5), 7,(8.0,9.13)]$} & {$[(4.25,5.5), 7,(8.0,9,13)]$} & {$[(8.5,9.5), 10,(10,10)]$} \\
\hline A2 & {$[(2.38,3.5), 5,(6.38,7.5)]$} & {$[(2.38,3.5), 5,(6.38,7.5)]$} & {$[(4.25,5.5), 7,(8.0,9.13)]$} & {$[(0.0,1.25), 2.5,(4.0,5.0)]$} & {$[(2.38,3.5), 5,(6.38,7.5)]$} & {$[(4.25,5.5), 7,(8.0,9.13)]$} \\
\hline A3 & {$[(4.25,5.5), 7,(8,0,9.13)]$} & {$[(6,7.5), 8.75,(9.25,9.88)]$} & {$[(6,7.5), 8.75,(9.25,9.88)]$} & {$[(4.25,5.5), 7,(8.0,9.13)]$} & {$[(4.25,5.5), 7,(8.0,9.13)]$} & {$[(2.38,3.5), 5,(6.38,7.5)]$} \\
\hline A4 & {$[(2.38,3.5), 5,(6.38,7.5)]$} & {$[(4.5,6), 7.5,(8.38,9.25)]$} & {$[(8.5,9.5), 10,(10.0,10.0)]$} & {$[(4.25,5.5), 7,(8.0,9.13)]$} & {$[(0,0.5), 1,(2.25,3.0)]$} & {$[(4.25,5.5), 7,(8,9.13)]$} \\
\hline
\end{tabular}


Table 17. The values of $S, R$, and $Q$ for the alternative sustainable suppliers.

\begin{tabular}{ccccccccc}
\hline & $\widetilde{\boldsymbol{S}}$ & $\widetilde{\boldsymbol{R}}$ & $\widetilde{\boldsymbol{Q}}(\boldsymbol{v}=\mathbf{0})$ & Ranking & $\widetilde{\boldsymbol{Q}}(\boldsymbol{v}=\mathbf{0 . 5})$ & Ranking & $\widetilde{\boldsymbol{Q}}(\boldsymbol{v}=\mathbf{1})$ & Ranking \\
\hline A1 & 0.499 & 0.057 & 0.306 & 2 & 0.372 & 2 & 0.437 & 2 \\
A2 & 0.728 & 0.071 & 1.000 & 4 & 1.000 & 4 & 1.000 & 4 \\
A3 & 0.518 & 0.070 & 0.962 & 3 & 0.723 & 3 & 0.484 & 3 \\
A4 & 0.321 & 0.050 & 0.000 & 1 & 0.000 & 1 & 0.000 & 1 \\
\hline
\end{tabular}
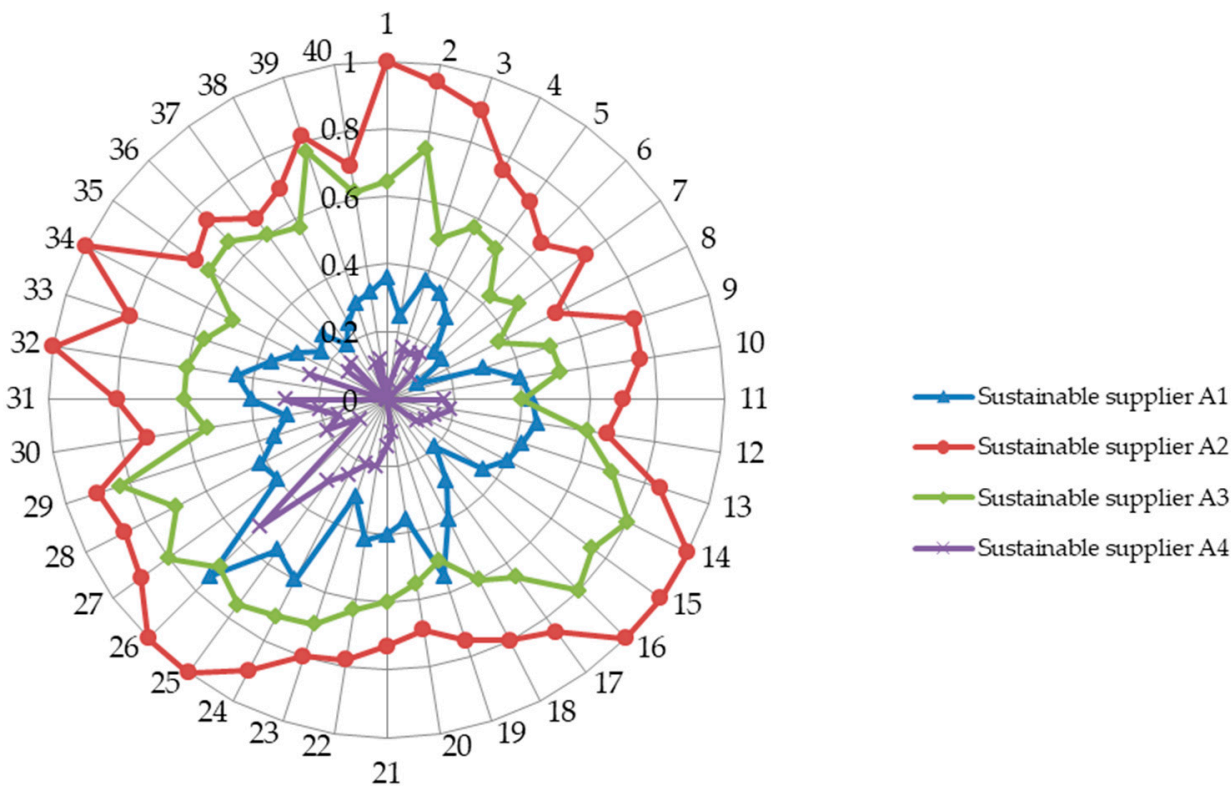

Figure 7. The sensitivity analysis under the VIKOR method.

\subsection{Comparative Study}

We also use the TOPSIS method to make the decision of the normalized decision matrix in the case analysis and to make a comparison of the results under these two integrated methods (DEMATEL-ANP-TOPSIS and DEMATEL-ANP-VIKOR). Ordered by the consolidation function $\varepsilon_{i}=D_{i}^{-} /\left(D_{i}^{-}+D_{i}^{+}\right)$for the alternatives, where $D_{i}^{+}$represents the weighted distance from supplier $A_{i}$ to the PIS and $D_{i}^{-}$represents the weighted distance from supplier $A_{i}$ to the NIS; based on the PIS $\left(f^{*}\right)$ and the NIS $\left(f^{-}\right)$calculated by the previous decision matrix, the weighted relative closeness coefficient of the four potential suppliers to PIS can be obtained as:

$$
\left(\varepsilon_{1}^{+}, \varepsilon_{2}^{+}, \varepsilon_{3}^{+}, \varepsilon_{4}^{+}\right)=(0.691,0.596,0.685,0.756)
$$

Then we can get the priority, which is $A_{4} \succ A_{1} \succ A_{3} \succ A_{2}$. Thus, the optimally sustainable supplier is $A_{4}$, the same as the result obtained by the VIKOR method. This paper has discussed the superiority of the VIKOR method to the TOPSIS method in the above chapters. Here we will verify the drawbacks of the TOPSIS method from the perspective of the simulation data. The sensitivity analysis is conducted to check the decision results obtained from TOPSIS. Similarly, for each criteria weight $w_{j}$, when taking different $\gamma$ values, using the TOPSIS method can get the corresponding potential supplier priority. In the proposed hybrid TOSIS algorithm, the weights of the 24 criteria are perturbed while assigning $\gamma$ to be $4,2,1 / 2$, and $1 / 4$, respectively, and repeating the experiment 40 times.

As shown in Figure 8, the $\widetilde{Q}_{i}$ value of supplier $A_{4}$ is also the smallest during the 40 experiments, but the orders involved with other suppliers changed a lot. The supplier $A_{1}$ has 6 occurrences of order changes in the 40 experiments, which means that the percentage of instability comes to $15 \%$. It can be seen that the TOPSIS decision method is relatively sensitive to the change of the weights of the 
evaluation value compared with the VIKOR method (the VIKOR method is $7.5 \%$ and the TOPSIS method is $15 \%$ ).

In conclusion, the DEMATEL-ANP-VIKOR method shows more advantages than the DEMATEL-ANP-TOPSIS method in terms of theoretical analysis, numerical experiment, and the sensitivity analysis. In this paper, the model of DEMATEL-ANP-VIKOR is more robust to deal with the hybrid data with incomparable information under an uncertain environment than the traditional TOPSIS method, and this result basically confirms and supports the argument of Opricovic and Tzeng [24].

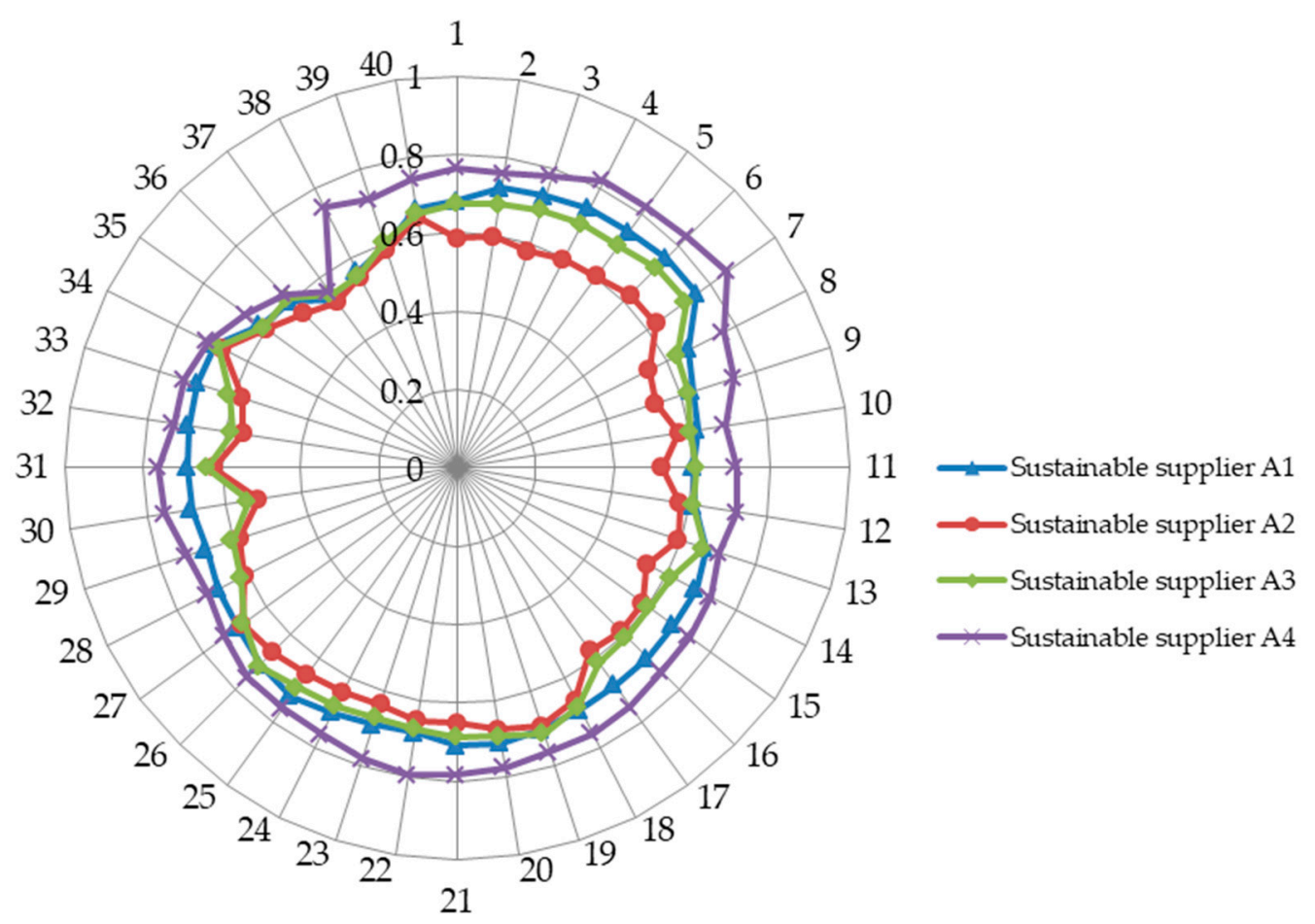

Figure 8. The sensitivity analysis under the TOPSIS method.

\section{Implications and Discussions}

Despite the increasing amount of literature on sustainable suppliers in recent years, there is still little research on supplier sustainability in retail enterprises. Correspondingly, the measure to evaluate and choose sustainable suppliers is imperfect and needs improving. This paper attempts to contribute a theoretical supplement. After extensive literature reviews and consultations with some experts in the industry, based on the TBL theory and stakeholder theory, a measure including economic, green (environmental), and social dimensions has been proposed. Among them, we introduce 4 primary criteria covering $\mathrm{CR}, \mathrm{OM}, \mathrm{PA}$, and $\mathrm{SC}$ to assess economic performance, and use Pollution production, Pollution control, and Energy consumption and Ecologic design to characterize GI. Most importantly, we require suppliers to provide evidence of their social responsibility fulfillment to internal and external stakeholders. Among the 6 primary criteria, SR obtains the greatest weight $(0.230)$, and PA $(0.229)$ is scored in second place with a very small gap, followed by SC, GI, OM, and CR. This weight ranking is intuitively devised, as we used to think that economic performance should be the most important, even among sustainable suppliers. Most experts in the case believe that the sustainability of suppliers should first be reflected in their corporate ethics, which is consistent with Zimmer, Froehling and Schultmann [7]. In spite of this, sub-criteria including cost, quality, delivery, and responsiveness are generally perceived to be foremost priorities in the traditional selection of suppliers [149], which are also important indicators when the retail company judges its suppliers. It is important to mention that 
Labor relations records, as transparent and measurable indicators of social responsibility, are regarded as the most important factors within the $24 \mathrm{~s}$ grade criteria. This evidence is consistent with the study of Amindoust, Ahmed, Saghafinia and Bahreininejad [4]. Moreover, the new indicators we proposed, such as Position in industry (0.033), Strategic alliance (0.028), Business process management (0.029), Learning (0.052), Customer satisfaction (0.045), Governmental relations (0.059), and Shareholder contract (0.061) have been given high weights, which also confirm the applicability and relative importance in SSS of retail enterprises. Nevertheless, in order to be more applicable and robust, the measures we have proposed for SSS cannot be static, and need to be dynamic adjusted, increased or reduced, according to the changes in the real environment and demand of retail enterprises.

Along with the logic of the DEMATEL-ANP-VIKOR method, we have improved the process of weight determination under DEMATEL-ANP, which reduces the amount of calculation required to get the same result. This evidence was reinforced through discussion with experts from the case company, in which they indicated that the DEMATEL-ANP was easy to implement in determining the weighting and causal relationships between multiple performance criteria [28]. The VIKOR method is applied to select suitable sustainable suppliers and to analyze gaps in the desired level of sustainable performance for each supplier. By conducting 40 sensitivity experiments, A4 was never changed as the best sustainable supplier in the case, while the other sort deviated only 3 times, which shows the robustness of the proposed method. To further verify the applicability of this method, we introduce another typical compromise method, TOPSIS, to find a sustainable alternative based on the same case. We obtained the same solution by TOPSIS, although the robustness of TOPSIS was weaker than the proposed method, as multiple deviations of the prioritizations produced by TOPSIS occurred in our sensitivity analysis. In contrast, the VIKOR algorithm showed robustness when the indicator weights shifted, which helped the DMs to provide decision-making references to a certain extent. This result provides realistic evidence for the comparative analysis of Opricovic and Tzeng [24].

Interestingly, the executives of FX Supermarket were particularly surprised when we told them about the results of sustainable suppliers, because in their view, $\mathrm{A} 3$ is the leading company in the market, and intuitively, it should be the most sustainable. The fact that A4 is more suitable than A3 is largely because the former performed better in terms of social criteria, while there was no big difference in the characteristics and distribution of the products they provide. We find it difficult to judge social responsibility based on solely experience and knowledge of scorers, instead of by a comprehensive measure. As for most companies, they are often more sensitive to economic performance than the social impact of suppliers. Our results inspire a deeper understanding of sustainable suppliers and sustainable procurement, and help managers devise strategies for effectively minimizing gaps in the sustainable performance of potential suppliers.

The introduction and use of the hybrid information aggregation is one of the main contributions in this paper, which can address the duality (qualitative and quantitative, precise and fuzzy) of semantic evaluation under a more realistic environment. This mechanism was recognized through discussion with the four managers from FX Supermarket, in which they thought the use of mixed information values could better characterize the scorer's judgment. We propose three types of criteria value, namely: precise number, interval number and fuzzy number. Quantitative indicators are characterized by precise number and interval number, while qualitative indicators are scored by IVTFNs. The use of IVTFNs makes it easier and faster for experts to make judgments and avoid mistakes caused by hesitation and non-intuition. Through the integration of hybrid information aggregation and DEMATEL-ANP-VIKOR, qualitative and quantitative indicators characterized by different data type can be measured and compared in the same dimension, which increases the systematic and comprehensive evaluation of sustainable supplier.

This paper focuses on the SSS of retail enterprises, because these enterprises have begun to place much attention on the sustainability of their product sources in recent years. For example, Swiss retail giant Migros decided to sell 100\% sustainable resources seafood before 2020; Wal-Mart introduced a Supplier Scorecard on Sustainability, and has constantly increased its applicable categories since 
2012. Considering that there are few sustainable performance measures and methods that have been widely accepted, this paper tries to promote an evaluation framework and model for the retail industry based on the FX case. The retail industry in emerging markets shows different features from that of developed countries, and has a slower pace of development, which means that the SSCM and sustainable procurement have not received widespread attention. However, nobody can ignore its importance; as we introduced in section one, due to the lack of supervision and proper selection of suppliers in emerging economies, Apple almost ruined their brand, even though they have taken many social initiatives within the company. For retail enterprises in emerging economies, global sustainable procurement has begun to be deployed, and the Chinese government has also called for more retail companies to participate in sustainable supplier programs. In the future, sustainable supplier management of retail companies in emerging markets will become indispensable for core firms to strengthen the sustainability of their supply chain.

\section{Conclusions and Future Research}

To facilitate a sustainable supply chain in the retail industry, a TBL-based conceptual measure for SSS was presented. By identifying the economic benefits, green impact, and social performance of alternative suppliers, a hybrid MCDM based on hybrid information aggregation was applied to a sample retail enterprise.

Little attention has been paid to SSS in retail industry, and there is almost no systemic and standard measure that could be used to assess the sustainability of suppliers. Based on this gap, through an extensive literature review and by consultations with experts in the industry, this paper proposes a sustainable performance measure in accordance with the principle of the TBL. In addition to the reservation of some traditional highly-cited criteria, new indicators such as strategic alliance, learning, governmental relations, and shareholder contracts have been presented and proved to be applicable to the evaluation framework. This paper also contributes to the measurement of supplier social responsibility by following the logic of the stakeholder theory. The measure has been approved by practitioners in retail enterprises who are committed to sustainable procurement, such as FX Supermarket and Wal-Mart.

On the other hand, considering the limitations of the supplier evaluation methods in previous studies, this paper proposes an improved DEMATEL-ANP-VIKOR method to seek sustainable suppliers. Based on the requirements of scorers in reality, we introduce the data types of precise number and interval number to characterize quantitative indicators and IVTFN to represent subjective judgment, which can further be integrated into a set of mixed information and become a hybrid input for DEMATEL-ANP-VIKOR method. This model was validated in the case of FX Supermarket, when we help them find the optimal sustainable supplier of "cuttlefish" based on the proposed measure and method, according to the market performance and operating conditions of four potential suppliers. Through the sensitivity analysis and comparison with TOPSIS, the proposed method shows more robustness, and embodies its superiority in selecting appropriate suppliers, as it considers both maximum group utility and individual regret to measure the gaps between alterative and ideal solutions, which can strengthen the ability to conduct social performance assessments of suppliers.

As more and more retail enterprises have joined the campaign of sustainable procurement, especially in the emerging market, the means to screen and manage sustainable suppliers will be an urgent question. Of course, there are many industries that also need to consider the choice of sustainable suppliers, such as construction. This paper provides a certain theoretical supplement for the discipline of sustainability and supplier selection. Also, the sustainable performance measure and integrated method can play an audit role for practitioners to evaluate the performance of the SSCM practices of relative suppliers.

Considering that the SSS is a complex engineering problem, there is still room for improvement. This paper proposed a social performance measure for supplier selection based on a retail enterprise, but it didn't consider some intangible factors such as supply chain relationship and binding trade 
secrets, which may affect the scorer's judgment to some degree. More indicators from various dimensions should be considered and chosen according to real-world applications. Considering that suppliers may change their sustainability due to the pressure of core enterprises, in order to select the suitable suppliers dynamically, evaluating the alternatives using the MCDM method at each stage can solve this issue, but it may require much time and financial investment. A dynamic monitoring and evaluation approach to quickly select suppliers could be applied in future research. The priority order of the sustainable suppliers using the integrated MCDM method with hybrid information aggregation in this study were only scored and determined by four related department managers. Also, the alternatives are limited to four suppliers. Increasing the number of scorers, especially those from the same industry and alternative suppliers, may allow us to better compare scenarios and validate the proposed models and methods.

Author Contributions: Z.X. and X.Z. designed the whole study, proposed the conceptualization and did the investigation; X.Z. conducted data collection, modeling, and results analysis and wrote the original draft; Z.X. was responsible for funding acquisition, project administration and supervision and also reviewed and edited the paper. All authors read the final manuscript and approved it for final submission.

Funding: This research received no external funding.

Acknowledgments: Our thanks go to Zhang, a dedicated CEO in the FX Supermarket, for his full support and guidance. And we also appreciate the experts from the manufacture and circulation industry and academy supporting our work.

Conflicts of Interest: The authors declare no conflict of interest.

\section{Appendix A}

Questionnaire for Influence Relationships of SSS Criteria

Dear Sir/Madam,

We are currently undertaking a questionnaire survey for influence relationships of each criterion in the hierarch criteria system.

This survey is an important part of the research on the sustainable supplier evaluation and has a direct impact to the final solution. The main purpose is to understand the mutual influence of the indicators in the sustainable supplier evaluation system, in order to remove factors that affect the follow-up weight judgment.

A questionnaire that requires you to assign the mutual influences for criteria is attached in the e-mail. We hope you could look over the questionnaire and thoughtfully make the decision under your practical experience and knowledge. The questionnaire should take you about 5-10 min to compete.

All answers are confidential and all identifying information will be kept anonymous. And there is not any right or wrong answer in the options setting, please make the judgment according to your own experience and real understanding.

Thanks for your support and help.

\section{PART ONE: The Basic Information of The Evaluator}

Please fill in the appropriate options in the space.

1. The following identity description is suitable for you
A. Government
B. Academy
C. Industry

\section{PART TWO: Evaluation of Mutual Influence of Indicators}

\section{Measurement scale for pair-wise comparisons}

In this questionnaire, the degree of interaction between the criteria in the sustainable supplier evaluation system is scored from $0-4$. The meaning of each score is shown below:

\begin{tabular}{cccccc}
\hline Score & $\mathbf{0}$ & $\mathbf{1}$ & $\mathbf{2}$ & 3 & $\mathbf{4}$ \\
\hline Impact & No Impact & Lower Impact & Moderate Impact & Higher Impact & Very higher Impact \\
\hline
\end{tabular}




\section{Illustrated example}

The following table shows that: (1) AS1 has no impact on AS2, so AS1/AS2 = 0; (2) AS2 has lower impact on AS3, so AS2 / AS3 = 1; (3) AS3 has moderate impact on AS4, so AS3 / AS4 = 2; (4) AS4 has higher impact on AS5, so AS4/AS5 = 3; (5) AS5 has very higher impact on AS6, so AS5 / AS6 = 4 .

\begin{tabular}{ccccccc}
\hline & AS1 & AS2 & AS3 & AS4 & AS5 & AS6 \\
\hline AS1 & 0 & 0 & & & & \\
AS2 & & 0 & 1 & & & \\
AS3 & & & 0 & 2 & & \\
AS4 & & & & 0 & 3 & \\
AS5 & & & & & 0 & 4 \\
AS6 & & & & & & 0 \\
\hline
\end{tabular}

Please rate the correlation between indicators according to your experience and understanding below (see the indicator from the measures proposed in Section 2.3. We provide a detailed explanation of the index, which is omitted here for shortening the length of this paper, similarly hereinafter).

\begin{tabular}{ccccccc}
\hline & AS1 & AS2 & AS3 & AS4 & AS5 & AS6 \\
\hline AS1 & 0 & & & & & \\
AS2 & & 0 & & & & \\
AS3 & & & 0 & & & \\
AS4 & & & & 0 & & \\
AS5 & & & & & 0 & 0 \\
AS6 & & & & & & 0 \\
\hline
\end{tabular}

This is the end of the questionnaire, thanks again for your participation and support!

\section{Appendix B}

Questionnaire for Assigning the Importance of SSS Criteria

Dear Sir/Madam,

We are currently undertaking a questionnaire survey for assigning the relative importance of each criterion in the hierarch index system. The weights assignment plays a significant role in our study and has a direct impact to the final results. We are very glad to invite you to participate in this research project.

A questionnaire that requires you to assign the relative importance for criteria is attached in the e-mail. We hope you could look over the questionnaire and thoughtfully make the decision under your practical experience and knowledge. The questionnaire should take you about 10-15 min to compete and you may be required to make the comparison again if inconsistency happens in the evaluation process.

We guarantee that your responses will only be used and accessed by researchers in order to keep confidential and private. We promise not to share your names, address and other personal/organization details. And there is not any right or wrong answer in the options setting, please make the judgment according to your own experience and real understanding. If you have any further assistance or questions about completing the questionnaire and our research, please contact us through the e-mail.

Thank you for your support and help.

\section{Measurement scale for pair-wise comparisons}

The questionnaire uses the 9-point scale to assess the importance of the evaluation index of the sustainable suppliers. The meanings of the scores are shown in the table below: 
Table A1. 1-9 scale of ANP

\begin{tabular}{lc}
\hline Importance & Numerical Judgments \\
\hline Elements $i$ and $j$ are equally important. & 1 \\
Element $i$ is equally to more important than $j$. & 2 \\
Element $i$ is more important than $j$. & 3 \\
Element $i$ is equally to moderately more important than $j$. & 4 \\
Element $i$ is moderately more important than $j$. & 5 \\
Element $i$ is equally to strongly more important than $j$. & 6 \\
Element $i$ is strongly more important than $j$. & 7 \\
Element $i$ is equally to extremely more important than $j$. & 8 \\
Element $i$ is extremely more important than $j$. & 9 \\
Source: Saaty (2000) & \\
\hline
\end{tabular}

\section{Illustrated example}

The following table shows that: (1) Both $\mathrm{A}$ and $\mathrm{B}$ are equally preferred, so $\mathrm{A} / \mathrm{B}=1$; (2) B is moderately preferred to $C$, so $B / C=3 ;(3) D$ is strongly preferred to $C$, so $D / C=5$ and $C / D$ is therefore $1 / 5$.

\begin{tabular}{ccccc}
\hline & A & B & C & D \\
\hline A & 1 & 1 & & \\
B & & 1 & 3 & \\
C & & & 1 & $1 / 5$ \\
D & & & & 1 \\
\hline
\end{tabular}

Please rate the relative importance between indicators according to your experience and understanding below.

\section{First class criteria}

\begin{tabular}{ccccccc}
\hline & AS1 & AS2 & AS3 & AS4 & AS5 & AS6 \\
\hline AS1 & 1 & & & & & \\
AS2 & & 1 & & & & \\
AS3 & & & 1 & & & \\
AS4 & & & & 1 & & \\
AS5 & & & & & 1 & \\
AS6 & & & & & & 1 \\
\hline
\end{tabular}

\section{Second class criteria}

Corporate reputation (AS1)_Pair-wise comparison of sub-criteria under AS1

\begin{tabular}{ccccc}
\hline AS1 & C1 & C2 & C3 & C4 \\
\hline C1 & 1 & & & \\
C2 & & 1 & & \\
C3 & & & 1 & \\
C4 & & & & 1 \\
\hline
\end{tabular}

Operations management (AS2)_Pair-wise comparison of sub-criteria under AS2

\begin{tabular}{ccccc}
\hline AS2 & C5 & C6 & C7 & C8 \\
\hline C5 & 1 & & & \\
C6 & & 1 & & \\
C7 & & & 1 & \\
C8 & & & & 1 \\
\hline
\end{tabular}


Product Advantage (AS3)—Pair-wise comparison of sub-criteria under AS3

\begin{tabular}{ccccc}
\hline AS3 & C9 & C10 & C11 & C12 \\
\hline C9 & 1 & & & \\
C10 & & 1 & & \\
C11 & & & 1 & \\
C12 & & & & 1 \\
\hline
\end{tabular}

Service capability (AS4) —Pair-wise comparison of sub-criteria under AS4

\begin{tabular}{ccccc}
\hline AS4 & C13 & C14 & C15 & C16 \\
\hline C13 & 1 & & & \\
C14 & & 1 & & \\
C15 & & & 1 & \\
C16 & & & & 1 \\
\hline
\end{tabular}

Green impact (AS5)—Pair-wise comparison of sub-criteria under AS5

\begin{tabular}{ccccc}
\hline AS5 & C17 & C18 & C19 & C20 \\
\hline C17 & 1 & & & \\
C18 & & 1 & & \\
C19 & & & 1 & \\
C20 & & & & 1 \\
\hline
\end{tabular}

Social responsibility (AS6)—Pair-wise comparison of sub-criteria under AS6

\begin{tabular}{ccccc}
\hline AS6 & C21 & C22 & C23 & C24 \\
\hline C21 & 1 & & & \\
C22 & & 1 & & \\
C23 & & & 1 & \\
C24 & & & & 1 \\
\hline
\end{tabular}

This is the end of the questionnaire, thanks again for your participation and support!

\section{Appendix C Questionnaire for Quantitative and Qualitative Criteria Ratings}

Dear Sir/Madam,

We are currently undertaking a questionnaire survey of quantitative and qualitative criteria ratings for sustainable supplier selection.

The quantitative and qualitative criteria scorings play a significant role in our study and have a direct impact to the final results. We are very glad to invite you to participate in this research project. The main purpose of the scoring table is to understand the status quo of four potential suppliers of FX Supermarket from partial qualitative indicators and to make scientific competitiveness to each firm on the basis of the combination of statistical data related to quantitative indicators evaluation.

A questionnaire that requires you to rate the evaluation indicators of the target company is attached in the e-mail. We hope you could look over the questionnaire and thoughtfully make the decision under your practical experience and knowledge. The questionnaire should take you about 10-20 min to compete.

All answers are confidential and all identifying information will be kept anonymous. And there is not any right or wrong answer in the options setting, please make the judgment according to your own experience and real understanding.

Thanks for your support and help. 


\section{PART ONE The Basic Information of The Evaluator}

Please fill in the appropriate options in the space.

1. Your department is
A. Finance
B. Purchasing
C. Product
D. Marketing

\section{PART TWO Quantitative Indicator Score}

Please rate the following quantitative indicators based on historical business information and your experience and knowledge.

$\square \quad$ Procurement cost (C9)

For each box of product $\mathrm{Y}$, please give the interval value of the procurement price listed by every supplier.

(Unit: USD)

\begin{tabular}{ll}
\hline & (USD/Box) \\
\hline Supplier 1 & {[} \\
Supplier 2 & {[} \\
Supplier 3 & {[} \\
Supplier 4 & {[}
\end{tabular}

Give the precise percentage of the following four indicators for every supplier.

$\square$ Supply flexibility (C11)

\begin{tabular}{ll}
\hline & $(\%)$ \\
\hline Supplier 1 \\
Supplier 2 \\
Supplier 3 \\
Supplier 4 \\
\hline
\end{tabular}

Product market share (C12)

\begin{tabular}{ll}
\hline & $(\%)$ \\
\hline Supplier 1 \\
Supplier 2 \\
Supplier 3 \\
Supplier 4 \\
\hline
\end{tabular}

Responsiveness (C13)

\begin{tabular}{ll}
\hline & $(\mathbf{\% )}$ \\
\hline Supplier 1 & \\
Supplier 2 & \\
Supplier 3 & \\
Supplier 4 & \\
\hline & \\
& \\
\hline & $(\%)$ \\
\hline Supplier 1 \\
Supplier 2 \\
Supplier 3 \\
Supplier 4 \\
\hline
\end{tabular}




\section{PART THREE Qualitative Indicator Score}

In the mark sheet, the 7-level language variables are used to rate the indicators of the sustainable suppliers. The meanings of the semantic variables are as follows:

\begin{tabular}{lccccccr}
\hline $\begin{array}{l}\text { Language } \\
\text { Variables }\end{array}$ & VP & $\mathbf{P}$ & MP & F & MG & G & VG \\
\hline Meaning & Very poor & Poor & Moderate poor & Fair & Moderately good & good & Very good \\
\hline
\end{tabular}

Please indicate with an $X$ in the box which is appropriate for each sustainable supplier's performance.

$\square$ Position in industry (C1)

\begin{tabular}{llllllll}
\hline & VP & P & MP & F & MG & G & VG \\
\hline Supplier 1 & & & & & & & \\
Supplier 2 & & & & & & & \\
Supplier 3 & & & & & & & \\
Supplier 4 & & & & & & \\
\hline
\end{tabular}

Financial status (C2)

\begin{tabular}{llllllll} 
& VP & P & MP & F & MG & G & VG \\
\hline Supplier 1 & & & & & & & \\
Supplier 2 & & & & & & & \\
Supplier 3 & & & & & & & \\
Supplier 4 & & & & & & \\
\hline
\end{tabular}

Contractual capacity (C3)

\begin{tabular}{llllllll} 
& VP & P & MP & F & MG & G & VG \\
\hline Supplier 1 & & & & & & & \\
Supplier 2 & & & & & & & \\
Supplier 3 & & & & & & & \\
Supplier 4 & & & & & & & \\
\hline
\end{tabular}

Strategic alliance (C4)

\begin{tabular}{llllllll} 
& VP & P & MP & F & MG & G & VG \\
\hline Supplier 1 & & & & & & & \\
Supplier 2 & & & & & & & \\
Supplier 3 & & & & & & & \\
Supplier 4 & & & & & & & \\
\hline
\end{tabular}

Business process management (C5)

\begin{tabular}{llllllll} 
& VP & P & MP & F & MG & G & VG \\
\hline Supplier 1 & & & & & & & \\
Supplier 2 & & & & & & & \\
Supplier 3 & & & & & & & \\
Supplier 4 & & & & & & & \\
\hline
\end{tabular}


$\square \quad$ Technical support (C6)

\begin{tabular}{llllllll} 
& VP & P & MP & F & MG & G & VG \\
\hline Supplier 1 & & & & & & & \\
Supplier 2 & & & & & & & \\
Supplier 3 & & & & & & & \\
Supplier 4 & & & & & & & \\
\hline
\end{tabular}

$\square \quad$ Quality management (C7)

\begin{tabular}{llllllll}
\hline & VP & P & MP & F & MG & G & VG \\
\hline Supplier 1 & & & & & & & \\
Supplier 2 & & & & & & & \\
Supplier 3 & & & & & & & \\
Supplier 4 & & & & & & & \\
\hline
\end{tabular}

Learning \& Innovation (C8)

\begin{tabular}{llllllll}
\hline & VP & P & MP & F & MG & G & VG \\
\hline Supplier 1 & & & & & & & \\
Supplier 2 & & & & & & & \\
Supplier 3 & & & & & & & \\
Supplier 4 & & & & & & & \\
\hline
\end{tabular}

Product quality (C10)

\begin{tabular}{llllllll}
\hline & VP & P & MP & F & MG & G & VG \\
\hline Supplier 1 & & & & & & & \\
Supplier 2 & & & & & & & \\
Supplier 3 & & & & & & & \\
Supplier 4 & & & & & & & \\
\hline
\end{tabular}

$\square$ Customer satisfaction (C15)

\begin{tabular}{llllllll} 
& VP & P & MP & F & MG & G & VG \\
\hline Supplier 1 & & & & & & & \\
Supplier 2 & & & & & & & \\
Supplier 3 & & & & & & & \\
Supplier 4 & & & & & & & \\
\hline
\end{tabular}

Maintenance \& Compensation (C16)

\begin{tabular}{llllllll}
\hline & VP & P & MP & F & MG & G & VG \\
\hline Supplier 1 & & & & & & & \\
Supplier 2 & & & & & & & \\
Supplier 3 & & & & & & & \\
Supplier 4 & & & & & & & \\
\hline
\end{tabular}

$\square$ Pollution production (C17)

\begin{tabular}{llllllll} 
& VP & P & MP & F & MG & G & VG \\
\hline Supplier 1 & & & & & & & \\
Supplier 2 & & & & & & & \\
Supplier 3 & & & & & & & \\
Supplier 4 & & & & & & & \\
\hline
\end{tabular}


Pollution control (C18)

\begin{tabular}{llllllll}
\hline & VP & P & MP & F & MG & G & VG \\
\hline Supplier 1 & & & & & & & \\
Supplier 2 & & & & & & & \\
Supplier 3 & & & & & & & \\
Supplier 4 & & & & & & & \\
\hline
\end{tabular}

$\square$ Energy consumption (C19)

\begin{tabular}{llllllll} 
& VP & P & MP & F & MG & G & VG \\
\hline Supplier 1 & & & & & & & \\
Supplier 2 & & & & & & & \\
Supplier 3 & & & & & & & \\
Supplier 4 & & & & & & & \\
\hline
\end{tabular}

Ecologic design (C20)

\begin{tabular}{llllllll} 
& VP & P & MP & F & MG & G & VG \\
\hline Supplier 1 & & & & & & & \\
Supplier 2 & & & & & & & \\
Supplier 3 & & & & & & & \\
Supplier 4 & & & & & & & \\
\hline
\end{tabular}

Labor relations record (C21)

\begin{tabular}{llllllll}
\hline & VP & P & MP & F & MG & G & VG \\
\hline Supplier 1 & & & & & & & \\
Supplier 2 & & & & & & & \\
Supplier 3 & & & & & & & \\
Supplier 4 & & & & & & & \\
\hline
\end{tabular}

$\square$ Governmental relations (C22)

\begin{tabular}{llllllll}
\hline & VP & P & MP & F & MG & G & VG \\
\hline Supplier 1 & & & & & & & \\
Supplier 2 & & & & & & & \\
Supplier 3 & & & & & & & \\
Supplier 4 & & & & & & & \\
\hline
\end{tabular}

Community welfare investment (C23)

\begin{tabular}{llllllll} 
& VP & P & MP & F & MG & G & VG \\
\hline Supplier 1 & & & & & & & \\
Supplier 2 & & & & & & & \\
Supplier 3 & & & & & & & \\
Supplier 4 & & & & & & & \\
\hline
\end{tabular}

Shareholder contract (C24)

\begin{tabular}{llllllll} 
& VP & P & MP & F & MG & G & VG \\
\hline Supplier 1 & & & & & & & \\
Supplier 2 & & & & & & & \\
Supplier 3 & & & & & & & \\
Supplier 4 & & & & & & & \\
\hline
\end{tabular}

This is the end of the questionnaire, thanks again for your participation and support! 


\section{Appendix D}

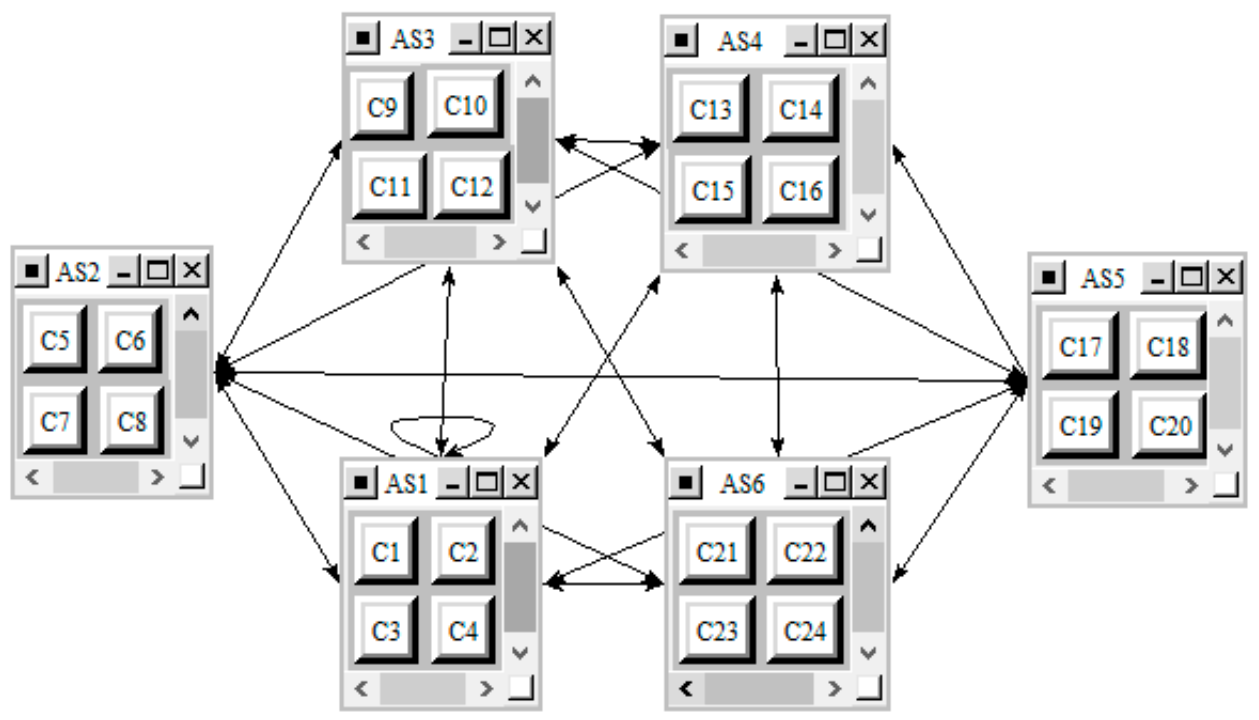

Figure A1. Implementation of Network Structure of the SSS. 


\section{Appendix E}

Table A2. ANP Unweighted Supermatrix for the SSS Decision Network.

\begin{tabular}{|c|c|c|c|c|c|c|c|c|c|c|c|c|c|c|c|c|c|c|c|c|c|c|c|c|c|}
\hline & & \multicolumn{4}{|c|}{ AS1 } & \multicolumn{4}{|c|}{ AS2 } & \multicolumn{4}{|c|}{ AS3 } & \multicolumn{4}{|c|}{ AS4 } & \multicolumn{4}{|c|}{ AS5 } & \multicolumn{4}{|c|}{ AS6 } \\
\hline & & C1 & C2 & C3 & $\mathrm{C} 4$ & C5 & C6 & C7 & C8 & C9 & C10 & C11 & $\mathrm{C} 12$ & C13 & C14 & C15 & C16 & $\mathrm{C} 17$ & C18 & C19 & $\mathrm{C} 20$ & C21 & C22 & $\mathrm{C} 23$ & $\mathrm{C} 24$ \\
\hline \multirow{4}{*}{ AS1 } & $\mathrm{C} 1$ & 0.237 & 0.237 & 237 & 0.237 & 0.237 & 237 & 0.237 & 37 & 0.237 & 0.237 & 37 & 0.237 & 0.237 & 0.237 & 237 & 0.237 & 0.237 & 0.237 & 0.237 & 237 & .237 & 0.237 & 0.237 & 0.237 \\
\hline & $\mathrm{C} 2$ & 0.319 & 0.319 & 0.319 & 0.319 & 0.319 & 0.319 & 0.319 & 0.319 & 0.319 & 0.319 & 0.319 & & 0.319 & 0.319 & 0.319 & 0.319 & 0.319 & 0.319 & 0.319 & 0.319 & 319 & 0.319 & 0.319 & 0.319 \\
\hline & C3 & 0.241 & 0.241 & 0.241 & 0.241 & 0.241 & 0.241 & 0.241 & 0.241 & 0.241 & 0.241 & 0.241 & 0.241 & 0.241 & 0.241 & 0.241 & 0.241 & 0.241 & 0.241 & 0.241 & 0.241 & 0.241 & 0.241 & 241 & 0.241 \\
\hline & $\mathrm{C} 4$ & 0.203 & 0.203 & 0.203 & 0.203 & 0.203 & 0.203 & 0.203 & 0.203 & 0.203 & 0.203 & 0.203 & 0.203 & 0.203 & 0.203 & 0.203 & 0.203 & 0.203 & 0.203 & 0.203 & 0.203 & 0.203 & 0.203 & 0.203 & 0.203 \\
\hline \multirow{4}{*}{ AS2 } & C5 & 203 & 0.203 & 203 & 0.203 & 000 & 000 & 0.000 & 000 & 0.203 & 203 & 0.203 & 3 & .203 & 0.203 & 0.203 & 0.203 & 0.203 & 0.203 & 0.203 & 0.203 & .203 & 0.203 & .203 & 0.203 \\
\hline & C6 & 0.156 & 0.156 & 0.156 & 0.156 & 0.000 & 0.000 & 0.000 & 0.000 & 0.1 & 0.156 & 0. & & 0.156 & 0.156 & 56 & & & 0.156 & & 56 & & 0.156 & & \\
\hline & C7 & 0.271 & 0.271 & 0.271 & 0.271 & 0.000 & 0.000 & 0.000 & 0.000 & 0.271 & 0.271 & 0.271 & 0.271 & 0.271 & 0.271 & 0.271 & 0.271 & 0.271 & 0.271 & 0.271 & 0.271 & 71 & 0.271 & 71 & 0.271 \\
\hline & $\mathrm{C} 8$ & 0.370 & 0.370 & 0.370 & 0.370 & 0.000 & 0.000 & 0.000 & 0.000 & 0.370 & 0.370 & 0.370 & 0.370 & 0.370 & 0.370 & 0.370 & 0.370 & 0.370 & 0.370 & 0.370 & 0.370 & 0.370 & 0.370 & 0.370 & 0.370 \\
\hline \multirow{4}{*}{ AS3 } & $\mathrm{C}$ & 311 & 311 & 311 & 11 & & 311 & & & & 000 & & & 11 & 11 & & & & 0.311 & & & & 311 & & $\overline{11}$ \\
\hline & C10 & 0.268 & 0.268 & 268 & 0.268 & 0.268 & 0.268 & 0.268 & 0.268 & 0.000 & 0.000 & 0.000 & & 0.268 & 0.268 & 0.268 & 0.268 & 0.268 & 0.268 & 0.268 & 0.268 & 0.268 & 0.268 & 0.268 & 0.268 \\
\hline & C11 & 0.230 & 0.230 & 0.230 & 0.230 & 0.230 & 0.230 & 0.230 & 0.230 & 0.000 & 0.000 & 0.000 & 0.000 & 0.230 & 0.230 & 0.230 & 0.230 & 0.230 & 0.230 & 0.230 & 0.230 & 0.230 & 0.230 & 0.230 & 0.230 \\
\hline & $\mathrm{C} 12$ & 0.191 & 0.191 & 0.191 & 0.191 & 0.191 & 0.191 & 0.191 & 0.191 & 0.000 & 0.000 & 0.000 & 0.000 & 0.191 & 0.191 & 0.191 & 0.191 & 0.191 & 0.191 & 0.191 & 0.191 & 0.191 & 0.191 & 0.191 & 0.191 \\
\hline \multirow{4}{*}{ AS4 } & & & 9 & 19 & & & 9 & & & & 419 & & & & & & & & & & & & & & \\
\hline & C14 & 0.144 & 0.144 & 0.144 & 0.144 & 0.144 & 0.144 & 0.144 & 144 & 0.144 & 0.144 & 0.144 & 0.144 & 0.000 & 0.000 & 0.000 & 0.000 & 0.144 & 0.144 & 0.144 & 0.144 & 0.144 & 0.144 & 0.144 & 0.144 \\
\hline & C15 & 0.297 & 0.297 & 0.297 & 0.297 & 0.297 & 0.297 & 0.297 & 0.297 & 0.297 & 0.297 & 0.297 & 0.297 & 0.000 & 0.000 & 0.000 & 0.000 & 0.297 & 0.297 & 0.297 & 0.297 & 0.297 & 0.297 & 0.297 & 0.297 \\
\hline & C16 & 0.140 & 0.140 & 0.140 & 0.140 & 0.140 & 0.140 & 0.140 & 0.140 & 0.140 & 0.140 & 0.140 & 0.140 & 0.000 & 0.000 & 0.000 & 0.000 & 0.140 & 0.140 & 0.140 & 0.140 & 0.140 & 0.140 & 0.140 & 0.140 \\
\hline \multirow{4}{*}{ AS5 } & C17 & $2 \angle 0$ & 0.120 & 120 & U & 20 & $1 \angle 0$ & 0. & 0 & 0 & $0.1 \angle 0$ & 0 & & & 0.000 & & & & 0.000 & 0.000 & & & 0.120 & & \\
\hline & C18 & 0.302 & 0.302 & 0.299 & 0.302 & 0.302 & 0.302 & 0.302 & 0.302 & 0.302 & 0.302 & 0.302 & & 0.000 & 0.000 & 0.000 & 0.000 & 0.000 & 0.000 & 0.000 & 0.000 & 0.302 & 0.302 & 0.302 & 0.302 \\
\hline & C19 & 0.207 & 0.207 & 0.210 & 0.207 & 0.207 & 0.207 & & 0.207 & & 0.207 & & & 0.000 & & & & & 0.000 & & 0.000 & 0.207 & 0.207 & 07 & 0.207 \\
\hline & $\mathrm{C} 20$ & 0.371 & 0.371 & 0.371 & 0.371 & 0.371 & 0.371 & 0.371 & 0.371 & 0.371 & 0.371 & 0.371 & 0.371 & 0.000 & 0.000 & 0.000 & 0.000 & 0.000 & 0.000 & 0.000 & 0.000 & 0.371 & 0.371 & 0.371 & 0.371 \\
\hline \multirow{4}{*}{ AS6 } & $\mathrm{C} 21$ & 0.318 & 0.318 & 0.318 & 8 & 318 & 0.318 & 0 & 318 & 8 & 0.318 & 318 & & 318 & 0.318 & 318 & 18 & 18 & 0.318 & 18 & 18 & 000 & 0.000 & 000 & 0.000 \\
\hline & $\mathrm{C} 22$ & 0.264 & 0.264 & 0.264 & 0.264 & 0.264 & 0.264 & 0.264 & 0.264 & 0.264 & 0.264 & 0.264 & 0.264 & 0.264 & 0.264 & 0.264 & 0.264 & 0.264 & 0.264 & 0.264 & 0.264 & 0.000 & 0.000 & 0.000 & 0.000 \\
\hline & $\mathrm{C} 23$ & 0.145 & 0.145 & 0.145 & 0.145 & 0.145 & 0.145 & 0.145 & 0.145 & 0.145 & 0.145 & 0.145 & 0.145 & 0.145 & 0.145 & 0.145 & 0.145 & 0.145 & 0.145 & 0.145 & 0.145 & 0.000 & 0.000 & 0.000 & 0.000 \\
\hline & $\mathrm{C} 24$ & 0.273 & 0.273 & 0.273 & 0.273 & 0.273 & 0.273 & 0.273 & 0.273 & 0.273 & 0.273 & 0.273 & 0.273 & 0.273 & 0.273 & 0.273 & 0.273 & 0.273 & 0.273 & 0.273 & 0.273 & 0.000 & 0.000 & 0.000 & 0.000 \\
\hline
\end{tabular}




\section{Appendix F}

Table A3. ANP Weighted Supermatrix for the SSS Decision Network.

\begin{tabular}{|c|c|c|c|c|c|c|c|c|c|c|c|c|c|c|c|c|c|c|c|c|c|c|c|c|c|}
\hline & & \multicolumn{4}{|c|}{ AS1 } & \multicolumn{4}{|c|}{ AS2 } & \multicolumn{4}{|c|}{ AS3 } & \multicolumn{4}{|c|}{ AS4 } & \multicolumn{4}{|c|}{ AS5 } & \multicolumn{4}{|c|}{ AS6 } \\
\hline & & C1 & C2 & C3 & $\mathrm{C} 4$ & C5 & C6 & C7 & C8 & C9 & C10 & C11 & $\mathrm{C} 12$ & 13 & C14 & C15 & C16 & $\mathrm{C} 17$ & C18 & C19 & $\mathrm{C} 20$ & C21 & C22 & $\mathrm{C} 23$ & $\mathrm{C} 24$ \\
\hline \multirow{4}{*}{ AS1 } & $\mathrm{C} 1$ & 0.027 & 0.027 & 27 & 027 & 032 & 32 & 32 & 32 & 34 & 34 & 34 & 0.034 & 031 & 0.031 & 031 & 0.031 & 0.032 & 0.032 & 032 & 0.032 & 0.037 & 0.037 & .037 & 0.037 \\
\hline & C2 & 0.036 & 0.036 & 0.036 & 0.036 & 0.043 & 0.043 & 0.043 & 043 & 0.045 & 0.045 & 045 & 0.045 & .042 & 0.042 & 042 & 0.042 & 0.044 & 0.044 & 044 & 0.044 & 051 & 0.051 & 051 & 0.051 \\
\hline & $\mathrm{C} 3$ & 0.027 & 0.027 & 0.027 & 0.027 & 0.032 & 0.032 & 0.032 & 0.032 & 0.034 & 0.034 & 0.034 & 0.034 & 0.032 & 0.032 & 0.032 & 0.032 & 0.033 & 0.033 & 0.033 & 0.033 & 0.038 & 0.038 & 0.038 & 0.038 \\
\hline & $\mathrm{C} 4$ & 0.023 & 0.023 & 0.023 & 0.023 & 0.027 & 0.027 & 0.027 & 0.027 & 0.029 & 0.029 & 0.029 & 0.029 & 0.027 & 0.027 & 0.027 & 0.027 & 0.028 & 0.028 & 0.028 & 0.028 & 0.032 & 0.032 & 0.032 & 0.032 \\
\hline \multirow{4}{*}{ AS2 } & $\mathrm{C} 5$ & 027 & 0.027 & 027 & 0.027 & 000 & 000 & 0.000 & 000 & 0.034 & 034 & .034 & 034 & 038 & 0.038 & 038 & 0.038 & 028 & 0.028 & 0.028 & 0.028 & 0.037 & 0.037 & 037 & 0.037 \\
\hline & C6 & 0.021 & 0.021 & 0.021 & 0.021 & 0.000 & 0.000 & 0.000 & 0.000 & 0.026 & 0.026 & 0. & 0.026 & 0.030 & 0.030 & 0.030 & 0. & 0.021 & 0.021 & & 21 & 28 & 0.028 & 28 & 0.028 \\
\hline & C7 & 0.036 & 0.036 & 0.036 & 0.036 & 0.000 & 0.000 & 0.000 & 0.000 & 0.045 & 0.045 & 0.045 & 0.045 & .051 & 0.051 & 0.051 & 0.051 & 0.037 & 0.037 & 37 & 0.037 & 49 & 0.049 & 49 & 0.049 \\
\hline & $\mathrm{C} 8$ & 0.049 & 0.049 & 0.049 & 0.049 & 0.000 & 0.000 & 0.000 & 0.000 & 0.061 & 0.061 & 0.061 & 0.061 & .070 & 0.070 & 0.070 & 0.070 & 0.050 & 0.050 & 0.050 & 0.050 & 0.067 & 0.067 & .067 & 0.067 \\
\hline \multirow{4}{*}{ AS3 } & $\mathrm{C}$ & 771 & 971 & 71 & 71 & & 87 & & & & 000 & & & & & & & & 0.084 & & & & 0.082 & 82 & 0.082 \\
\hline & C10 & 0.061 & 0.061 & 0.061 & 0.061 & 0.075 & 0.075 & 0.075 & 0.075 & 0.000 & 0.000 & 0.000 & & 0.095 & 0.095 & 0.095 & 0.095 & 0.073 & 0.073 & 0.073 & 0.073 & 0.071 & 0.071 & 0.071 & 0.071 \\
\hline & C11 & 0.053 & 0.053 & 0.053 & 0.053 & 0.065 & 0.065 & 0.065 & 0.065 & 0.000 & 0.000 & 0.000 & 0.000 & 0.082 & 0.082 & 0.082 & 0.082 & 0.063 & 0.063 & 0.063 & 0.063 & 0.061 & 0.061 & 0.061 & 0.061 \\
\hline & $\mathrm{C} 12$ & 0.044 & 0.044 & 0.044 & 0.044 & 0.054 & 0.054 & 0.054 & 0.054 & 0.000 & 0.000 & 0.000 & 0.000 & 0.068 & 0.068 & 0.068 & 0.068 & 0.052 & 0.052 & 0.052 & 0.052 & 0.050 & 0.050 & 0.050 & 0.050 \\
\hline \multirow{4}{*}{ AS4 } & & $P$ & 3 & & & (נ) & 058 & & 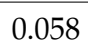 & & & & & & & & & & & & & & 086 & 36 & \\
\hline & C14 & 0.022 & 0.022 & 0.022 & 0.022 & 0.020 & 0.020 & 0.020 & 020 & 0.027 & 0.027 & 0.027 & 0.027 & 0.000 & 0.000 & 0.000 & 0.000 & 0.026 & 0.026 & 0.026 & 0.026 & 0.030 & 0.030 & 0.030 & 0.030 \\
\hline & C15 & 0.045 & 0.045 & 0.045 & 0.045 & 0.041 & 0.041 & 0.041 & 0.041 & 0.055 & 0.055 & 0.055 & 0.055 & 0.000 & 0.000 & 0.000 & 0.000 & 0.054 & 0.054 & 0.054 & 0.054 & 0.061 & 0.061 & 0.061 & 0.061 \\
\hline & C16 & 0.021 & 0.021 & 0.021 & 0.021 & 0.019 & 0.019 & 0.019 & 0.019 & 0.026 & 0.026 & 0.026 & 0.026 & 0.000 & 0.000 & 0.000 & 0.000 & 0.026 & 0.026 & 0.026 & 0.026 & 0.029 & 0.029 & 0.029 & 0.029 \\
\hline \multirow{4}{*}{ AS5 } & C17 & 110 & 4 & & 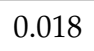 & $5<2$ & 02 & 0.022 & $0<2$ & 0.022 & 0.022 & 0.022 & 0.022 & 0.000 & 0.000 & 0.000 & & 0.000 & 0.000 & 0.000 & 0.000 & 0.023 & 0.023 & & 0.023 \\
\hline & C18 & 0.044 & 0.044 & 0.044 & 0.044 & 0.056 & 0.056 & 0.056 & 0.056 & 0.057 & 0.057 & 0.057 & 0.057 & 0.000 & 0.000 & 0.000 & 0.000 & 0.000 & 0.000 & 0.000 & 0.000 & 0.059 & 0.059 & 0.059 & 0.059 \\
\hline & C19 & 0.030 & 0.030 & 0.031 & 0.030 & 0.038 & 0.038 & & 0.038 & 0.039 & 0.039 & 0.039 & & 0.000 & & & & & 0.000 & & 0.000 & 0.040 & 0.040 & 0.040 & 0.040 \\
\hline & $\mathrm{C} 20$ & 0.054 & 0.054 & 0.054 & 0.054 & 0.069 & 0.069 & 0.069 & 0.069 & 0.069 & 0.069 & 0.069 & 0.069 & 0.000 & 0.000 & 0.000 & 0.000 & 0.000 & 0.000 & 0.000 & 0.000 & 0.072 & 0.072 & 0.072 & 0.072 \\
\hline \multirow{4}{*}{ AS6 } & $\mathrm{C} 21$ & 0.073 & 0.073 & 0.073 & 0.073 & 0.083 & 083 & 0.083 & 083 & 1 & 0.101 & 1 & & 03 & 33 & 03 & 33 & 87 & 0.087 & & 887 & 000 & 0.000 & 000 & 0.000 \\
\hline & $\mathrm{C} 22$ & 0.061 & 0.061 & 0.061 & 0.061 & 0.069 & 0.069 & 0.069 & 0.069 & 0.084 & 0.084 & 0.084 & 0.084 & 0.085 & 0.085 & 0.085 & 0.085 & 0.072 & 0.072 & 0.072 & 0.072 & 0.000 & 0.000 & 0.000 & 0.000 \\
\hline & $\mathrm{C} 23$ & 0.033 & 0.033 & 0.033 & 0.033 & 0.038 & 0.038 & 0.038 & 0.038 & 0.046 & 0.046 & 0.046 & 0.046 & 0.047 & 0.047 & 0.047 & 0.047 & 0.040 & 0.040 & 0.040 & 0.040 & 0.000 & 0.000 & 0.000 & 0.000 \\
\hline & $\mathrm{C} 24$ & 0.063 & 0.063 & 0.063 & 0.063 & 0.072 & 0.072 & 0.072 & 0.072 & 0.087 & 0.087 & 0.087 & 0.087 & 0.088 & 0.088 & 0.088 & 0.088 & 0.075 & 0.075 & 0.075 & 0.075 & 0.000 & 0.000 & 0.000 & 0.000 \\
\hline
\end{tabular}




\section{Appendix G}

Table A4. ANP Limit Supermatrix for the SSS Decision Network.

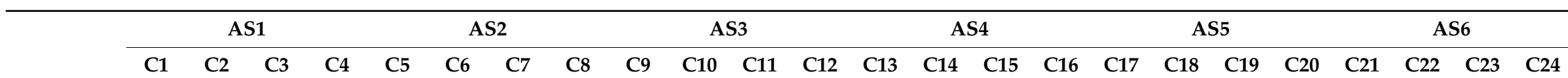

$\begin{array}{llllllllllllllllllllllllllll}\mathbf{C} 1 & 0.033 & 0.033 & 0.033 & 0.033 & 0.033 & 0.033 & 0.033 & 0.033 & 0.033 & 0.033 & 0.033 & 0.033 & 0.033 & 0.033 & 0.033 & 0.033 & 0.033 & 0.033 & 0.033 & 0.033 & 0.033 & 0.033 & 0.033 & 0.033\end{array}$ $\begin{array}{llllllllllllllllllllllllllll}\mathbf{C} 2 & 0.044 & 0.044 & 0.044 & 0.044 & 0.044 & 0.044 & 0.044 & 0.044 & 0.044 & 0.044 & 0.044 & 0.044 & 0.044 & 0.044 & 0.044 & 0.044 & 0.044 & 0.044 & 0.044 & 0.044 & 0.044 & 0.044 & 0.044 & 0.044\end{array}$

$\begin{array}{lllllllllllllllllllllllllllllllllllllll}\text { AS1 } & \text { C2 } 3 & 0.033 & 0.033 & 0.033 & 0.033 & 0.033 & 0.033 & 0.033 & 0.033 & 0.033 & 0.033 & 0.033 & 0.033 & 0.033 & 0.033 & 0.033 & 0.033 & 0.033 & 0.033 & 0.033 & 0.033 & 0.033 & 0.033 & 0.033 & 0.033\end{array}$ \begin{tabular}{lllllllllllllllllllllllllllllll} 
C4 & 0.028 & 0.028 & 0.028 & 0.028 & 0.028 & 0.028 & 0.028 & 0.028 & 0.028 & 0.028 & 0.028 & 0.028 & 0.028 & 0.028 & 0.028 & 0.028 & 0.028 & 0.028 & 0.028 & 0.028 & 0.028 & 0.028 & 0.028 & 0.028 \\
\hline
\end{tabular}

$\begin{array}{lllllllllllllllllllllllllllll}\text { C5 } & 0.029 & 0.029 & 0.029 & 0.029 & 0.029 & 0.029 & 0.029 & 0.029 & 0.029 & 0.029 & 0.029 & 0.029 & 0.029 & 0.029 & 0.029 & 0.029 & 0.029 & 0.029 & 0.029 & 0.029 & 0.029 & 0.029 & 0.029 & 0.029\end{array}$ $\begin{array}{llllllllllllllllllllllllllll}\text { C6 } & 0.022 & 0.022 & 0.022 & 0.022 & 0.022 & 0.022 & 0.022 & 0.022 & 0.022 & 0.022 & 0.022 & 0.022 & 0.022 & 0.022 & 0.022 & 0.022 & 0.022 & 0.022 & 0.022 & 0.022 & 0.022 & 0.022 & 0.022 & 0.022\end{array}$

$\begin{array}{lllllllllllllllllllllllllllllll}\text { AS2 } & \text { C7 } & 0.038 & 0.038 & 0.038 & 0.038 & 0.038 & 0.038 & 0.038 & 0.038 & 0.038 & 0.038 & 0.038 & 0.038 & 0.038 & 0.038 & 0.038 & 0.038 & 0.038 & 0.038 & 0.038 & 0.038 & 0.038 & 0.038 & 0.038 & 0.038\end{array}$ $\begin{array}{llllllllllllllllllllllllllllll}\text { C8 } & 0.052 & 0.052 & 0.052 & 0.052 & 0.052 & 0.052 & 0.052 & 0.052 & 0.052 & 0.052 & 0.052 & 0.052 & 0.052 & 0.052 & 0.052 & 0.052 & 0.052 & 0.052 & 0.052 & 0.052 & 0.052 & 0.052 & 0.052 & 0.052\end{array}$

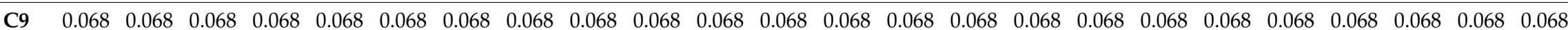

$\begin{array}{llllllllllllllllllllllllllllllll}\text { AS3 } & \mathbf{C 1 0} & 0.059 & 0.059 & 0.059 & 0.059 & 0.059 & 0.059 & 0.059 & 0.059 & 0.059 & 0.059 & 0.059 & 0.059 & 0.059 & 0.059 & 0.059 & 0.059 & 0.059 & 0.059 & 0.059 & 0.059 & 0.059 & 0.059 & 0.059 & 0.059\end{array}$

$\begin{array}{llllllllllllllllllllllllllllllll}\mathbf{C} 11 & 0.050 & 0.050 & 0.050 & 0.050 & 0.050 & 0.050 & 0.050 & 0.050 & 0.050 & 0.050 & 0.050 & 0.050 & 0.050 & 0.050 & 0.050 & 0.050 & 0.050 & 0.050 & 0.050 & 0.050 & 0.050 & 0.050 & 0.050 & 0.050\end{array}$

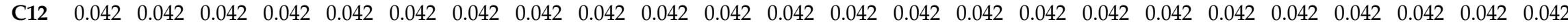

$\begin{array}{lllllllllllllllllllllllllll}\text { C13 } & 0.063 & 0.063 & 0.063 & 0.063 & 0.063 & 0.063 & 0.063 & 0.063 & 0.063 & 0.063 & 0.063 & 0.063 & 0.063 & 0.063 & 0.063 & 0.063 & 0.063 & 0.063 & 0.063 & 0.063 & 0.063 & 0.063 & 0.063 & 0.063\end{array}$ $\begin{array}{llllllllllllllllllllllllll}\mathbf{C} 14 & 0.022 & 0.022 & 0.022 & 0.022 & 0.022 & 0.022 & 0.022 & 0.022 & 0.022 & 0.022 & 0.022 & 0.022 & 0.022 & 0.022 & 0.022 & 0.022 & 0.022 & 0.022 & 0.022 & 0.022 & 0.022 & 0.022 & 0.022 & 0.022\end{array}$

$\begin{array}{lllllllllllllllllllllllllllllllllll}\text { AS4 } & \mathrm{C} 15 & 0.045 & 0.045 & 0.045 & 0.045 & 0.045 & 0.045 & 0.045 & 0.045 & 0.045 & 0.045 & 0.045 & 0.045 & 0.045 & 0.045 & 0.045 & 0.045 & 0.045 & 0.045 & 0.045 & 0.045 & 0.045 & 0.045 & 0.045 & 0.045\end{array}$ $\begin{array}{lllllllllllllllllllllllllllllllll}\mathrm{C} 16 & 0.021 & 0.021 & 0.021 & 0.021 & 0.021 & 0.021 & 0.021 & 0.021 & 0.021 & 0.021 & 0.021 & 0.021 & 0.021 & 0.021 & 0.021 & 0.021 & 0.021 & 0.021 & 0.021 & 0.021 & 0.021 & 0.021 & 0.021 & 0.021\end{array}$

$\begin{array}{llllllllllllllllllllllllllll}\text { C17 } & 0.016 & 0.016 & 0.016 & 0.016 & 0.016 & 0.016 & 0.016 & 0.016 & 0.016 & 0.016 & 0.016 & 0.016 & 0.016 & 0.016 & 0.016 & 0.016 & 0.016 & 0.016 & 0.016 & 0.016 & 0.016 & 0.016 & 0.016 & 0.016\end{array}$

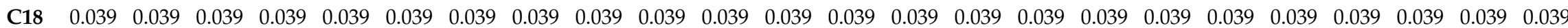

$\begin{array}{llllllllllllllllllllllllllllllll}\text { AS5 } & \text { C19 } & 0.027 & 0.027 & 0.027 & 0.027 & 0.027 & 0.027 & 0.027 & 0.027 & 0.027 & 0.027 & 0.027 & 0.027 & 0.027 & 0.027 & 0.027 & 0.027 & 0.027 & 0.027 & 0.027 & 0.027 & 0.027 & 0.027 & 0.027 & 0.027\end{array}$

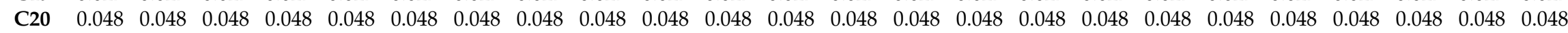

$\begin{array}{lllllllllllllllllllllllllllllll}\text { C21 } & 0.071 & 0.071 & 0.071 & 0.071 & 0.071 & 0.071 & 0.071 & 0.071 & 0.071 & 0.071 & 0.071 & 0.071 & 0.071 & 0.071 & 0.071 & 0.071 & 0.071 & 0.071 & 0.071 & 0.071 & 0.071 & 0.071 & 0.071 & 0.071\end{array}$ $\begin{array}{llllllllllllllllllllllllllll}\text { C22 } & 0.059 & 0.059 & 0.059 & 0.059 & 0.059 & 0.059 & 0.059 & 0.059 & 0.059 & 0.059 & 0.059 & 0.059 & 0.059 & 0.059 & 0.059 & 0.059 & 0.059 & 0.059 & 0.059 & 0.059 & 0.059 & 0.059 & 0.059 & 0.059\end{array}$ $\begin{array}{lllllllllllllllllllllllllllll}\text { AS6 } & \text { C23 } & 0.032 & 0.032 & 0.032 & 0.032 & 0.032 & 0.032 & 0.032 & 0.032 & 0.032 & 0.032 & 0.032 & 0.032 & 0.032 & 0.032 & 0.032 & 0.032 & 0.032 & 0.032 & 0.032 & 0.032 & 0.032 & 0.032 & 0.032 & 0.032\end{array}$ $\begin{array}{lllllllllllllllllllllllllllllllllllll}\text { C24 } & 0.061 & 0.061 & 0.061 & 0.061 & 0.061 & 0.061 & 0.061 & 0.061 & 0.061 & 0.061 & 0.061 & 0.061 & 0.061 & 0.061 & 0.061 & 0.061 & 0.061 & 0.061 & 0.061 & 0.061 & 0.061 & 0.061 & 0.061 & 0.061\end{array}$ 


\section{References}

1. Seuring, S.; Müller, M. From a literature review to a conceptual framework for sustainable supply chain management. J. Clean Prod. 2008, 16, 1699-1710. [CrossRef]

2. Hashemi, S.H.; Karimi, A.; Tavana, M. An integrated green supplier selection approach with analytic network process and improved Grey relational analysis. Int. J. Prod. Econ. 2015, 159, 178-191. [CrossRef]

3. Apple Wakes Up to Chinese Pollution Concerns. https:/ /www.theguardian.com/environment/2011/oct/ 04/apple-chinese-pollution-concerns (accessed on 4 October 2011).

4. Amindoust, A.; Ahmed, S.; Saghafinia, A.; Bahreininejad, A. Sustainable supplier selection: A ranking model based on fuzzy inference system. Appl. Soft Comput. 2012, 12, 1668-1677. [CrossRef]

5. Bai, C.; Sarkis, J. Determining and applying sustainable supplier key performance indicators. Supply Chain Manag. 2014, 19, 275-291. [CrossRef]

6. Buyukozkan, G.; Cifci, G. A novel fuzzy multi-criteria decision framework for sustainable supplier selection with incomplete information. Comput. Ind. 2011, 62, 164-174. [CrossRef]

7. Zimmer, K.; Froehling, M.; Schultmann, F. Sustainable supplier management-A review of models supporting sustainable supplier selection, monitoring and development. Int. J. Prod. Res. 2016, 54, 1412-1442. [CrossRef]

8. Esfahbodi, A.; Zhang, Y.; Watson, G. Sustainable supply chain management in emerging economies: Trade-offs between environmental and cost performance. Int. J. Prod. Econ. 2016, 181, 350-366. [CrossRef]

9. Vahidi, F.; Torabi, S.A.; Ramezankhani, M.J. Sustainable supplier selection and order allocation under operational and disruption risks. J. Clean Prod. 2018, 174, 1351-1365. [CrossRef]

10. Guo, X.; Yuan, Z.; Tian, B. Supplier selection based on hierarchical potential support vector machine. Expert Syst. Appl. 2009, 36, 6978-6985. [CrossRef]

11. Ghodsypour, S.H.; O'Brien, C. The total cost of logistics in supplier selection, under conditions of multiple sourcing, multiple criteria and capacity constraint. Int. J. Prod. Econ. 2001, 73, 15-27. [CrossRef]

12. Shemshadi, A.; Shirazi, H.; Toreihi, M.; Tarokh, M.J. A fuzzy VIKOR method for supplier selection based on entropy measure for objective weighting. Expert Syst. Appl. 2011, 38, 12160-12167. [CrossRef]

13. Handfield, R.; Walton, S.V.; Sroufe, R.; Melnyk, S.A. Applying environmental criteria to supplier assessment: A study in the application of the Analytical Hierarchy Process. Eur. J. Oper. Res. 2002, 141, 70-87. [CrossRef]

14. Lee, A.H.I.; Kang, H.Y.; Hsu, C.F.; Hung, H.C. A green supplier selection model for high-tech industry. Expert Syst. Appl. 2009, 36, 7917-7927. [CrossRef]

15. Song, W.; Xu, Z.; Liu, H.C. Developing sustainable supplier selection criteria for solar air-conditioner manufacturer: An integrated approach. Renew. Sust. Energ. Rev. 2017, 79, 1461-1471. [CrossRef]

16. Fallahpour, A.; Olugu, E.U.; Musa, S.N.; Wong, K.Y.; Noori, S. A decision support model for sustainable supplier selection in sustainable supply chain management. Comput. Ind. Eng. 2017, 105, 391-410. [CrossRef]

17. Tavana, M.; Yazdani, M.; Di Caprio, D. An application of an integrated ANP-QFD framework for sustainable supplier selection. Int. J. Logist.-Res. Appl. 2017, 20, 254-275. [CrossRef]

18. Kannan, D. Role of multiple stakeholders and the critical success factor theory for the sustainable supplier selection process. Int. J. Prod. Econ. 2018, 195, 391-418. [CrossRef]

19. Elkington, J. Cannibals with forks : The triple bottom line of 21st century business. Environ. Qual. Manage. 1998, 8, 37-51. [CrossRef]

20. Ou Yang, Y.P.; Shieh, H.M.; Leu, J.D.; Tzeng, G.H. A novel hybrid MCDM model combined with DEMATEL and ANP with applications. Int. J. Oper. Res. 2008, 5, 160-168.

21. Hsu, C.H.; Wang, F.K.; Tzeng, G.H. The best vendor selection for conducting the recycled material based on a hybrid MCDM model combining DANP with VIKOR. Resour. Conserv. Recycl. 2012, 66, 95-111. [CrossRef]

22. Chiu, W.Y.; Tzeng, G.H.; Li, H.L. A new hybrid MCDM model combining DANP with VIKOR to improve e-store business. Knowledge-Based Syst. 2013, 37, 48-61. [CrossRef]

23. Wang, Y.L.; Tzeng, G.H. Brand marketing for creating brand value based on a MCDM model combining DEMATEL with ANP and VIKOR methods. Expert Syst. Appl. 2012, 39, 5600-5615. [CrossRef]

24. Opricovic, S.; Tzeng, G. Compromise solution by MCDM methods: A comparative analysis of VIKOR and TOPSIS. Eur. J. Oper. Res. 2004, 156, 445-455. [CrossRef]

25. Sanayei, A.; Mousavi, S.F.; Yazdankhah, A. Group decision making process for supplier selection with VIKOR under fuzzy environment. Expert Syst. Appl. 2010, 37, 24-30. [CrossRef] 
26. Lin, Y.H.; Tseng, M.L. Assessing the competitive priorities within sustainable supply chain management under uncertainty. J. Clean Prod. 2016, 112, 2133-2144. [CrossRef]

27. Kuo, M.S.; Liang, G.S. A soft computing method of performance evaluation with MCDM based on interval-valued fuzzy numbers. Appl. Soft Comput. 2012, 12, 476-485. [CrossRef]

28. Kuo, T.C.; Hsu, C.W.; Li, J.Y. Developing a green supplier selection model by using the DANP with VIKOR. Sustainability 2015, 7, 1661-1689. [CrossRef]

29. Luthra, S.; Govindan, K.; Kannan, D.; Mangla, S.K.; Garg, C.P. An integrated framework for sustainable supplier selection and evaluation in supply chains. J. Clean Prod. 2017, 140, 1686-1698. [CrossRef]

30. Jauhar, S.K.; Pant, M. Integrating DEA with DE and MODE for sustainable supplier selection. J. Comput. Sci. 2017, 21, 299-306. [CrossRef]

31. Drumwright, M.E. Socially responsible organizational buying: Environmental concern as a noneconomic buying criterion. J. Mark. 1994, 58, 1-19. [CrossRef]

32. Murphy, P.R.; Poist, R.F.; Braunschwieg, C.D. Management of environmental issues in logistics: Current status and future potential. Transp. J. 1994, 34, 48-56.

33. Green, K.; Morton, B.; New, S. Purchasing and environmental management: Interactions, politics and opportunities. Bus. Strateg. Environ. 1996, 5, 188-197. [CrossRef]

34. Min, H.; Galle, W.P. Green purchasing practices of US firms. Int. J. Oper. Prod. Manage. 2001, 21, $1222-1238$. [CrossRef]

35. Carter, C.R.; Jennings, M.M. Logistics social responsibility: An integrative framework. J. Bus. Logist. 2002, 23, 145-180. [CrossRef]

36. Mentzer, J.T.; Dewitt, W.; Keebler, J.S.; Min, S.; Nix, N.W.; Smith, C.D.; Zacharia, Z.G. Defining supply chain management. J. Bus. Logist. 2001, 22, 1-25. [CrossRef]

37. Linton, J.D.; Klassen, R.; Jayaraman, V. Sustainable supply chains: An introduction. J. Oper. Manag. 2007, 25, 1075-1082. [CrossRef]

38. Carter, C.R.; Rogers, D.S. A framework of sustainable supply chain management: Moving toward new theory. Int. J. Phys. Distrib. Logist. Manag. 2008, 38, 360-387. [CrossRef]

39. Handfield, R.; Sroufe, R.; Walton, S. Integrating environmental management and supply chain strategies. Bus. Strateg. Environ. 2005, 14, 1-19. [CrossRef]

40. Lamming, R.; Hampson, J. The environment as a supply chain management issue. Brit. J. Manage. 1996, 7, S45-S62. [CrossRef]

41. Preuss, L. Buying into our future: Sustainability initiatives in local government procurement. Bus. Strateg. Environ. 2007, 16, 354-365. [CrossRef]

42. Leppelt, T.; Kai, F.; Reuter, C.; Hartmann, E. Sustainability management beyond organizational boundaries-sustainable supplier relationship management in the chemical industry. J. Clean. Prod. 2013, 56, 94-102. [CrossRef]

43. Grimm, J.H.; Hofstetter, J.S.; Sarkis, J. Critical factors for sub-supplier management: A sustainable food supply chains perspective. Int. J. Prod. Econ. 2014, 152, 159-173. [CrossRef]

44. Baskaran, V.; Nachiappan, S.; Rahman, S. Indian textile suppliers' sustainability evaluation using the grey approach. Int. J. Prod. Econ. 2012, 135, 647-658. [CrossRef]

45. Sarkis, J.; Talluri, S. A model for strategic supplier selection. J. Supply Chain Manag. 2002, 38, 18-28. [CrossRef]

46. Verma, R.; Pullman, M.E. An analysis of the supplier selection process. Omega-Int. J. Manag. Sci. 1998, 26, 739-750. [CrossRef]

47. Şen, S.; Başligil, H.; Şen, C.G.; BaraÇli, H. A framework for defining both qualitative and quantitative supplier selection criteria considering the buyer-supplier integration strategies. Int. J. Prod. Res. 2008, 46, 1825-1845. [CrossRef]

48. Choi, T.Y.; Hartley, J.L. An exploration of supplier selection practices across the supply chain. J. Oper. Manag. 1996, 14, 333-343. [CrossRef]

49. Freeman, J.; Chen, T. Green supplier selection using an AHP-Entropy-TOPSIS framework. Supply Chain Manag. 2015, 20, 327-340. [CrossRef]

50. Bai, C.; Sarkis, J. Integrating sustainability into supplier selection with grey system and rough set methodologies. Int. J. Prod. Econ. 2010, 124, 252-264. [CrossRef]

51. Dickson, G. An analysis of vendor selection systems and decision. J. Purch. 1966, 2, 5-17. [CrossRef] 
52. Weber, C.A.; Current, J.R.; Benton, W.C. Vendor selection criteria and methods. Eur. J. Oper. Res. 1991, 50, 2-18. [CrossRef]

53. Dixon, J.R.; Arnold, P.; Heineke, J.; Kim, J.S.; Mulligan, P. Business process reengineering: Improving in new strategic directions. Calif. Manag. Rev. 1994, 36, 93-108. [CrossRef]

54. Chang, S.C.; Lin, N.P.; Sheu, C. Aligning manufacturing flexibility with environmental uncertainty in high-tech industry. Int. J. Prod. Res. 2002, 40, 4765-4780. [CrossRef]

55. Bruntland, G. Our Common Future: UN World Commission on Environment and Development; Oxford University Press: Oxford, UK, 1987; p. 383.

56. Walton, S.V.; Handfield, R.B.; Melnyk, S.A. The green supply chain: Integrating suppliers into environmental management processes. In Proceedings of the Annual Meeting of the Decision-Science-Institute, San Diego, CA, USA, 22-25 November 1997; pp. 1114-1116.

57. Awasthi, A.; Govindan, K.; Gold, S. Multi-tier sustainable global supplier selection using a fuzzy AHP-VIKOR based approach. Int. J. Prod. Econ. 2018, 195, 106-117. [CrossRef]

58. Yahya, S.; Kingsman, B. Vendor rating for an entrepreneur development programme: A case study using the Analytic Hierarchy Process method. J. Oper. Res. Soc. 1999, 50, 916-930. [CrossRef]

59. Schan, F.T. Interactive selection model for supplier selection process: An analytical hierarchy process approach. Int. J. Prod. Res. 2003, 41, 3549-3579.

60. Boer, L.D.; Dijkhuizen, G.V.; Telgen, J. A basis for modelling the costs of supplier selection: The economic tender quantity. J. Oper. Res. Soc. 2000, 51, 1128-1135. [CrossRef]

61. Chen, C.T.; Lin, C.T.; Huang, S.F. A fuzzy approach for supplier evaluation and selection in supply chain management. Int. J. Prod. Econ. 2006, 102, 289-301. [CrossRef]

62. Hamdan, S.; Cheaitou, A. Green supplier selection and order allocation using an integrated fuzzy TOPSIS, AHP and IP approach. In Proceedings of the IEEE International Conference on Industrial Engineering and Operations Management (IEOM), Dubai, United Arab Emirates, 3-5 March 2015; pp. 1-10.

63. Kuo, R.J.; Wang, Y.C.; Tien, F.C. Integration of artificial neural network and MADA methods for green supplier selection. J. Clean Prod. 2010, 18, 1161-1170. [CrossRef]

64. Zhu, Q.; Dou, Y.; Sarkis, J. A portfolio-based analysis for green supplier management using the analytical network process. Supply Chain Manag. 2010, 15, 306-319. [CrossRef]

65. Kannan, D.; Jabbour, C.J.C. Selecting green suppliers based on GSCM practices: Using fuzzy TOPSIS applied to a Brazilian electronics company. Eur. J. Oper. Res. 2014, 233, 432-447. [CrossRef]

66. Awasthi, A.; Chauhan, S.S.; Goyal, S.K. A fuzzy multicriteria approach for evaluating environmental performance of suppliers. Int. J. Prod. Econ. 2010, 126, 370-378. [CrossRef]

67. Keskin, G.A.; İlhan, S.; Özkan, C. The fuzzy ART algorithm: A categorization method for supplier evaluation and selection. Expert Syst. Appl. 2010, 37, 1235-1240. [CrossRef]

68. Govindan, K.; Khodaverdi, R.; Jafarian, A. A fuzzy multi criteria approach for measuring sustainability performance of a supplier based on triple bottom line approach. J. Clean Prod. 2013, 47, 345-354. [CrossRef]

69. Ciliberti, F.; Groot, G.D.; Haan, J.D.; Pontrandolfo, P. Codes to coordinate supply chains: SMEs' experiences with SA8000. Supply Chain Manag. 2013, 14, 117-127. [CrossRef]

70. Ciliberti, F.; Pontrandolfo, P.; Scozzi, B. Investigating corporate social responsibility in supply chains: A SME perspective. J. Clean Prod. 2008, 16, 1579-1588. [CrossRef]

71. Cruz, J.M.; Wakolbinger, T. Multiperiod effects of corporate social responsibility on supply chain networks, transaction costs, emissions, and risk. Int. J. Prod. Econ. 2008, 116, 61-74. [CrossRef]

72. Azadnia, A.H.; Saman, M.Z.M.; Wong, K.Y.; Ghadimi, P.; Zakuan, N. Sustainable supplier selection based on self-organizing map neural network and multi criteria decision making approaches. In Proceedings of the International Congress on Interdisciplinary Business and Social Sciences, Jakarta, Indonesia, 1-2 December 2012; pp. 879-884.

73. Hutchins, M.J.; Sutherland, J.W. An exploration of measures of social sustainability and their application to supply chain decisions. J. Clean Prod. 2008, 16, 1688-1698. [CrossRef]

74. Sarkis, J.; Dhavale, D.G. Supplier selection for sustainable operations: A triple-bottom-line approach using a Bayesian framework. Int. J. Prod. Econ. 2015, 166, 177-191. [CrossRef]

75. Yu, Q.; Hou, F. An approach for green supplier selection in the automobile manufacturing industry. Kybernetes 2016, 45, 571-588. [CrossRef] 
76. Büyüközkan, G.; Çifçi, G. A novel hybrid MCDM approach based on fuzzy DEMATEL, fuzzy ANP and fuzzy TOPSIS to evaluate green suppliers. Expert Syst. Appl. 2012, 39, 3000-3011. [CrossRef]

77. Chiou, C.Y.; Hsu, C.W.; Hwang, W.Y. Comparative investigation on green supplier selection of the American, Japanese and Taiwanese Electronics Industry in China. In Proceedings of the IEEE International Conference on Industrial Engineering and Engineering Management, Singapore, 8-11 December 2008; pp. 1909-1914.

78. Yeh, W.C.; Chuang, M.C. Using multi-objective genetic algorithm for partner selection in green supply chain problems. Expert Syst. Appl. 2011, 38, 4244-4253. [CrossRef]

79. Sawik, T. On the risk-averse optimization of service level in a supply chain under disruption risks. Int. J. Prod. Res. 2016, 54, 98-113. [CrossRef]

80. Hsu, C.W.; Hu, A.H. Applying hazardous substance management to supplier selection using analytic network process. J. Clean Prod. 2009, 17, 255-264. [CrossRef]

81. Tseng, M.L.; Chiu, A.S.F. Evaluating firm's green supply chain management in linguistic preferences. J. Clean Prod. 2013, 40, 22-31. [CrossRef]

82. Rajesh, R.; Ravi, V. Supplier selection in resilient supply chains: A grey relational analysis approach. J. Clean Prod. 2015, 86, 343-359. [CrossRef]

83. Chen, Y.-J. Structured methodology for supplier selection and evaluation in a supply chain. Inf. Sci. 2011, 181, 1651-1670. [CrossRef]

84. Punniyamoorthy, M.; Mathiyalagan, P.; Parthiban, P. A strategic model using structural equation modeling and fuzzy logic in supplier selection. Expert Syst. Appl. 2011, 38, 458-474. [CrossRef]

85. Guarnieri, P.; Sobreiro, V.A.; Nagano, M.S.; Serrano, A.L.M. The challenge of selecting and evaluating third-party reverse logistics providers in a multicriteria perspective: A Brazilian case. J. Clean Prod. 2015, 96, 209-219. [CrossRef]

86. Tam, M.C.Y.; Tummala, V.M.R. An application of the AHP in vendor selection of a telecommunications system. Omega-Int. J. Manag. Sci. 2001, 29, 171-182. [CrossRef]

87. Büyüközkan, G.; Çifçi, G. Evaluation of the green supply chain management practices: A fuzzy ANP approach. Prod. Plan. Control 2012, 23, 405-418. [CrossRef]

88. Rezaei, J.; Ortt, R. Multi-criteria supplier segmentation using a fuzzy preference relations based AHP. Eur. J. Oper. Res. 2013, 225, 75-84. [CrossRef]

89. Akman, G. Evaluating suppliers to include green supplier development programs via fuzzy c-means and VIKOR methods. Comput. Ind. Eng. 2015, 86, 69-82. [CrossRef]

90. Chan, F.T.S.; Kumar, N. Global supplier development considering risk factors using fuzzy extended AHP-based approach. Omega-Int. J. Manag. Sci. 2007, 35, 417-431. [CrossRef]

91. Wang, J.W.; Cheng, C.H.; Huang, K.C. Fuzzy hierarchical TOPSIS for supplier selection. Appl. Soft Comput. 2009, 9, 377-386. [CrossRef]

92. Ustun, O.; Demirtas, E.A. An integrated multi-objective decision-making process for multi-period lot-sizing with supplier selection. Omega-Int. J. Manag. Sci. 2008, 36, 509-521. [CrossRef]

93. Adobor, H.; McMullen, R. Supplier diversity and supply chain management: A strategic approach. Bus. Horiz. 2007, 50, 219-229. [CrossRef]

94. Saghiri, S.S.; Barnes, S.J. Supplier flexibility and postponement implementation: An empirical analysis. Int. J. Prod. Econ. 2016, 173, 170-183. [CrossRef]

95. Hosseini, S.; Barker, K. A Bayesian network model for resilience-based supplier selection. Int. J. Prod. Econ. 2016, 180, 68-87. [CrossRef]

96. Zhang, H.C.; Li, J.; Merchant, M.E. Using fuzzy multi-agent decision-making in environmentally conscious supplier management. CIRP Ann-Manuf. Technol. 2003, 52, 385-388. [CrossRef]

97. Humphreys, P.K.; Wong, Y.K.; Chan, F.T.S. Integrating environmental criteria into the supplier selection process. J. Mater. Process. Technol. 2003, 138, 349-356. [CrossRef]

98. Humphreys, P.; McIvor, R.; Chan, F. Using case-based reasoning to evaluate supplier environmental management performance. Expert Syst. Appl. 2003, 25, 141-153. [CrossRef]

99. Kannan, D.; Govindan, K.; Rajendran, S. Fuzzy Axiomatic Sesign approach based green supplier selection: A case study from Singapore. J. Clean Prod. 2015, 96, 194-208. [CrossRef]

100. Mahdiloo, M.; Saen, R.F.; Lee, K.H. Technical, environmental and eco-efficiency measurement for supplier selection: An extension and application of data envelopment analysis. Int. J. Prod. Econ. 2015, 168, 279-289. [CrossRef] 
101. Humphreys, P.; McCloskey, A.; McIvor, R.; Maguire, L.; Glackin, C. Employing dynamic fuzzy membership functions to assess environmental performance in the supplier selection process. Int. J. Prod. Res. 2006, 44, 2379-2419. [CrossRef]

102. Mafakheri, F.; Breton, M.; Ghoniem, A. Supplier selection-order allocation: A two-stage multiple criteria dynamic programming approach. Int. J. Prod. Econ. 2011, 132, 52-57. [CrossRef]

103. Chen, C.C.; Tseng, M.L.; Lin, Y.H.; Lin, Z.S. Implementation of green supply chain management in uncertainty. In Proceedings of the IEEE International Conference on Industrial Engineering and Engineering Management, Macao, China, 7-10 December 2010; pp. 260-264.

104. Bai, C.; Sarkis, J. Green supplier development: Analytical evaluation using rough set theory. J. Clean Prod. 2010, 18, 1200-1210. [CrossRef]

105. Zhu, Q.; Sarkis, J.; Lai, K. Initiatives and outcomes of green supply chain management implementation by Chinese manufacturers. J. Environ. Manag. 2007, 85, 179-189. [CrossRef] [PubMed]

106. Chiou, T.Y.; Chan, H.K.; Lettice, F.; Chung, S.H. The influence of greening the suppliers and green innovation on environmental performance and competitive advantage in Taiwan. Transp. Res. Pt. e-Logist. Transp. Rev. 2011, 47, 822-836. [CrossRef]

107. Sarkis, J.; Zhu, Q.; Lai, K. An organizational theoretic review of green supply chain management literature. Int. J. Prod. Econ. 2011, 130, 1-15. [CrossRef]

108. Ehrgott, M.; Reimann, F.; Kaufmann, L.; Carter, C.R. Social Sustainability in Selecting Emerging Economy Suppliers. J. Bus. Ethics 2011, 98, 99-119. [CrossRef]

109. Awasthi, A.; Kannan, G. Green supplier development program selection using NGT and VIKOR under fuzzy environment. Comput. Ind. Eng. 2016, 91, 100-108. [CrossRef]

110. Blome, C.; Hollos, D.; Paulraj, A. Green procurement and green supplier development: Antecedents and effects on supplier performance. Int. J. Prod. Res. 2014, 52, 32-49. [CrossRef]

111. Cardozo, R.N.; Cagley, J.W. Experimental Study of Industrial Buyer Behavior. J. Mark. Res. 1971, 8, 329-334. [CrossRef]

112. Taylor, T.A.; Plambeck, E.L. Supply chain relationships and contracts: The impact of repeated interaction on capacity investment and procurement. Manag. Sci. 2007, 53, 1577-1593. [CrossRef]

113. Monczka, R.M.; Petersen, K.J.; Handfield, R.B.; Ragatz, G.L. Success factors in strategic supplier alliances: The buying company perspective. Decis. Sci. 1998, 29, 553-577. [CrossRef]

114. Chen, I.J.; Popovich, K. Understanding customer relationship management (CRM): People, process and technology. Bus. Process. Manag. J. 2003, 9, 672-688. [CrossRef]

115. Tallon, P.P.; Kraemer, K.L.; Gurbaxani, V. Executives' perceptions of the business value of information technology: A process-oriented approach. J. Manag. Inform. Syst. 2000, 16, 145-173. [CrossRef]

116. González-Benito, J. A theory of purchasing's contribution to business performance. J. Oper. Manag. 2007, 25, 901-917. [CrossRef]

117. Shen, L.; Olfat, L.; Govindan, K.; Khodaverdi, R.; Diabat, A. A fuzzy multi criteria approach for evaluating green supplier's performance in green supply chain with linguistic preferences. Resour. Conserv. Recycl. 2013, 74, 170-179. [CrossRef]

118. Carter, C.R.; Jennings, M.M. The role of purchasing in the socially responsible management of the supply chain: A structural equation analysis. J. Bus. Logist. 2004, 25, 145-186. [CrossRef]

119. Hillman, A.J.; Keim, G.D. Shareholder value, stakeholder management, and social issues: What's the bottom line? Strateg. Manag. J. 2001, 22, 125-139. [CrossRef]

120. Jabbour, A.B.L.S.; Jabbour, C.J.C. Are supplier selection criteria going green? Case studies of companies in Brazil. Ind. Manag. Data Syst. 2009, 109, 477-495. [CrossRef]

121. Huber, V.L.; Neale, M.A.; Nofthcraft, G.B. Judgment by heuristics: Effects of ratee and rater characteristics and performance standards on performance-related judgments. Organ. Behav. Hum. Decis. 1987, 40, 149-169. [CrossRef]

122. Chan, L.K.; Kao, H.P.; Wu, M.L. Rating the importance of customer needs in quality function deployment by fuzzy and entropy methods. Int. J. Prod. Res. 1999, 37, 2499-2518. [CrossRef]

123. Ashlaghi, M.J. A new approach to green supplier selection based on fuzzy multi-criteria decision making method and linear physical programming. Teh. Vjesn. 2014, 21, 591-597.

124. Sarkar, A.; Mohapatra, P.K.J. Evaluation of supplier capability and performance: A method for supply base reduction. J. Purch. Supply Manag. 2006, 12, 148-163. [CrossRef] 
125. Kilincci, O.; Onal, S.A. Fuzzy AHP approach for supplier selection in a washing machine company. Expert Syst. Appl. 2011, 38, 9656-9664. [CrossRef]

126. Shaw, K.; Shankar, R.; Yadav, S.S.; Thakur, L.S. Supplier selection using fuzzy AHP and fuzzy multi-objective linear programming for developing low carbon supply chain. Expert Syst. Appl. 2012, 39, 8182-8192. [CrossRef]

127. Thongchattu, C.; Siripokapirom, S. Notice of retraction green supplier selection consensus by neural network. In Proceedings of the 2nd International Conference on Mechanical and Electronics Engineering, Kyoto, Japan, 1-3 August 2010; pp. 313-316.

128. Yan, G. Research on green suppliers' evaluation based on AHP \& Genetic algorithm. In Proceedings of the International Conference on Signal Processing Systems (ICSPS), Singapore, 15-17 May 2009; pp. 615-619.

129. Ramanathan, R. Supplier selection problem: Integrating DEA with the approaches of total cost of ownership and AHP. Supply Chain Manag. 2007, 12, 258-261. [CrossRef]

130. Hatefi, S.M.; Tamosaitiene, J. Construction projects assessment based on the sustainable development criteria by an integrated fuzzy AHP and improved GRA model. Sustainability 2018, 10, 991. [CrossRef]

131. Junior, F.R.L.; Osiro, L.; Carpinetti, L.C.R. A comparison between fuzzy AHP and fuzzy TOPSIS methods to supplier selection. Appl. Soft Comput. 2014, 21, 194-209. [CrossRef]

132. Beikkhakhian, Y.; Javanmardi, M.; Karbasian, M.; Khayambashi, B. The application of ISM model in evaluating agile suppliers selection criteria and ranking suppliers using fuzzy TOPSIS-AHP methods. Expert Syst. Appl. 2015, 42, 6224-6236. [CrossRef]

133. Vinodh, S.; Anesh Ramiya, R.; Gautham, S.G. Application of fuzzy analytic network process for supplier selection in a manufacturing organisation. Expert Syst. Appl. 2011, 38, 272-280. [CrossRef]

134. Kuo, R.J.; Lin, Y.J. Supplier selection using analytic network process and data envelopment analysis. Int. J. Prod. Res. 2012, 50, 2852-2863. [CrossRef]

135. Chung, C.C.; Chao, L.C.; Lou, S.J. The establishment of a green supplier selection and guidance mechanism with the ANP and IPA. Sustainability 2016, 8, 259. [CrossRef]

136. Kilic, H.S.; Zaim, S.; Delen, D. Selecting “The Best" ERP system for SMEs using a combination of ANP and PROMETHEE methods. Expert Syst. Appl. 2015, 42, 2343-2352. [CrossRef]

137. Tadić, S.; Zečević, S.; Krstić, M. A novel hybrid MCDM model based on fuzzy DEMATEL, fuzzy ANP and fuzzy VIKOR for city logistics concept selection. Expert Syst. Appl. 2014, 41, 8112-8128. [CrossRef]

138. Lin, R.H. An integrated model for supplier selection under a fuzzy situation. Int. J. Prod. Econ. 2012, 138, 55-61. [CrossRef]

139. Chen, J.K.; Chen, I.S. Using a novel conjunctive MCDM approach based on DEMATEL, fuzzy ANP, and TOPSIS as an innovation support system for Taiwanese higher education. Expert Syst. Appl. 2010, 37, 1981-1990. [CrossRef]

140. Vujanović, D.; Momčilović, V.; Bojović, N.; Papić, V. Evaluation of vehicle fleet maintenance management indicators by application of DEMATEL and ANP. Expert Syst. Appl. 2012, 39, 10552-10563. [CrossRef]

141. Wu, C.S.; Lin, C.T.; Lee, C. Optimal marketing strategy: A decision-making with ANP and TOPSIS. Int. J. Prod. Econ. 2010, 127, 190-196. [CrossRef]

142. Sevkli, M.; Oztekin, A.; Uysal, O.; Torlak, G.; Turkyilmaz, A.; Delen, D. Development of a fuzzy ANP based SWOT analysis for the airline industry in Turkey. Expert Syst. Appl. 2012, 39, 14-24. [CrossRef]

143. Azadi, M.; Jafarian, M.; Mirhedayatian, S.M.; Mirhedayatian, S.M. A new fuzzy DEA model for evaluation of efficiency and effectiveness of suppliers in sustainable supply chain management context. Comput. Oper. Res. 2015, 54, 274-285. [CrossRef]

144. Fallahpour, A.; Olugu, E.U.; Musa, S.N.; Khezrimotlagh, D.; Wong, K.Y. An integrated model for green supplier selection under fuzzy environment: Application of data envelopment analysis and genetic programming approach. Neural Comput. Appl. 2016, 27, 707-725. [CrossRef]

145. Li, X.; Zhao, C. Selection of suppliers of vehicle components based on green supply chain. In Proceedings of the 16th International Conference on Industrial Engineering and Engineering Management, Beijing, China, 21-23 October 2009; pp. 1588-1591.

146. Dou, Y.; Zhu, Q.; Sarkis, J. Evaluating green supplier development programs with a grey-analytical network process-based methodology. Eur. J. Oper. Res. 2014, 233, 420-431. [CrossRef]

147. Fu, X.; Zhu, Q.; Sarkis, J. Evaluating green supplier development programs at a telecommunications systems provider. Int. J. Prod. Econ. 2012, 140, 357-367. [CrossRef] 
148. Su, C.M.; Horng, D.J.; Tseng, M.L.; Chiu, A.S.F.; Wu, K.J.; Chen, H.P. Improving sustainable supply chain management using a novel hierarchical grey-DEMATEL approach. J. Clean Prod. 2016, 134, 469-481. [CrossRef]

149. Govindan, K.; Sivakumar, R. Green supplier selection and order allocation in a low-carbon paper industry: Integrated multi-criteria heterogeneous decision-making and multi-objective linear programming approaches. Ann. Oper. Res. 2016, 238, 243-276. [CrossRef]

150. Zandi, A.; Roghanian, E. Extension of fuzzy ELECTRE based on VIKOR method. Comput. Ind. Eng. 2013, 66, 258-263. [CrossRef]

151. Opricovic, S. Multicriteria Optimization of Civil Engineering Systems; Faculty of Civil Engineering: Belgrade, Serbia, 1998.

152. Ou Yang, Y.P.; Shieh, H.M.; Tzeng, G.H. A VIKOR technique based on DEMATEL and ANP for information security risk control assessment. Inf. Sci. 2013, 232, 482-500. [CrossRef]

153. Sayadi, M.K.; Heydari, M.; Shahanaghi, K. Extension of VIKOR method for decision making problem with interval numbers. Appl. Math. Modell. 2009, 33, 2257-2262. [CrossRef]

154. Liu, H.C.; Liu, L.; Liu, N.; Mao, L.X. Risk evaluation in failure mode and effects analysis with extended VIKOR method under fuzzy environment. Expert Syst. Appl. 2012, 39, 12926-12934. [CrossRef]

155. Li, S.Y.; Li, H.X. An approximation method of intuitionistic fuzzy numbers. J. Intell. Fuzzy Syst. 2017, 32, 4343-4355. [CrossRef]

156. You, X.Y.; You, J.X.; Liu, H.C.; Zhen, L. Group multi-criteria supplier selection using an extended VIKOR method with interval 2-tuple linguistic information. Expert Syst. Appl. 2015, 42, 1906-1916. [CrossRef]

157. Liu, P.D.; Jin, F. A multi-attribute group decision-making method based on weighted geometric aggregation operators of interval-valued trapezoidal fuzzy numbers. Appl. Math. Modell. 2012, 36, 2498-2509. [CrossRef]

158. Saaty, T.L. Decision Making with Dependence and Feedback: The Analytic Network Process; RWS Publications: Pittsburgh, PA, USA, 1996.

159. Gabus, A.; Fontela, E. World Problems, an Invitation to Further Thought within the Framework of DEMATEL; Battelle Geneva Research Centre: Geneva, Switzerland, 1972; pp. 1-8.

160. Wu, W.W. Choosing knowledge management strategies by using a combined ANP and DEMATEL approach. Expert Syst. Appl. 2008, 35, 828-835. [CrossRef]

161. Lioua, J.J.H.; Tzengb, G.H.; Changa, H.C. Airline safety measurement using a hybrid model. J. Air Transp. Manag. 2007, 13, 243-249. [CrossRef]

162. Li, C.W.; Tzeng, G.H. Identification of a threshold value for the DEMATEL method: Using the maximum mean De-Entropy algorithm. Expert Syst. Appl. 2009, 36, 9891-9898. [CrossRef]

163. Tzeng, G.; Chiang, C.; Li, C. Evaluating intertwined effects in e-learning programs: A novel hybrid MCDM model based on factor analysis and DEMATEL. Expert Syst. Appl. 2007, 32, 1028-1044. [CrossRef]

164. Wu, W.W.; Lee, Y.T. Developing global managers' competencies using the fuzzy DEMATEL method. Expert Syst. Appl. 2007, 32, 499-507. [CrossRef]

165. Tsai, W.H.; Chou, W.C. Selecting management systems for sustainable development in SMEs: A novel hybrid model based on DEMATEL, ANP, and ZOGP. Expert Syst. Appl. 2009, 36, 1444-1458. [CrossRef]

166. Zhang, S.F.; Liu, S.Y.; Zhai, R.H. An extended GRA method for MCDM with interval-valued triangular fuzzy assessments and unknown weights. Comput. Ind. Eng. 2011, 61, 1336-1341. [CrossRef]

167. Ashtiani, B.; Haghighirad, F.; Makui, A.; Montazer, G.A. Extension of fuzzy TOPSIS method based on interval-valued fuzzy sets. Appl. Soft Comput. 2009, 9, 457-461. [CrossRef]

(C) 2018 by the authors. Licensee MDPI, Basel, Switzerland. This article is an open access article distributed under the terms and conditions of the Creative Commons Attribution (CC BY) license (http://creativecommons.org/licenses/by/4.0/). 